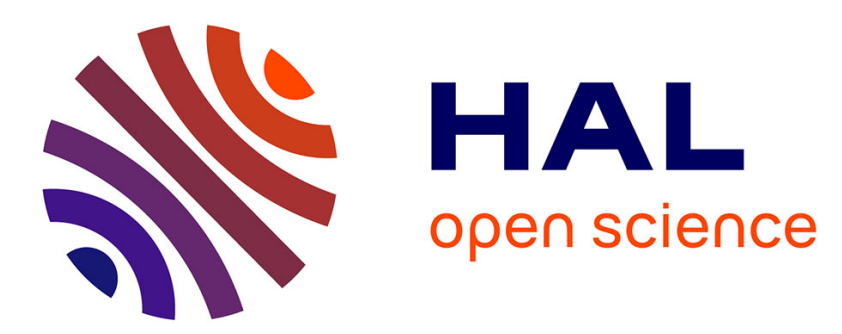

\title{
Osteology and Functional Morphology of the Forelimb of the Marine Sloth Thalassocnus (Mammalia, Tardigrada)
}

Eli Amson, Christine Argot, H. Gregory Mcdonald, Christian de Muizon

\section{To cite this version:}

Eli Amson, Christine Argot, H. Gregory Mcdonald, Christian de Muizon. Osteology and Functional Morphology of the Forelimb of the Marine Sloth Thalassocnus (Mammalia, Tardigrada). Journal of Mammalian Evolution, 2015, 22 (2), pp.169-242. 10.1007/s10914-014-9268-3 . hal-01157507

\section{HAL Id: hal-01157507 https://hal.sorbonne-universite.fr/hal-01157507}

Submitted on 28 May 2015

HAL is a multi-disciplinary open access archive for the deposit and dissemination of scientific research documents, whether they are published or not. The documents may come from teaching and research institutions in France or abroad, or from public or private research centers.
L'archive ouverte pluridisciplinaire HAL, est destinée au dépôt et à la diffusion de documents scientifiques de niveau recherche, publiés ou non, émanant des établissements d'enseignement et de recherche français ou étrangers, des laboratoires publics ou privés. 
Osteology and functional morphology of the forelimb of the marine sloth Thalassocnus (Mammalia, Tardigrada)

\author{
by \\ Eli Amson ${ }^{1, \dagger}$, \\ Christine Argot ${ }^{1}$, \\ H. Gregory McDonald ${ }^{2}$, \\ and \\ Christian de Muizon ${ }^{1}$
}

${ }^{1}$ Département Histoire de la Terre, Muséum national d'Histoire naturelle - Centre de Recherche sur la

Paléobiodiversité et les Paléoenvironnements (CR2P: CNRS, MNHN, UPMC-Paris 06; Sorbonne Universités), 57

rue Cuvier, CP38, F-75005, Paris, France

${ }^{2}$ Park Museum Management Program, National Park Service, 1201 Oakridge Drive, Fort Collins, Colorado, 80525, U.S.A.

† Corresponding author: e-mail: eli.amson@edu.mnhn.fr; phone: +33 (0)1 40793032 


\section{ABSTRACT}

Thalassocnus is a genus of "ground sloths" known from Neogene deposits, for the great majority of specimens, of the Pisco Formation (Peru). Five species are recognized, their description being currently restricted, for the most part, to the skull, mandible, and dentition. The bones of the forelimb are here described, and compared among the species of Thalassocnus and to other pilosans. The main characteristics of the forelimb of Thalassocnus relative to other sloths are the shortness of the humerus and radius, and the specialized digits. Moreover, the late species of the genus are characterized by the development of the pronator ridge of the radius, stoutness of the ulna, widening of the proximal carpal row, and shortening of the metacarpals. Analogies with extant tetrapods are proposed in order to infer plausible aquatic functions of the forelimb of Thalassocnus. In addition to paddling, it is argued that the forelimb of Thalassocnus was involved in bottom-walking, a function similarly found in extant sirenians.

However, the function of the forelimb of Thalassocnus differs drastically from that of the latter, since it was likely involved in an activity related to obtaining food such as uprooting seagrass rhizomes.

Keywords: Aquatic adaptation; forelimb; functional anatomy; marine mammal; Pisco Formation; Xenarthra. 


\section{INTRODUCTION}

The Tardigrada (or Phyllophaga, or more commonly called sloths; Fariña and Vizcaíno 2003) form, along with the Cingulata (armadillos and closely related extinct taxa) and the Vermilingua (anteaters), the Xenarthra, a distinctive superorder of American placental mammals. Sloths are more closely related to anteaters than to armadillos, the two former groups forming the Pilosa (Gaudin and McDonald 2008). Sloths constitute one of the most significant examples of mammalian taxa with a small extant diversity compared to that of its fossil record. This is true in terms of taxonomic richness, since only two genera, Bradypus Linnaeus, 1758 and Choloepus Illiger, 1811, which represent two of the five tardigradan families recognized (namely Bradypodidae, Mylodontidae, Megalonychidae, Nothrotheriidae, and Megatheriidae; Gaudin 2004), are still living. This is also true in terms of size range and functional adaptation (Pujos et al. 2012), since sloths range from small-bodied arboreal forms to elephant-size terrestrial forms (Fariña et al. 1998). Additionally, the fact that one of the extant genera is regarded as sister-group of all other sloths (see Gaudin 2004), which, in other words, means the diphyly of "tree sloths," points the likelihood of future discoveries regarding the paleoecology of sloths. The subject of the present publication, Thalassocnus Muizon and McDonald, 1995, is a sloth of average size. Even though De Esteban-Trivigno et al. (2008) regarded their results as unreliable for Thalassocnus, it can be mentioned that their body mass estimations range from around $130 \mathrm{~kg}$ to 300 $\mathrm{kg}$ (depending on which measurements were used for the regressions). Thalassocnus is remarkable in being the only representative of its superorder to have a lifestyle reconstructed as semi-aquatic to aquatic (Muizon and McDonald 1995).

The first reference to material that was subsequently attributed to Thalassocnus is found in the first report of abundant fossils in the Sacaco outcrops by Hoffstetter (1968). But the genus, monotypic at that time, was only named nearly 30 years later (Muizon and McDonald 1995). Based on taphonomic arguments as well as the remarkable morphology of the hind limb and caudal vertebrae, the first species of Thalassocnus to be described, T. natans Muizon and McDonald, 1995, was interpreted as having aquatic habits. Following publications described other species of the genus, one stratigraphically earlier than T. natans, T. antiquus Muizon et al., 2003, and three later species, T. littoralis McDonald and Muizon, 2002, T. carolomartini McDonald and Muizon, 2002, and T. yaucensis Muizon et al., 2004. A morphofunctional analysis of the skull, mandible, and dentition concluded that there was an increasing adaptation to feeding on marine vegetation (i.e., specialized grazing) from the earliest to the latest species of the genus (Muizon et al. 2004b). 
All Thalassocnus material studied here comes from the Pisco Formation, Peru (Fig. 1). Even if we only refer to its Neogene deposits, the quantity and quality of preservation of fossils that were unearthed in this formation is noteworthy. Along with the Thalassocnus material, these deposits revealed a diversified fauna typical of a littoral environment that includes molluscs, brachiopods, crustaceans, teleosteans, selachians, spheniscids, cetaceans, and pinnipeds (the specific diversity of the last was recently increased; Amson and Muizon 2014). Several absolute ages were obtained by means of isotopic analyses (Muizon and DeVries 1985; Muizon et al. 2004a; Ehret et al. 2012). Two tuffs of the same locality as that of the holotype of T. antiquus (Aguada de Lomas horizon) were dated to 8 and 8.8 Ma (Huayquerian). Molluscs from the horizon of the holotype of T. natans (Montemar horizon) were dated to 7.30 Ma (Huayquerian). Different levels were dated for the horizons containing T. littoralis (SAS horizon), of which the ages range from 7.1 $\pm 1 \mathrm{Ma}$ to $5.93 \mathrm{Ma}$ (late Huayquerian or early Montehermosan). An age of $5.75 \pm 0.5 \mathrm{Ma}$ (Montehermosan) was found for the Sacaco horizon, from which the holotype of T. carolomartini comes. No dating exists for the level that has yielded the specimens of $T$. yaucensis. However, because these beds are later than those of the Sacaco horizon (which has yielded the specimens of T. carolomartini), it is estimated that T. yaucensis is Pliocene (probably early Pliocene) of age.

A few isolated elements referred to Thalassocnus have also been found in the Bahía Inglesa Formation of northern Chile (Canto et al. 2008; Pyenson et al. 2014) (Fig. 1). Based on the attribution of the femur to T. natans, Pyenson et al. (2014) correlated the upper bound of the age of the unit of the Bahía Inglesa Formation found at the Cerro Ballena locality to the age of the Montemar Horizon of the Pisco Formation. Precisions regarding this attribution will be given in a subsequent publication that concerns the hind limb of Thalassocnus.

While some remarks concerning the forelimb material of Thalassocnus can be found in the literature, a proper full anatomical description has not yet been done. The first aim of this study is to describe the forelimb morphology. Each of the five species is known from at least one sub-complete skeleton, and one of the species, $T$. littoralis (found in the extremely productive SAS level; Muizon and DeVries 1985), is known by hundreds of additional elements (associated and isolated), allowing an assessment of the intraspecific variation. Secondly, a morphofunctional interpretation of the gross morphology of the forelimb will be proposed. This interpretation takes into account the recent functional analysis of the bone microanatomy of Thalassocnus (Amson et al. 2014). This analysis argues that ribs and limb bones of Thalassocnus are osteosclerotic; ribs were also found to be pachyostotic. As will be seen in the discussion, the recognition of these adaptations corroborates the assumption of an aquatic 
lifestyle of Thalassocnus. Moreover, it more specifically defines the type of aquatic lifestyle probably practiced by Thalassocnus, since these adaptations are found in only one extant analogue taxon, sirenians.

This work does not tackle the hind limb and axial skeleton, which will both be covered in subsequent publications.

Institutional abbreviations:

BMNH, British Museum of Natural History, London, United Kingdom; LACM, Natural History Museum of Los Angeles County, Los Angeles, California, USA; MCL, Museu de Ciencias Naturais da Pontifícia Universidade Católica de Minas Gerais, Belo Horizonte, Brazil; MNHN, Muséum national d'Histoire naturelle, Paris, France; MUSM, Museo de Historia Natural de la Universidad Nacional Mayor de San Marcos, Lima, Peru; SMNK, Staatliches Museum für Naturkunde, Karlsruhe, Germany; YPM, Yale Peabody Museum, New Haven, Connecticut, USA.

\section{MATERIAL AND METHODS}

In the following description, differences among the five species of Thalassocnus, namely $T$. antiquus, $T$. natans, T. littoralis, T. carolomartini, and T. yaucensis, will be discussed only when they are distinctive. Otherwise, and unless indicated, the anatomical descriptions will be applicable to all species. For each specimen, all of the sufficiently complete bones were measured. The measurements are presented in a separate table for each bone (except for the manus for which all measurements are gathered in a single common table). All of the material for each species of Thalassocnus and each element of the forelimb is listed in the Online Resource 1. The definition of the tardigradan clades cited follows those of Gaudin (2004), except that of the Nothrotheriini, which follows the definition of De Iuliis et al. (2011), and which only comprises Nothrotheriops Hoffstetter, 1954 and Nothrotherium Lydekker, 1889. Comparisons were made with Nothrotheriops shastensis (Sinclair, 1905) (personal observations; Stock 1925; Lull 1929), Nothrotherium maquinense (Lund, 1839) from caves of the Bahia region, Brazil (personal observations; Cartelle and Fonseca 1983), Nothrotherium escrivanense (Reinhardt, 1878), and Mionothropus cartellei De Iuliis et al., 2011 (LACM 4609/117533) from the Rio Acre, Brazil (personal observations; De Iuliis et al. 2011). Comparisons with Hapalops Ameghino, 1887 (personal observations; Scott 1903-1904) and Planops martini Hoffstetter, 1961 (personal observation of casts; Hoffstetter 1961) were also made since these taxa are likely to display, for a good number of their characters, the plesiomorphic condition for Megatherioidea. Megatherium 
americanum Cuvier, 1796, was also studied. Myological reconstructions are for the most part based on the extant myrmecophagids, since, among extant xenarthrans, they are probably functionally the closest to extinct "ground sloth" when dealing with the postcranial skeleton. This assumption is based on the fact that myrmecophagids are the phylogenetically closest terrestrial extant forms (Gaudin and McDonald 2008), and is also argued by Toledo et al. (2013). Along with the data of Pouchet (1867) and Taylor (1978), an anterior limb of Myrmecophaga Linnaeus, 1758 with preserved muscles was available for study (specimen MNHN1942-125), and was therefore used for myological reconstructions as well.

The five species of Thalassocnus were initially described for the most part based on cranial, mandibular, and dental material. They are found in five successive levels of the Pisco Formation. The postcranial material is consistent with this stratigraphic repartition, i.e., only one morphotype was recognized in each level, which allows referring to early and late species of the genus. This is true except for MNHN.F.SAS57. This partial skeleton was recovered in the level that preserves $T$. littoralis, and while it has features that are mostly characteristic of this species, it appears to retain states more reminiscent of those of $T$. natans concerning the shape of the radius and articulation between the scaphoid and magnum (see below).

Great variations of the skull and mandible were described among the five species of Thalassocnus (McDonald and Muizon 2002; Muizon et al. 2003; 2004a). Obtaining proportions of postcranial elements relative to a cranial or mandibular measurement hence requires the recognition of an area that is as little affected by these variations as possible. Moreover, the completeness of each specimen is also a limiting factor. Taking into account these restrictions, the maximum depth of the horizontal ramus of the mandible appeared to be the most relevant craniomandibular measurement.

In order to refer to mediolateral, proximodistal, and anteroposterior directions of the long bones, we have conventionally used the terms width, length, and depth, respectively.

\section{COMPARATIVE DESCRIPTION}

Forelimb as a whole

The most complete forelimb pertains to the holotype of T. natans (MNHN.F.SAS734; Fig. 2). The proximodistal length of the sub-complete articulated forelimb of the holotype of $T$. natans is roughly $72 \mathrm{~cm}, 95 \mathrm{~cm}$ with the scapula. Thalassocnus can be considered being intermediate in size within the range of sloths. See subsequent study of the hind limb of Thalassocnus for further consideration of the general size of Thalassocnus 
(based on femoral length), including intra- and interspecific variation. Thalassocnus differs from other nothrotheriids in having an antebrachium longer than the brachium. However, the proportions of the two are not constant within the genus, as will be discussed below.

Scapula

The scapula is known by complete or sub-complete specimens in all species except for T. carolomartini (only an isolated glenoid cavity was recovered from the SAO level, MNHF.F.SAO207; Table 1). The general shape of the scapula approximates an isosceles triangle with the lengths of the anterior and dorsal margins being equal and shorter than the length from the posterodorsal angle to the edge of the coracoid process (Fig. 3a). The dorsal edge of the bone is concave. This concavity, located just anterior to the primary spine, separates two surfaces bearing wellmarked muscle scars, on the anterodorsal and posterodorsal angles of the scapula. This may embody a strong (if not complete) separation between the rhomboid major and rhomboid capitis muscles. This is the case in Choloepus, as described by Nyakatura and Fischer (2011) and Miller (1935) (termed occipito-cervical and thoracic divisions by the latter). The supraspinous fossa is larger than the infraspinous, as in Hapalops and other Megatheria, and as in $N$. maquinense according to Reinhardt (1878). It is noteworthy that Cartelle and Fonseca (1983: 149) describe an opposite condition, concerning the relative importance of the fossae in N. maquinense. However, after examination of the specimens on which this description is based, as well as additional material referred to N. maquinense, it appears more likely that these authors erroneously oriented the fragmentary scapula they had available, hence confusing the two fossae. The coraco-scapular foramen is large and just dorsal to the anterior portion of the glenoid fossa. In $T$. antiquus and T. natans, the primary spine of the scapula is tall ventrally but declines in height dorsally and is only a low crest when it reaches the dorsal margin. In T. littoralis and T. yaucensis (no data for T. carolomartini), the crest is even less extended dorsally, since it does not reach the dorsal margin of the bone. Its lateral margin is narrow dorsally, but forms a distinct tuberosity (posterior process of spine of scapula sensu Taylor [1978] approximately at mid-length and then expands anteroposteriorly for the ventral remaining portion to form a wide acromion process that joins the coracoid, forming a complete acromiocoracoid arch. A similar posterior process of the spine can be found in myrmecophagids and, to a lesser extent, in Planops, but not in M. americanum or Nothrotheriops, in which the lateral margin of the primary spine expands ventrad progressively, without forming a distinct process. The primary spine is slightly tilted anteriorly, as in Planops (Hoffstetter 1961: 75). On the posterior edge of the proximal extremity of the acromiocoracoid arch, anterior to the glenoid fossa, is a rugose depressed area, probably to make room for the greater 
tuberosity during extension of the shoulder joint and medial rotation of the humerus. Another hypothesis, not favored here, would be that this surface is for the articulation of the clavicle. The former assumption is corroborated by absence of an articular facet on the acromial end of the clavicle. Moreover, Cuenca Anaya (1995) described in Scelidotherium Owen, 1839 a large facet on the medial side of the scapula at the base of the acromiocoracoid arch, a location more consistent with that of other claviculate mammals. Such a facet was observed in Nothrotheriops.

The infraspinous fossa is bordered posteriorly by a strong and prominent secondary scapular spine. This secondary spine extends from the posterolateral margin of the glenoid fossa to the posterodorsal margin of the scapula. The proximal third of the secondary spine is slightly deflected ventrally. In T. antiquus and T. natans, on the proximal portion of the secondary spine and on the posterior edge of the glenoid cavity is a strong scar for the origin of the scapular head of the triceps brachii muscle.

The relative size of the postscapular fossa (posterior to the secondary spine) in T. antiquus and T. natans approaches that of Hapalops and other Megatheria, but is smaller than that of myrmecophagids. This fossa bears in its distal extremity a small triangular scar, probably for the origin of the teres major muscle, as described in Myrmecophaga (Pouchet 1867) and Tamandua Gray, 1825 (Taylor 1978). This region of the scapula is slightly expanded posteriorly in T. littoralis (Fig. 3b) when compared to T. natans (Fig. 3a; no data for the later species), the ratio between the maximum anteroposterior lengths of the postscapular and infraspinous fossae being slightly higher in T. littoralis than in T. natans (Table 2). The surface anterior to the teres major scar was probably for the origin of a portion of the long head of the triceps brachii muscle, the 'accessoire interne' of Pouchet (1867), as is the case in Myrmecophaga. A round fossa, denoting a tendinous insertion, is present at the proximal end of the postscapular fossa.

The glenoid fossa is ovoid with the anterior portion slightly narrower than the posterior, as in the Nothrotheriini, but in contrast with M. americanum in which the medial and lateral edges of the fossa are almost parallel. The posterior border of the glenoid fossa forms an obtuse angle with the proximal end of the secondary spine, a condition shared with Nothrotherium (personal observation; Cartelle and Fonseca 1983) and M. americanum but not with Nothrotheriops, where it forms almost a right angle. The articular surface curves ventrally so the anterior portion extends farther ventrally than the posterior and forms a small lip. Some specimens bear a shallow concavity (T. carolomartini, MNHN.F.SAO207) or small fossa (T. littoralis, MNHN.F.SAS10) just posterior to the middle of the glenoid fossa, probably for the insertion of a glenohumeral ligament. 
On the medial side of the scapula the subscapular fossa is divided into two shallow sub-fossae. They are separated by a low broad ridge that extends from the middle of the glenoid fossa to the anterodorsal angle. The smaller of the two sub-fossae is located along the anterior margin and includes the coraco-scapular foramen. The second sub-fossa is triangular and covers the posterior two-thirds of the medial surface. These ridges are smooth and, contrary to the condition observed in Nothrotheriops and M. americanum, the subscapular fossa does not bear any sharp ridges oriented proximodistally and converging toward the glenoid fossa. Just below the anterodorsal angle is a region of irregular surface showing several small tubercles, probably for the insertion of the levator scapulae dorsalis muscle.

\section{Clavicle}

The clavicle is only known in T. natans, T. littoralis, and T. yaucensis (Table 3). A great variation of size and shape of the clavicle was observed in Nothrotheriops. The available material of Thalassocnus also suggests such variation, although few specimens preserve this bone. While this renders characterization and comparison difficult, a few comments can be given. The clavicle of MNHN.F.SAS734 (holotype of T. natans) shows a slight sigmoid curvature (Fig. 4a). The shaft is oval in cross-section with a slight dorsoventral flattening. This flattening is most pronounced at the sternal end and includes the presence of a small crest along the anterior edge. This crest is part of a muscle scar that starts on the dorsal edge of the sternal end, connects with this crest on the anterior margin, and then crosses the dorsal surface of the clavicle at about the midpoint of the bone to the posterior edge where it joins the tuberous scapular end. Both ends are expanded and rugose; the sternal one is larger. Moreover, on the holotype of $T$. natans, the sternal end shows a small but clear articular facet. Although not indisputable, this facet probably articulates with the other clavicle, since 1) there is no apparent articular facet for the clavicle on the manubrium (see subsequent study of the axial postcranium of Thalassocnus), 2) such an articulation is described in M. americanum (Owen 1858: 264). In the species later than T. natans (no data for T. antiquus and T. carolomartini), the sternal end is proportionally smaller, and the articular facet on it is only incipiently developed or even absent (Fig. 4b). There is a small but well-marked fossa on the ventral surface of the shaft at the junction with the tuberosity for the acromial articulation.

Humerus 
Complete humeri are known for all species except T. carolomartini and T. yaucensis (Table 4). In overall proportions the humerus of Thalassocnus is stouter and lacks the more gracile appearance of other nothrotheriids and Planops (Fig. 5-8). This is due, in all Thalassocnus species (except T. yaucensis for which there is no data), to the proximodistal shortness of this bone (relative to the width of its distal articular surface, Table 5; relative to the depth of the horizontal ramus of the mandible, Table 6). However, the humerus of Thalassocnus is more gracile than that of M. americanum.

The articular surface of the head is oval in proximal view. The major axis of this oval is directed posteromedially, with an angle of approximately $10-20^{\circ}$ to the sagittal plane. The posterior margin of the greater tubersosity and the anterolateral margin of the articular surface of the head form a shallow groove. The greater and lesser tuberosities are well developed and salient laterally and medially, respectively. Because of this condition, in anterior or posterior view, the proximal extremity of the humerus is more expanded transversely than in Hapalops and other Megatheria, except maybe for Planops. The greater tuberosity is expanded anteroposteriorly on its lateral side and narrows medially. Its medial side is continuous with the pectoral crest (the denomination of the humeral crests and ridge follows that of De Iuliis 2003), which continues distally on the midline of the anterior margin of the shaft. The greater tuberosity is somewhat angular, as in other Megatheria, featuring two distinct surfaces: one dorsal and anterior, for the insertion of the supraspinatus; the other posterior and lateral, for the insertion of the infraspinatus, putatively as in Myrmecophaga (Pouchet 1867). Distal to the lateral side of the greater tuberosity is a small but sharp and elevated crest that extends on the diaphysis (Fig. 6). It is more or less developed depending on the specimen. This crest is more developed than in the Nothrotheriini and M. americanum but is present in Hapalops. This crest is probably the location of the insertion of the teres minor, as described in Tamandua (Taylor 1978) and Myrmecophaga (Pouchet 1867). The two tuberosities are separated by a well-developed bicipital groove. This is a primitive character for nothrotheriids and sloths in general but this structure is reduced or absent in Nothrotheriops. There is a fossa between the anterior margin of the head and the bicipital groove. Its opening is reniform and it is internally subdivided into several round foramina. This region is badly preserved in most of the specimens, probably because of its initial cartilaginous nature. The lesser tuberosity is a prominent and distinct structure well demarcated from the rest of the proximal end. It is separated from the head by a distinct groove that is well defined along its whole anteroposterior length. A similar condition is present in the Nothrotheriini and Mionothropus. Hapalops departs from this condition, since this groove is less extended anteriorly. There is a shallow broad groove on the anterior surface of the lesser tuberosity so that it is subdivided into a larger medial process and a smaller process on 
the lateral edge of the tuberosity. This groove probably accommodated the tendon of the coracobrachialis muscle and possibly the biceps brachii muscle (putatively united at this level, as in Myrmecophaga; Pouchet 1867). The welldefined bicipital groove may suggest that the tendon biceps muscle was not running over the lesser tuberosity. Such a structure of the lesser tuberosity is also present in the Nothrotheriini and Mionothropus but reduced in $T$. carolomartini and T. yaucensis. As in other sloths, neither of the tuberosities extends above the head, which is an indication of a greater mobility of the shoulder.

At about the distal two-thirds level of the shaft, the pectoral crest joins two other crests located on its lateral side (Figs. 5b, c, 6b, c). This condition is present in the four latest species but absent in T. antiquus, in which there is only one other lateral crest (Figs. 5a, 6a). In the species later than T. antiquus, the junction of the three crests forming the deltopectoral plate - forms a conspicuous elevation on the shaft. The most lateral crest is the deltoid crest (Figs. 5-7). The smallest of the three, absent in T. antiquus, lies between the pectoral and deltoid crests and is the insertion for the brachiocephalicus muscle (Figs. 5, 6; De Iuliis 2003). The junction of the deltoid and brachiocephalic crests is more pronounced than their junction with the pectoral crest, which is less pronounced distally. Compared to that of $T$. antiquus and T. natans, the deltoid crest of $T$. littoralis (no data for the later species) is clearly expanded laterally, enlarging conspicuously the deltopectoral plate.

On the posterior surface of the shaft, distal to the lateral margin of the head, a crest of variable development is observable. This crest is probably for the origin of the lateral head of the triceps brachii (personal observation in Myrmecophaga) (Fig. 7).

Two crests are visible on the proximal half of the diaphysis in medial view. The first one is on the medial margin of the shaft, just distal to the lesser tuberosity, oriented proximodistally, and vanishing just proximal to the half-length of the diaphysis (Fig. 8). It is probably for the insertions of the teres major and latissimus dorsi muscles, as in Myrmecophaga (personal observation; Pouchet 1867). The other, located more posteriorly, is oblique to the axis of the shaft, since it starts proximally at the level of the medial margin of the head and joins the former crest on the medial edge of the shaft, where both crests vanish. It is probably for the origin of the medial head of the triceps. When well developed, both crests form a V-shaped pattern pointing distally (Fig. 8c).

As in sloths in general, the distal end of the humerus is expanded transversally. This expansion is produced by the formation of the epicondylar ridge, which extends proximally from the lateral epicondyle. It differs from the condition of Hapalops and other Megatheria in being strongly expanded lateroproximally. This ridge is also greatly laterally convex in anterior view while it is only slightly convex to almost straight in the Nothrotheriini. The 
epicondylar crest probably provides the origin for the extensor carpi radialis and brachioradialis muscles anteriorly and the anconeus posteriorly. The transverse expansion of the distal extremity in the species of Thalassocnus earlier than T. yaucensis is symmetrical, with equal development of the lateral and medial epicondyles, in contrast to the condition of the Nothrotheriini and Mionothropus, in which the medial epicondyle is more expanded medially. The latter condition is found in T. yaucensis because of the reduction of the lateral epicondyle found in this species (Fig. 5d), when compared to earlier species of the genus (Fig. 5a-c). Furthermore, the medial epicondyle is rounded and lies close to the distal end, as in Planops, and in contrast to other megatherioids (and more generally Pilosa) in which the process is more pointed and more proximally positioned. On the anterior surface of the crest and proximal to the capitulum is a deep radial fossa. This fossa is present in the Nothrotheriini and Mionothropus but not as well developed and almost absent in M. americanum. This condition hence seems to be a derived feature in Thalassocnus. While it is always conspicuous and subject to intraspecific variations, the radial fossa is clearly shallower on all specimens (holotype or referred) of T. yaucensis (Fig. 5d; no data for T. carolomartini) than in the earlier species of Thalassocnus (Fig. 5a-c). In T. antiquus and T. natans, a sulcus is present between the medial edge of the lateral epicondyle and the lateral edge of the capitulum. This sulcus accommodates the anteroposterior expansion of the head of the radius (see description of the radius below) when the antebrachium is pronated (i.e., when the pronator crest of the radius is facing medially), especially during flexion of the elbow joint. This indicates that, while the semisupinated antebrachium (i.e., when the pronator crest of the radius is facing anteriorly) is the normal position inferred (see below), a fully pronated position was possible.

An entepicondylar foramen is present, as in other megatherioids except megatheriines. This foramen is large and its axis parallels the shaft of the humerus. The anterior opening of the entepicondylar foramen is more distal than in the Nothrotheriini. Distally it opens into a large excavation that extends to the proximal edge of the medial condyle, homologous with the coronoid fossa. This fossa is separated from the radial fossa by a low ridge. This fossa is less excavated distally in T. carolomartini and T. yaucensis (Fig. 5d) than in the earlier species of the genus (Fig. 5a-c). The entepicondylar bar is especially strong in T. antiquus and T. natans (Fig. 5a, b) and forms a continuous surface with the medial epicondyle. The width of this bar is conspicuously reduced in $T$. littoralis (Fig. 5c) and $T$. yaucensis (Fig. 5d; no data for T. carolomartini). A very young individual of T. littoralis (MNHN.F.SAS2) shows a proportionally wide entepicondylar bar (more resembling that of the holotype of $T$. natans), which would indicate a reduction of this structure with the ontogeny of $T$. littoralis and $T$. yaucensis (and possibly $T$. carolomartini). The medial margin of the humerus shows, between the proximal opening of the entepicondylar foramen and medial 
epicondyle, a conspicuous crest (entepicondylar crest), probably for the origin of the epitrochleo-anconeus muscle posteriorly but mainly for the pronator teres muscle anteriorly. Flexors of the carpus and digits also originate on this process, but their origins are of less importance in Myrmecophaga (Pouchet 1867) and Tamandua (Taylor 1978). The flexors of the carpus and digits originate more distally in Tamandua (Taylor 1978) and Myrmecophaga (personal observation). Such an origin is impossible in Thalassocnus - or other Megatheria - since the entepicondylar crest does not project as far medially as in myrmecophagids, so the muscles are shifted away from the elbow joint. The posterior surface of the distal extremity of the humerus has a wide and deep olecranon fossa for the anconeal process of the ulna (Fig. 7). This fossa is proportionally deeper than that of other Megatherioidea, although approaching the condition seen in Mionothropus. Even the very young individual represented by MNHN.F.SAS2 shows a decidedly deep olecranon fossa. This fossa is not uniformly excavated, since the distal two-thirds are more excavated than the rest.

The distal articular surface is constructed as in sloths in general, with a hemispherical capitulum and a flattened anteromedial part of the trochlea. As in all sloths, the hemispherical capitulum allows great mobility of the radius on the ulna and therefore great pronation-supination capability. The capitulum is less hemispherical in $T$. yaucensis than in the earlier species of the genus. Anteroproximally, the capitulum and trochlea are separated by a Vshaped notch. This notch is large in T. natans (Fig. 5b; no data for T. antiquus) but is narrower in T. littoralis (Fig. 5c). It is almost absent in T. yaucensis (Fig. 5d). This notch probably embodies a strong oblique reinforcement of the anterior ligament of the elbow joint. This notch is also present in M. americanum. The capitulum is primarily confined to the anterior surface and narrows distally so it does not continue onto the posterior surface. The anteroproximal edge of the trochlea is distinctly convex and extends proximally almost to the same level as (only slightly distal to) the anteroproximal edge of the capitulum. This proximal extension is greater in Thalassocnus than in the Nothrotheriini and Mionothropus, in which the anteroproximal edge of the trochlea slopes mediodistally. The posterior portion of the trochlea is wide and extends proximally to form the distal margin of the olecranon fossa. In anterior view, the distal margin of the trochlea of $T$. antiquus and $T$. natans is distinctively sloping mediodistally (although very weakly in the Nothrotheriini and Mionothropus), and the medial crest of the trochlea is located clearly distal to the level of the lateral edge of the trochlea (Fig. 5a, b). This condition is also present in other Megatherioidea and Myrmecophaga. A different condition is observed in later species of Thalassocnus (Fig. 5c, d), in which the distal margin of the trochlea slopes only slightly mediodistally, being almost perpendicular to the proximodistal axis of the shaft. It can be noted that such morphology is not unique to the later species of 
Thalassocnus, since a reminiscent condition is present in Valgipes Gervais, 1874 and, to a lesser extent, in the Nothrotheriini and Mionothropus.

Ten complete humeri of $T$. littoralis representing six individuals are preserved and indicate a large size range for the species (Table 4). The proximodistal length of the smallest humerus of this species represents $80 \%$ of that of the largest. The length of the humeri of the holotypes of $T$. antiquus and $T$. natans falls within the size range of the T. littoralis sample. The current sample size is not large enough to allow any clear differentiation of two size classes of intraspecific variation. But taking into account the ontogenetic stage of each specimen (based on the completeness of epiphyseal closure), three groups can be recognized: humeri longer than $250 \mathrm{~mm}$ - putatively males (the longest, MNHN.F.SAS44, does not even feature a complete epiphyseal closure); humeri around $230 \mathrm{~mm}$ in length, with complete epiphyseal closure - putatively adult females (MNHN.F.SAS54 and 256); and specimens displaying incomplete epiphyseal closure - juveniles or subadults. Tremendously larger males are seen in some modern pinnipeds (Weckerly 1998). However, larger females are found in Bradypus torquatus Illiger, 1811 (LaraRuiz and Chiarello 2005). The arbitrary choice concerning Thalassocnus is based on the fact that a specimen representing the small morphotype was already interpreted as a female, as it was associated with an individual that is either unborn or a neonate (Muizon et al. 2004). This would not be the first sexual dimorphism inferred in Megatheria, since Cartelle and Bohorquez (1982) documented a case in Eremotherium laurillardi Lund, 1842. The holotype of T. natans would fall in the first group, i.e., males; the large specimen of T. littoralis, MNHN.F.SAS44, much longer, would corroborate (since the humerus is not lengthened in T. littoralis compared to the rest of the skeleton, see below) the assumption based on cranial material of McDonald and Muizon (2002), i.e., that T. littoralis is larger than T. natans. The holotype of T. antiquus is among the smallest mature specimens; two specimens referred to T. carolomartini (MNHN.F.SAO201 and MUSM 1995) are larger than any other specimen referred to an earlier species of the genus. The largest specimen is from the Yauca locality (MUSM 347). It is referred to T. yaucensis and features an incomplete epiphyseal closure. On the whole the humeral sizes observed in the five species of Thalassocnus are consistent with a general increase in size from the earliest to the latest species, but with a marked intraspecific variation.

To give proportions of the humerus relative to the skull or mandible for each species is difficult, because of the scarcity of articulated specimens including well-preserved skulls. However, several specimens with associated mandible allowed a comparison. The ratios of maximum depth of the horizontal ramus/ mediolateral width at the proximal tuberosities or mediolateral width of the head are not greatly different between the holotypes of $T$. 
antiquus, T. natans, one specimen referred to T. littoralis, and one referred to T. yaucensis (no data for $T$. carolomartini; Table 7). Moreover, the ratio of the proximodistal length of the humerus to one of the dimensions (length, width or depth) of the centrum of T7 does not differ conspicuously between T. natans (holotype, MNHN.F.SAS734), T. littoralis (MUSM 223), and T. carolomartini (MUSM 1995; Table 8). It is noteworthy that the proportions of the humerus relative to the femur do not appear as constant among the species of Thalassocnus, implying that interspecific variation affects the femur (see subsequent study of the hind limb of Thalassocnus).

Ulna

Complete ulnae are known in T. natans, T. littoralis, and T. yaucensis; T. antiquus and T. carolomartini are each represented by one fragmentary specimen (holotype, MUSM 228 and MUSM 156 respectively) (Table 9). The general shape of the ulna in the species earlier than T. yaucensis is roughly similar to other nothrotheriids in its slenderness (Figs. 9a-c, 10a-b, 11a-d, 12a-d). In T. antiquus, T. natans, T. littoralis and T. carolomartini, the diameter of the diaphysis progressively decreases distally, which gives to the ulna a gracile appearance and proportions found in non-thalassocnine nothrotheriids (Table 10). In T. yaucensis, the ulna has a stouter shaft, which is distinctly wider anteroposteriorly especially on the proximal portion of the epiphysis (Figs. 9d, 10c, 11e, 12e; Table 10). The distal end is much less gracile, being stouter and more robust and cylindrical. The massive ulnar proportions of the latest species are probably correlated with the shorter antebrachium (see below).

The olecranon process is proximodistally long, resembling that of Hapalops and Mionothropus but differing from the condition in Nothrotheriini. On the holotype of T. natans (Figs. 9a, 10a; no data for T. antiquus), this process is transversally wide (in posterior view) and inflected medially with a distinct medial extension of its posteromedial edge. On specimens of the other species of Thalassocnus, the size and development of the medial extension is variable, being reduced or absent in some specimens. This medial extension seems to be homologous with the anterior thickening of the mediodistal angle of the olecranon of Myrmecophaga, which bears the origin of the ulnar head of the flexor carpi ulnaris muscle (personal observation). In Myrmecophaga, the medial expansion of the ulna shows a posterior crest providing insertion for the dorso-epithroclearis muscle (muscle also described in Tamandua; Taylor 1978). Such a crest is absent in Thalassocnus. The posterior face of the olecranon process continues distally and forms a strong ridge on the posterior margin of the bone at the level of the humeral articulation. Distally it merges with the rest of the posterior surface of the diaphysis. In profile, the posterior margin of the diaphysis is slightly concave on the holotype of T. natans and straight or slightly convex on the other specimens of 
Thalassocnus (no data for T. antiquus) and in the Nothrotheriini, Mionothropus and M. americanum. In posterior view, none of the specimens of Thalassocnus displays a medially bent shaft as is seen in the Nothrotheriini and Mionothropus.

The medial side of the proximal extremity of the ulna of T. natans (no data for T. antiquus) has a welldeveloped fossa for the flexor digitorum profundus muscle that extends from the medial extension of the olecranon about half the length of the diaphysis (Fig. 11). In several well-preserved specimens referred to T. littoralis (Fig. 11c), the proximal part of this fossa is subdivided by one or more crests, more or less elevated depending on the specimen. This is probably related to the several sheets of muscle forming the fleshy ulnar origin of the muscle as in Myrmecophaga (personal observation). The fossa for the flexor digitorum profundus muscle is apparently more developed in Thalassocnus than in other nothrotheriids. On the lateral side of the proximal extremity is a fossa probably for the insertion of the anconeus and triceps brachii muscles (Fig. 12). Distally this fossa becomes a broad plane surface, concave on some specimens, for the origin of the extensor digitorum profundus muscle, and possibly for a separate extensor pollicis longus, but since this fossa shows no clear separation, there is no reason to believe that these two muscles were distinct. In Tamandua, as described by Taylor (1978), this lateral fossa presents a distinct oblique division (anterodistally oriented). Such a division occurs in Myrmecophaga, in which the entire lateral side of the ulna is marked by a deep fossa of irregular surface embodying strong muscle attachment (Pouchet 1867). In any case, in Thalassocnus, the fossa for the origin of the muscle(s) extending the digits I and II is not nearly as conspicuous as that of Nothrotheriops (which approaches the condition of Myrmecophaga), but resembles more that of Mionothropus. This origin is also well marked in Nothrotherium, mature specimens featuring a deep fossa with muscular scars. The condition of Thalassocnus is probably correlated with the reduction of digit I observed in this genus (see below).

The trochlear notch, which articulates with the trochlea of the humerus, is narrow, and both the coronoid and anconeal processes are remarkably prominent. The degree of development of these processes (relative to the anteroposterior depth at midshaft), especially the anconeal process, is greater than in Hapalops or in other Megatheria (Table 11). It is only a low ridge in both Nothrotherium and Nothrotheriops and barely forms a lip along the proximal edge of the humeral articular surface. In lateral view, the anteriormost tip of the anconeal process is posterior to the level of that of the coronoid process. However, these processes are relatively shorter in T. yaucensis, but this is due to the greater stoutness of shaft found in this species (Table 10). In proximal view, the anterior edge of the anconeal process is mediolaterally wide in Thalassocnus and is roughly rectangular. The lateral process, bearing 
the articular surface for the radius, is a high but narrow crest (often broken off) positioned lateral to the coronoid process. This lateral process is not developed to such an extent in other nothrotheriids or in M. americanum. In Nothrotherium it is very weak and does not bear an articular facet for the radius; in Nothrotheriops it is also weak, but on some specimens the facet (which is relatively small) may extend onto this process. It is noteworthy that Mionothropus shows a more developed process, approaching the condition of Thalassocnus. The articular surface for the radius (the radial notch) is well developed and circular. It is separated from the humeral articular surface in most specimens, but may occasionally contact it proximally. It is always separated from the coronoid process by a sulcus. The trochlear notch is expanded by a supplementary, laterally-oriented articular surface on the posterolateral edge of the coronoid process (the size of which is variable; Fig. 12). This supplementary articular surface contacts the articular circumference of the head of the radius. The proximal articulation for the radius is therefore discontinuous because of this medial addition from the trochlear notch. There is a sharp crest (often broken off), probably for the interosseous ligament, extending from the lateral edge of the process for the radial articular surface along the anterolateral edge of the diaphysis to the distal two-thirds of the diaphysis. This crest is reinforced in its mid-part, on some specimens referred to T. littoralis, by a large tuberosity. Proximal to this tuberosity the crest is distinctly lowered, making room for the radial tuberosity in pronation of the antebrachium. In Thalassocnus the proximal end of this crest is located more medially and is discontinuous with the process for the articular surface for the radius. The disposition is different in Nothrotheriops, in which the crest continues distally up to the articular circumference. On the anterolateral edge of the coronoid process there is a small tuberosity for the insertion of the brachialis muscle (inferred from Myrmecophaga; Pouchet 1867).

The distal articular surface for the carpus is offset to the medial side of the diaphysis (Figs. 9, 11). It is a small, flat oval surface with its long axis extending anteromedially to posterolaterally. This differs from the two-sided surface found in Nothrotheriops. Relative to the shaft, this facet is smaller in Thalassocnus than in other nothrotheriids (Table 12). This is also true when the latest species of Thalassocnus are compared to the earliest ones. However, this is probably related to the stouter ulnar proportions found in the latest species (see above). The articular circumference is a small process on the midline of the distal end of the diaphysis. It is more developed in T. littoralis than in the earlier species of the genus, forming a long and wide knob protruding from the distal end of the shaft and distal epiphysis in profile. In T. carolomartini and T. yaucensis, the articular circumference is well developed but does not protrude as much, because of the enlargement of the distal end of the bone in these species, especially $T$. yaucensis. 
In Thalassocnus, the proximodistal length of the ulna is long relative to that of the humerus, due to the shortness of the latter bone (see above). However, the ulna (and the radius, see below) is shorter when compared to humeral length in T. littoralis and T. carolomartini than in T. natans (no data for the other species). The antebrachium is hence roughly as long as the brachium in T. littoralis and T. carolomartini (no data for T. yaucensis; Table 13).

Radius

Complete or sub-complete radii are known for all species of Thalassocnus. In the following description the convention of orientation of the radius is follows: pronator crest is anterior, the face bearing the grooves for the extensor muscles' tendons is lateral, the edge with the interosseous ligament scar is posterior, and the face bearing the bicipital tuberosity and opposite to the lateral face is medial. This convention of orientation does not follow that used by Pujos et al. (2007) and De Iuliis et al. (2011) who identify our lateral face as anterior, our anterior edge as medial, our medial face as posterior, and our posterior edge as lateral. Our choice is motivated by the actual neutral position of the radius of Thalassocnus, which was semi-supinated (see below), a position in which the extensor face of the radius is clearly lateral. It is noteworthy that in most mammals with pronation-supination abilities, the extensor face of the radius in a neutral position is not exactly anterior as conventionally accepted by Pujos et al. (2007) and De Iuliis et al. (2011) but anterolateral (Davis 1964; Barone 1966; Lessertisseur and Saban 1967). Therefore, we believe that the convention adopted here more closely reflects the actual anatomy and antebrachium neutral position of Thalassocnus.

The general conformation of the radius is one of the features distinguishing most Thalassocnus from other sloths, and the five species of Thalassocnus from each other as well (Figs. 13-16; Table 15). Firstly, the radius of Thalassocnus is proximodistally short (relative to the depth of the horizontal ramus of the mandible) when compared to that of other sampled nothrotheriids (Table 14). Additionally, the radius is shorter in T. yaucensis (and probably $T$. carolomartini, judging from the length of the radius relative to that of the humerus) when compared to the earlier species of the genus. Because of the absolute shortness of its humerus, Thalassocnus differs from the other nothrotheriids in having a radius longer than the humerus (Table 13). However, since the radius is shorter relative to the humerus in T. littoralis and T. carolomartini than in T. antiquus or T. natans, it is in the late species of the genus almost as long as the humerus (this cannot be confirmed for T. yaucensis, in which a specimen with a complete humerus and radius is lacking). 
Secondly, when seen in lateral view, the shaft is distinctly bent posteriorly. This morphology produces an offset of the proximal epiphysis, which is posterior to the distal epiphysis. In all species of Thalassocnus this offset is clearly more pronounced than in the other Megatheria. The bend in the shaft producing this offset occurs at about $25 \%$ of the shaft length distal from the proximal end. This bend occurs farther distally in other nothrotheriids, at about 30\% of the diaphysis, and even farther in Hapalops and M. americanum, where it is located almost at midshaft. As in most sloths, at the bend of the shaft is a distinct ridge, the pronator ridge (Muizon et al. 2003). In Thalassocnus, especially T. littoralis, T. carolomartini, and T. yaucensis, the ridge has transformed into a sharp and elevated crest. This condition differs from that of Hapalops and other Megatheria in which the ridge projects less anteriorly. A difference in the development of this ridge among the species of Thalassocnus was already mentioned by Muizon et al. (2003). Note that, in figure 4 therein, the specimen MUSM 37 was provisionally referred to "Thalassocnus cf. carolomartini" pending the description of the rest of its skeleton, especially its skull. It was subsequently made, along with the rest of the skeleton, the holotype of $T$. yaucensis by Muizon et al. (2004a). Differential development of the pronator ridge is well shown by the ratio of the anteroposterior depth of the radius at midshaft to its proximodistal length (Table 16). While other nothrotheriids display ratios lower than or approaching those of T. antiquus and $T$. natans, a stepwise increase of the development of the pronator ridge is found when the earlier species of Thalassocnus are compared to the later ones. This ridge is remarkably developed even in juveniles referred to $T$. littoralis (such as MNHN.F.SAS499 and MNHN.F.SAS1637, which are extremely small and which lack both epiphyses). Moreover, in T. yaucensis the ridge reaches the distal epiphysis without forming a concavity (on the medial edge of the bone, in anterior or posterior view), expanding conspicuously the width of the distal radius. Therefore, in medial or lateral view, the anterior margin of the diaphysis is sigmoid in T. antiquus, T. natans and T. littoralis (Figs. 13a-c, 14a-c; as in most other Megatheria), and regularly convex throughout its length in T. yaucensis (Figs. 13e, 14e). Even though it is incomplete (a distal half of the bone), MUSM 156, referred to T. carolomartini, seems to be very similar to the morphology observed in T. yaucensis (Figs. 13d, 14d). However, the morphology of MUSM 1995, a specimen also referred to this species, is more reminiscent of that of the earliest species. In $T$. carolomartini and T. yaucensis, species in which the anterior expansion of the pronator ridge is the most pronounced, the shaft is drastically widened (in medial or lateral view) and flattened (in anterior or posterior view) when compared to the earliest species of Thalassocnus as well as to other nothrotheriids (Table 17). The lateral side of this ridge is, for the proximal half of the diaphysis, the area of insertion of the supinator muscle (inferred from Tamandua; Taylor 1978). The anterior edge of the pronator ridge is thickened and rugose from its proximal end down to the level 
where it starts to blend with the shaft (just distal to midshaft; Fig. 15). This is probably the area of insertion of the pronator teres muscle. This insertion is relatively inconspicuous, since it does not form a deep fossa delimited by two well-elevated crests on the medial side of the shaft, as in Myrmecophaga. In Mionothropus and Hapalops, De Iuliis et al. (2011) described a prominent anterior scar (termed medial by these authors) at the level of the anterior bend of the radius where the pronator teres muscle would have inserted. A similar inference has been proposed for Santacrucian sloths (including Hapalops) by Toledo et al. (2013). Such a scar was also observed in Nothrotheriops. However, the anterior margin of the pronator ridge is distinctly thickened in T. yaucensis when compared to that of the earlier species of the genus. Even MUSM 1034, a specimen that is interpreted as a young individual of $T$. yaucensis, features a well-thickened medial edge of this ridge. The medial surface of this ridge is probably one of the origins of the flexor digitorum profundus muscle (Fig. 14). The lateral surface of the distal half of the radius is smooth in Thalassocnus, and not marked by an oblique crest as in Hapalops. Furthermore, in anterior or posterior view, the largest specimens of Thalassocnus feature a diaphysis strongly convex laterally and concave medially. A similar condition is found in mature specimens of Nothrotheriini.

The proximal articular surface is roughly circular. In species earlier than T. carolomartini, the posterior margin of the head extends a little farther proximally than the anterior margin, forming a capitular eminence. A similar condition is observed in Mionothropus. Moreover, these species also feature a deeply concave humeral facet, which is reminiscent of that of Mionothropus, and differs from the condition seen in the Nothrotheriini. This capitular eminence is reduced in the late species, especially T. yaucensis, in which the head is regularly rounded and shallower. The latest species is in this respect reminiscent of the Nothrotheriini. A feature not seen in Hapalops or other Megatheria and present in all species of Thalassocnus is the offset of the radial head, positioned partly lateral to the diaphysis, which causes the lateral margin of the proximal diaphysis to be deeply concave in anterior view. On both radii pertaining to the holotype of $T$. natans and several specimens referred to T. littoralis and T. yaucensis, a small and shallow but well-marked round fossa is present approximately at the center of the proximal articular surface. On the posterior margin of the head is a well-developed semicircular articular surface for the ulna, the articular circumference (Fig. 16). This orientation of the proximal radioulnar articular surface is indicative of the semisupinated position in which the antebrachium would have been maintained. A similar condition is found in extant Pilosa, Myrmecophaga for instance. This facet is much reduced in the Nothrotheriini (corresponding to the morphology of the ulna, see above). This articular surface is extended medially in Thalassocnus thanks to a distal thickening of the proximal border of the head, forming a large lip in several specimens (Fig. 14). In the normal semi- 
supinated position of the antebrachium, this extension articulates with the supplementary articular surface that is laterally oriented and on the posterolateral edge of the coronoid process of the ulna. The bicipital tuberosity is well developed, and for the most part located on the medial side of the shaft, but extends slightly onto its posterior side. This tuberosity is located only a short distance distally from the proximal end. The bicipital tuberosity is weaker on all specimens of species later than T. natans. This tuberosity is also weakly developed in the Nothrotheriini. Distal to the bicipital tuberosity, on the medial edge of the bone, there is a grossly oval scar, which extends distally as a roughened line along about two-thirds of the diaphysis. This scar, probably for the interosseous ligament, is usually well developed in Thalassocnus. On MNHN.F.SAS499 and MUSM 1034, specimens representing young individuals (referred to T. littoralis and T. yaucensis, respectively), this scar for the interosseous ligament is already well developed. When the radius is placed in its usual semi-supinated position, this scar is exactly facing the crest that issues from the radial articulation of the ulna and which also extends along the diaphysis on about two-thirds of its length.

The lateral side of the distal end has three prominent tendinal grooves (Fig. 13). On the anterior edge, at the level of the styloid process, extending obliquely distally and anteriorly, the first groove, for the tendon of the abductor pollicis longus muscle, is narrow and deep. The middle groove, for the extensor carpi radialis muscle, is broad and shallow. In T. natans (no data for T. antiquus), it forms on the distal edge of the epiphysis, in lateral view, a concavity conspicuously deeper posteriorly than anteriorly, hence anteroposteriorly asymmetrical, as it is also the case in Mionothropus. This groove is wider and less asymmetrical in T. littoralis. In T. carolomartini and T. yaucensis, it is even wider, shallower, and symmetrical. The posterior margin of the distal end has a large process (herein called the posterodistal process), which is crossed by a groove for the tendon of the extensor digitorum communis muscle. The ulnar notch, almost absent in T. natans (no data for T. antiquus), is shallow but well marked in T. littoralis. In T. carolomartini and T. yaucensis, this notch is well extended proximally, forming a triangular surface on the posterior side of the bone. The distal articular surface for the carpus is roughly oval. This surface is conspicuously elongated anteroposteriorly in Thalassocnus when compared to other nothrotheriids, and in the species of Thalassocnus later than T. littoralis when compared to the early ones (Table 18). In all species earlier than $T$. carolomartini there is a sulcus extending from the groove for the extensor carpi radialis muscle about midway onto the articular surface. This sulcus coincides with the position where the scaphoid and lunar articulate. Reduced in $T$. carolomartini, this sulcus is absent in T. yaucensis. The posterodistal process mentioned above is very well developed in Thalassocnus, often reaching as far distally as the distal tip of the styloid process. A similar condition is 
found in M. americanum. This process is not developed to such an extent in Hapalops, Nothrotherium, and Mionothropus and is virtually absent in Nothrotheriops and Myrmecophaga.

Manus as a whole

The most complete manus belongs to SMNK-PAL 3815, a specimen referred to T. carolomartini that is represented by the articulated left and right manus (Fig. 17; see also Muizon et al. 2004b:fig. 9). This specimen was associated with the skull and mandible of the holotype (SMNK-PAL 3814; McDonald and Muizon 2002). Beside, another fairly complete right manus is part of the holotype of T. natans (Fig. 18). Each bone will be described independently (see Table 19 for measurements), but some general remarks can be given beforehand.

Relative to its proximodistal length, the carpus is wider mediolaterally in the latest species of Thalassocnus. This is most conspicuous when comparing the lunar of the different species (because of its otherwise conservative morphology in the different species). Another peculiarity of the carpus of Thalassocnus, more particularly the cuneiform, is its articulation with the fifth metacarpal, but this trait is only well developed on specimens referred to $T$. littoralis and T. carolomartini.

The metacarpals increase in length from medial to lateral, with the fourth and fifth being the longest and approximately equal in length. When articulated, the three central metacarpals are only slightly diverging distally, implying a narrow interdigital space. This condition is not observed in any other nothrotheriids, but is present in megatheriids. Furthermore, all the metacarpals show conspicuous scars of partial synostosis with the adjacent ones (except for the trapezium-Mc I complex, which only shows a fossa for an interosseous metacarpal ligament), even on the specimens referred to young individuals. This is also seen in megatheriines (Tito and De Iuliis 2003: 82), and to a lesser extent in the Nothrotheriini. As for the carpus, the proportions of the metacarpus also vary between the species of Thalassocnus (except for the trapezium-Mc I complex that is reduced in all species). On the whole the Mc II to V are slender in the early species and acquire stouter proportions (ratio of proximodistal length to dorsopalmar depth) in the later ones (see description of each metacarpal).

The ungual process of each digit (except for the fifth, which lacks one) displays a singular morphology that departs from that usually seen in sloths. These specializations are found in all species of Thalassocnus, and some of them that affect the second digit are more pronounced in the latest species of Thalassocnus. The subungual processes are not especially well developed in Thalassocnus when compared to that of Nothrotherium, and approach the condition seen in Nothrotheriops. 
Scaphoid

The general conformation of the scaphoid in Thalassocnus is similar to that of other nothrotheriids and megatheriines (Fig. 19a-e). The scaphoid is mediolaterally wider (when compared to its proximodistal length) in $T$. carolomartini than in other Megatheria (Table 20; no data for the earlier species). Thalassocnus yaucensis features an even wider scaphoid than T. carolomartini. The proximal articular surface for the radius is strongly convex. The medial side of the bone has a hook-like process, which bears a small, slightly convex to flat articular facet for the medioproximal process of the trapezium-Mc I complex (Fig. 19b). The articulation with the trapezium-Mc I complex is continued laterally and distally by a small articular surface, very slightly concave, that articulates with the lateral surface of the lateroproximal process of the trapezium-Mc I complex. In Thalassocnus, the lateral side of the bone is completely covered by the articular surface for the lunar (Fig. 19c). This differs from the narrow and crescent-shaped facet of Nothrotheriops and Mionothropus. This surface is clearly convex in T. antiquus and T. natans, slightly convex in T. littoralis, and almost flat in T. carolomartini and T. yaucensis. Dorsal to this surface a round and deep fossa is present. The articular surface for the lunar extends onto the lateral side of the process that contacts the magnum and separates the trapezoid from the lunar. In the description below, this process is referred to as the distodorsal process. The distal surface of this process articulates with the magnum. The articulation between the scaphoid and lunar is tight and forms a continuous articular surface for the radius that is convex both mediolaterally and dorsopalmarly. Medial to the distodorsal process on the distal side of the scaphoid is a triangular articular surface for the trapezoid. This surface is subdivided into two shallow concavities. Thalassocnus yaucensis differs from the earlier species of the genus in featuring a facet for the trapezoid that is clearly convex dorsopalmarly, in which the two concavities are separated by an elevation of the facet. The articular surface for the trapezoid extends onto the medial side of the distodorsal process. This facet differs from that of Nothrotheriops, in which it is discontinuous, formed by a dorsal part (borne by the distodorsal process; on some specimens divided itself into a medial and a lateral part, which results in a three-point articulation) and a palmar one. Megatherium americanum also differs in displaying a facet restricted to the dorsal half of the bone. In T. littoralis, the distodorsal process is more developed dorsally and more angular (since its distal and medial sides form an almost right angle) than in T. antiquus and T. natans (Fig. 20a, b). In that manner the scaphoid of the species later than T. natans resembles more that of Hapalops and other Megatheria. This process is even more developed dorsally (and slightly distally) and is also angular in $T$. carolomartini (Fig. 20c) and even more so in T. yaucensis (Fig. 20d). Another process, much smaller than the former, 
is located on the distopalmar edge of the bone (this process is herein referred to as the distopalmar process). The morphology of this process varies sensibly in the different species of Thalassocnus. On the holotype of T. antiquus (Fig. 20a), it is relatively well developed (compared to the other species), and bears on its medial side the palmar continuation of the facet for the trapezoid, which has a notable lateral extension; on its lateral side, the bone displays a small contact with the magnum. On the holotype of T. natans (Fig. 20b) and MNHN.F.SAS57 (?T. natans or ?T. littoralis), the process is also relatively well developed and bears a round and isolated facet for the magnum. In $T$. littoralis, the distopalmar process is lower, and features only one articular surface, on its medial side, for the continuation of the facet for the trapezoid, which is less extended laterally than that of the earlier species of the genus. In T. carolomartini (Fig. 20c) and T. yaucensis (Fig. 20d), the distopalmar process is vestigial or absent, and the palmar continuation of the facet for the trapezoid is reduced.

\section{Lunar}

The intraspecific variation of the carpus of Thalassocnus is probably most conspicuous when one considers the general shape of the lunar (Figs. 21a-c, 22a-c). In T. antiquus (Fig. 22a), it closely resembles that of other nothrotheriids, being proximodistally longer than mediolaterally wide (a relatively wide lunar is found in Nothrotheriops, but that is due to a local palmar widening). The three later species (no data for T. yaucensis) differ from T. antiquus in having a wider lunar (relative to its length), especially in T. carolomartini (Fig. 22b, c; Table 21), resulting in a bone that is wider than long. The proximal end is completely covered by the radial articular surface. It features a pronounced dorsopalmar convexity. This articular surface continues onto the dorsal surface, reaching the distal edge of the bone in T. antiquus (Fig. 22a) and T. natans (Fig. 22b) or covering only half of the proximodistal length in T. littoralis and T. carolomartini (Fig. 22c; including MNHN.F.SAS57) (no data for T. yaucensis). In this respect the condition of these late species is more reminiscent of that of other Megatheria. Viewed dorsally the bone is wedge shaped, broadest proximally and narrowing distally (Figs. 21a, 22a-b). It is even relatively narrower distally in the species later than T. antiquus, because of the widening of the bone that occurs mainly proximally. The articular surfaces for the scaphoid, magnum, and cuneiform are confluent so that the distal side of the lunar is completely covered by a continuous articular surface. The median part of the distal surface is formed by two processes, called herein dorsal and palmar processes (Fig. 21b, c). The latter reaches slightly farther distally than the former. The magnum fits into the notch between these two processes and also articulates on their medial sides. A notch of similar depth is found in Mionothropus, but it is shallower in Nothrotheriops. On the medial side of the bone (Fig. 21b), the 
surface for the scaphoid is concave in T. antiquus and T. natans, slightly concave in T. littoralis, and almost flat in $T$. carolomartini, corresponding to the morphology of the scaphoid (see above, no data for $T$. yaucensis but putatively as in T. carolomartini, given the morphology of the scaphoid). This surface contacts the articular surface for the magnum by forming a slight ridge. The lateral side of the bone is partly covered by the confluent facets for the cuneiform (proximally) and unciform (distally) (Fig. 21c). The surface is flat proximally and concave distally, and provides a tight articulation and close fit in Thalassocnus. This tight articulation is also provided by the presence of a proximodistally-elongated lip on the laterodistal edge of the bone that fits in a fossa on the mediodistal edge of the cuneiform. A contact with the unciform is also found in M. americanum and the Nothrotheriini, which is not the case in Hapalops and Mionothropus.

\section{Cuneiform}

The cuneiform (or ulnare) is shallow dorsopalmarly, and in the species later than T. antiquus, widened mediolaterally (Figs. 23a-c, 24a-d). The widening found in the other carpals of the later species of Thalassocnus is not as clear for this bone, due to the possible presence of a facet for the fifth metacarpal (see below). The proximal articular surface, for the antebrachium, is roughly flat and continuous palmarly with the facet for the pisiform. This condition differs from that of the Nothrotheriini in which the pisiform facet is located more proximally. The distal extension of this surface decreases when proceeding laterally. The proximal facet is broad as in Megalonyx Jefferson, 1799, Hapalops, and the Nothrotheriini, which contrast with the extremely reduced or absent one (as described by Owen 1858: 269) of M. americanum. The articular surface for the lunar on the medial side of the bone is composed of two continuous surfaces that meet at an obtuse angle (Fig. 23c). This facet occupies most of the medial side of the bone, contrasting with the condition of Nothrotheriops. This wedge shape fits into a notch on the lunar. The mediodistal angle of the bone is tapered and located between the lunar and unciform when the carpus is articulated. This angle is conspicuously extended distally in T. carolomartini (Fig. 24c, d) and T. yaucensis compared to that of the three earlier species of the genus (Fig. 24a, b). Most of the palmar side of the bone is covered by the articular surface for the pisiform, which is shifted to the lateral edge of the bone. In T. antiquus and T. natans, this surface is concave medially and convex laterally, while it is simply concave in the later species of the genus. Moreover, this articular surface almost reaches the distal edge of the bone in T. antiquus and T. natans, but has a weaker distal and medial extension in the later species of the genus. The entire distal surface is an articulation for the unciform. It is concave medially and convex laterally. A supplementary articular facet, absent on the holotypes of T. antiquus and $T$. 
natans (Fig. 24a) but present in all specimens referred to T. littoralis (Fig. 24b), extends lateral and dorsal to the articular surface for the unciform, forming an obtuse angle with it. This facet faces distally, laterally, and dorsally. This area of the bone is preserved on two specimens referred to T. carolomartini; one shows a large facet (Fig. 24c), as in T. littoralis, the other features a more reduced facet (Fig. 24d). On the only specimen referred to T. yaucensis in which this part of the bone is preserved, the facet is absent, but a conspicuous depression is found where it would have been located. This articular facet, for the proximal end of the fifth metacarpal, is not found in Hapalops and other Megatheria but in Megalonyx (although one of the 26 cuneiforms of Nothrotheriops in the LACM collection has a small facet that might have articulated with Mc V). Between the proximal and distal articular surfaces, the dorsal surface of the bone is marked by an elevated rugosity in T. antiquus and T. natans (but not as elevated as that of Nothrotheriops), or a rugose surface punctuated by small foramina in all the specimens referred to later species of the genus. The bone is therefore dorsopalmarly shallower in these species.

\section{Pisiform}

The pisiform has, in lateral or medial view, an overall semi-oval shape (Fig. 25a, b). It is mediolaterally compressed, bearing on its dorsal face the articular facet for the cuneiform, and on its palmar face a tuberosity for the insertion of the flexor carpi ulnaris muscle (inference from Myrmecophaga; Pouchet 1867). This tuberosity has a slight medial curvature. The facet for the cuneiform is flat or slightly concave and oval, differing from that of the Nothrotheriini (in which there are two continuous facets set at an obtuse angle to each other) and from $M$.

americanum in which it is an oval but distinctly concave facet. The morphology of this bone seems to vary intraspecifically, with two morphotypes. The first evidence for this hypothesis consists in the fact that specimens that display an articular facet of approximately the same size and also similar mediolateral widths differ greatly in their proximodistal and dorsopalmar lengths. Secondly, proximodistal and dorsopalmar lengths of pisiforms pertaining to specimens in which the other bones are similar in size differ conspicuously. Finally, in one morphotype, below called the 'large morphotype' (Fig. 25a), the articular facet does not reach the proximal edge of the bone, while it does so on the 'small morphotype' (Fig. 25b). In MNHN.F.SAS53, a specimen referred to T. littoralis that is interpreted as a subadult, putatively a male (humerus shows no complete epiphyseal closure but is longer than some specimens with complete closure, see humerus description above), a 'large morphotype' is found (Fig. 25a). 
This bone is unknown in T. natans. The trapezoid of Thalassocnus is relatively small (Figs. 26a-c, 27a, b), and its proportions relative to the manus are more reminiscent of that of M. americanum than that of other Megatheria or Hapalops. The shape of the trapezoid found in all species of Thalassocnus except T. antiquus (including MNHN.F.SAS57) is triangular in proximal view, with the dorsal edge wider than the palmar (Fig. 27b). That of $T$. antiquus differs from this morphology in presenting a well-developed lateral extension at the level of the palmar end of the bone (lateropalmar process, see below; Fig. 27a). Moreover, in T. yaucensis, the bone is lengthened proximodistally when compared to the earlier species of the genus, resulting in very stout proportions. The articular surface for the scaphoid covers the entire proximal surface (Fig. 26b), which differs from the two or three discontinuous facets found in Nothrotheriops. The dorsal half of this surface is mediolaterally convex, which corresponds to the articulation with the distodorsal process of the scaphoid and the surface medial to it, respectively. Consistent with the morphology of the scaphoid (see above), the whole surface is much more concave dorsopalmarly in T. yaucensis than in the other species of the genus. The laterodorsal part of the surface for the scaphoid does not reach the dorsal margin of the bone, as it does in Nothrotheriops and Mionothropus. Furthermore, dorsal to the laterodorsal part of the proximal articular surface, the trapezoid features a distally-directed small tubersosity. Therefore, when the carpus is articulated, the dorsal end of the trapezoid is dorsal to the distodorsal process of the scaphoid, forming an elevation on the dorsal surface of the carpus. The palmar half of the proximal surface is elongated proximally by a small process on the lateral edge of the bone. This process, herein called the lateropalmar process, is blunt and well expanded laterally in T. antiquus (Fig. 27a). In T. littoralis (including MNHN.F.SAS57), this process is sharper, less developed laterally, and forms a crest on the palmar half of the bone. This forms an acute angle with the distal side that fits between the dorsal and distopalmar processes of the scaphoid. In T. carolomartini and T. yaucensis, this process is less developed, a continuous crest being found on the entire dorsopalmar length of the lateral edge of the bone (Fig. 27b). In dorsal view, the trapezoid is approximately diamond-shaped (lozengeshaped) in T. littoralis, but more rectangular in T. carolomartini.

The distal articular surface is developed on the entire dorsopalmar length of the bone, and consists of a triangular articular surface, wider dorsally, marked by an elevated crest, elongated dorsopalmarly, located in its dorsal half (Fig. 26c). This entire triangular and dorsally-convex articular surface is for the Mc II. This disposition is reminiscent of that of Mionothropus in its triangular shape and its extension on the whole mediolateral width of the bone, but it differs in reaching the palmar margin of the bone. In Nothrotheriops, the facet reaches the palmar end of the bone but is restricted to the lateral half of it. The lateral side of the bone shows a dorsopalmarly elongated and 
proximodistally narrow surface for the magnum (Fig. 26a). Consequently, the dorsal contact between the two bones is reduced compared to that of Mionothropus. This facet forms an obtuse angle with the distal side of the bone. In $T$. antiquus, a supplementary rounded facet isolated from the other articular surface is borne by the laterally expanded lateropalmar process found in this species (Fig. 27a). In T. yaucensis, the contact with the magnum seems to be much reduced (well-preserved trapezoid and magnum are not known for this species). There is consequently no contact between the Mc III and trapezoid in Thalassocnus. This articulation is also absent in M. americanum and Hapalops (Scott 1903-1904: 193). Since Scott (1903-1904) describes in Prepotherium Ameghino, 1891 a contact between the Mc II and the magnum and since this contact is associated (in observed taxa) with the presence of a lateroproximal process of the Mc II (see description below) that separates the Mc III from the trapezoid, we assume that a contact between the trapezoid and Mc III is also absent in Prepotherium. A contact between the Mc III and trapezoid is found in Nothrotheriops (personal observations; Paula Couto 1974), although the trapezoid is fused to the magnum in the latter.

\section{Magnum}

This bone is unknown in T. natans. The magnum of Thalassocnus is wedge shaped with a prominent round process on the palmar edge of the proximal surface, herein called the palmar process (Figs. 28a-d, 29a, b). In other nothrotheriids this process is more angular. Thalassocnus also departs from Nothrotheriops in lacking the prominent palmar tuberosity found in the latter genus. This process fits into a concavity formed by the articulation of the scaphoid and lunar; their junction is marked by a low ridge on the dorsal surface of the process. The dorsal end in dorsal view approximates in outline an irregular heptagon, with the proximal side contacting the lunar, the medioproximal side contacting the distodorsal process of the scaphoid, the medial side contacting the trapezoid, the mediodistal side contacting the Mc II, the distal and laterodistal sides both contacting the Mc III, and the lateroproximal side contacting the unciform (Figs. 17, 28a). Therefore, as in M. americanum and other nothrotheriids except for Mionothropus, the magnum does not contact the cuneiform (although it is very close to it in Nothrotherium). The contact with the lunar is less extensive in T. carolomartini and T. yaucensis than in T. littoralis and T. antiquus.

The entire distal surface is covered by two articular areas elongated dorsopalmarly (Fig. 28d). The lateral one, entirely for the third metacarpal, and representing almost all the articular surface, faces laterodistally and is gently convex dorsally and concave palmarly, except for $T$. yaucensis in which it is flat. The smaller medial area 
features different morphologies among the species of Thalassocnus. In T. antiquus and T. littoralis, this area shows two facets, separated by an oblique low ridge. The first facet, the smaller, forms a triangle restricted to the distodorsal quarter of the medial area, is continuous and forms an acute angle with the lateral area (Fig. 29a, c). This facet articulates with the lateral side of the medioproximal process of the Mc III (see below). This facet on the magnum was putatively present in $T$. natans, since a similar process is present on the Mc III of this species. In $T$. carolomartini, this facet is either very minute or absent (Fig. 29b, d); this facet is absent on the only specimen referred to T. yaucensis that preserves this area of the bone. The rest of the medial area (or all of it when the small facet for the Mc III is absent) of the distal articular surface is for the lateroproximal process of the Mc II. For this facet a slight difference was putatively present between the magna of the different species, i.e. a strongly concave facet in the early species T. antiquus and T. natans (for the latter this is inferred from the morphology of their Mc II, see description below), a less concave facet in T. littoralis and T. carolomartini, and a flat facet in T. yaucensis. A facet for the Mc II on the magnum is lacking in other nothrotheriids, but was observed in M. americanum and described in Prepotherium (Scott 1903-1904: 339).

On the holotype of $T$. antiquus, on the medial side of the bone, palmar to the proximal process, is a small, isolated, flat and sub-circular facet directed mediopalmarly for the trapezoid (Fig. 29a). Such a facet is found on MNHN.F.SAS57 (?T. natans or ?T. littoralis), but it articulates directly with the scaphoid (as if the large lateropalmar process of the trapezoid of T. antiquus was in this specimen included in the distopalmar process of the scaphoid). More specimens referred to T. natans are necessary to make a secure assessment, but in view of the similar morphology of the holotype of this species and that of MNHN.F.SAS57, the morphology of the magnum of the latter specimen was probably found in $T$. natans. The rest of the contact with this bone is by another facet, dorsopalmarly elongated, restricted to the dorsal half of the bone. A similar condition is found in Nothrotheriops. Moreover, a minute facet for the scaphoid is found on the mediopalmar end of the proximal process, but it is not clearly isolated from the rest of the articular surface. In the later species, T. littoralis, T. carolomartini, and $T$. yaucensis, the facet for the trapezoid is not discontinuous, but rather forms an elongated strip on all of the dorsopalmar depth of the bone (Fig. 29b). No homologous facet for the trapezoid as mentioned for T. antiquus can be observed in the other species. Distal to the facet for the Mc III, the lateral side of the bone shows a facet for the unciform, extending on the lateral side of the proximal process. This facet contacts that for the Mc III and forms a salient ridge, restricted to the dorsal half of the bone. This ridge inserts in a corresponding dorsopalmarly-elongated fossa on the unciform. This ridge is more developed in T. yaucensis than in the earlier species of the genus. In all 
species except T. yaucensis, this facet joins that of the lunar and forms a low ridge. In the latest species, this ridge appears as a convex surface.

\section{Unciform}

This bone is unknown in T. natans. The bone is short proximodistally as in other Megatheria (Figs. 30a-d, 31a-c). The dorsal side of the unciform is sub-rectangular in outline in all species (Fig. 31a, b) except T. yaucensis, in which it is trapezoidal, with the distal side being the shorter (Fig. 31c). Moreover, in this species, the dorsal side of the bone is lengthened proximodistally, and hence is relatively narrower mediolaterally. Viewed proximally, the unciform is somewhat triangular in shape with the dorsal edge wider than the mediopalmar or distopalmar. The entire proximal surface forms an articulation that mostly contacts the cuneiform, except for the mediopalmar corner (Fig. $30 \mathrm{a}, \mathrm{c})$. This is a raised cuboid process that fits between the cuneiform and the lunar. This process is much reduced in T. yaucensis when compared to that of the earlier species of the genus, forming only a short protrusion on the proximal side of the bone. The medial side of this process, oriented medioproximally, shows an articular surface, continuing dorsally to reach the dorsal edge of the bone, for the corresponding surface on the magnum. This facet is mostly on the medial side of the bone, but visible in distal view, and separated from the distal articular surface on its palmar half by a sulcus. In $T$. littoralis, at the laterodorsal corner of the bone, a proximal protrusion slightly expands laterally the proximal facet. When the unciform is articulated with the cuneiform, this protrusion is at the level of the facet for the $\mathrm{Mc} \mathrm{V}$ of the latter bone (see above). This protrusion seems to be absent in the other species.

The distal surface is composed of two articular facets, separated from each other by a dorsopalmar ridge (Fig. 30d). The medial facet, concave dorsally and convex palmarly, articulates with the lateral surface of the lateroproximal process of the third metacarpal. In T. antiquus (no data for T. natans, but putatively the same, as inferred from the morphology of the Mc III), the dorsal part of this facet faces mediodistally; it faces more distally in T. littoralis and even more in T. carolomartini; it is reduced in T. yaucensis. In T. antiquus and T. littoralis, the lateral facet is divided into two areas. The first area, restricted to the dorsal half of the bone, gently concave, is for the proximodorsal process of the fourth metacarpal. The rest of the lateral facet, irregularly concave, is for the rest of the proximal facet of the Mc IV. In some specimens, there is no clear demarcation between the two areas, corresponding to the reduction of the proximodorsal process of the Mc IV (see description below). Moreover, the dorsal third of this facet is marked in T. yaucensis by a rounded elevation. The palmar junction of the medial and lateral facets forms a ridge, more marked in the later species than in T. antiquus. On the lateral side of the bone, on the holotype of $T$. 
antiquus (Fig. 31a; no data for T. natans, but it presumably showed a similar condition, as inferred from the morphology of the cuneiform), a non-articular triangular area is found. Therefore the earliest species of Thalassocnus show either a very minute or no articulation between the unciform and the fifth metacarpal; the lack of a preserved proximal $\mathrm{Mc} \mathrm{V}$ in T. antiquus and T. natans prevents any determination as to which of the two possibilities is more likely. In any case, the two bones were positioned mainly proximodistally to one another, as in other Megatheria. However, in T. littoralis and T. carolomartini an articular facet for the Mc $\mathrm{V}$ is found at this triangular area, which is restricted to the dorsal half of the bone (Fig. 31b, c). This articulation differs conspicuously from that of all other Megatheria in being reduced and lateral to the carpus, and not laterodistally as in the latter. This laterally oriented facet is part of the peculiar articulation between the Mc V and the carpus, as will be described below. On the only specimen referred to T. yaucensis that preserves this area, the facet for the Mc V is lacking.

Trapezium-first metacarpal complex (MCC)

As it is widespread among Tardigrada, the first metacarpal is co-ossified with the trapezium, forming a complex, the MCC sensu De Iuliis and Cartelle (1994) (Fig. 32a-c). In Thalassocnus the two bones are never found unfused, even in the specimens MNHN.F.SAS2 and MUSM 1034 that are interpreted as young individuals. In Nothrotherium these bones are fused (although a fissure marks the fusion of the two bones); in Mionothropus they are only found unfused. Nothrotheriops is represented by specimens in which the bones may be either separate or coossified (Stock 1925). Since Nothrotheriops is represented by the greatest number of specimens, it is possible that the variation observed in this taxon was present in the other nothrotheriids, Thalassocnus included. Another possibility is that the bone identified as the free trapezium is in fact an ossified meniscus, its shape being reminiscent of that structure, already described in Thalassocnus (Salas et al. 2005).

The MCC is short and stout, unlike those of other nothrotheriids in which this bone is more elongated proximodistally and slender, hence being in Thalassocnus more reminiscent of the reduced complex of $M$. americanum (Table 22). The mediolateral width is roughly equal to the proximodistal length. In dorsal view the proximal half of the complex presents a short and massive lateral process for the articular surface for the second metacarpal. The distal limit of the process and the rest of the bone are separated by a deep groove, which is responsible for the broad reversed L-shape of the dorsal view of the complex. The articular surface for the scaphoid is an excavation bounded on the lateral side by a proximal extension of the lateral process (lateroproximal process) and medially by a smaller proximal extension of the tuberosity for the insertion of the abductor pollicis longus muscle 
(medioproximal process). It should be added that the medial side of this process is, in all specimens referred to $T$. littoralis and T. carolomartini, conspicuously smoothed and flattened. Laterally, the articular surface for the second metacarpal is composed, in T. antiquus and T. littoralis (no data for T. natans), of two facets set at an angle to each other and forming a wedge-shaped structure that lodges in a complementary recess on the medial side of the second metacarpal. In T. carolomartini (no data for T. yaucensis), the facet is flattened, being only slightly convex. The distal articular surface covers the entire distal end. The primary curvature is dorsal-palmar, and the facet is gently convex due to a vestigial keel on its palmar edge that extends dorsopalmarly. This keel appears slightly more conspicuous in T. antiquus than in the later species of the genus (no data for T. natans). The condition of T. antiquus is reminiscent of that of Nothrotherium, while the smooth surface of the later species of the genus is reminiscent of Nothrotheriops. On MNHN.F.SAS53 (referred to a subadult T. littoralis), there is a small but marked fossa proximal to this keel for the proximal spur of the ungual phalanx (on the bone pertaining to the same specimen) when the articulation is flexed. In some specimens referred to T. littoralis (e.g., MNHN.F.SAS163), there is a small ridge on the medial side of the distal facet. In T. carolomartini the distal articular surface extends more proximally on its mediodorsal corner.

\section{Digit One}

The proximal and ungual phalanges of digit one of the manus of Thalassocnus are assumed to be fused (Fig. 33). This assumption is based on the anatomy of Nothrotherium and Mionothropus, in which the distal end of the MCC is similar (especially to that of T. antiquus), featuring a dull distal carina. Moreover, in these other taxa the proximal end of the ungual phalanx features a 'classical' morphology with an overhanging process and a trochleated surface. We hence understand that Thalassocnus differs from the condition present in other nothrotheriids, in which the first digit has two phalanges. It can be added that in Eremotherium eomigrans De Iuliis and Cartelle, 1999, both phalanges of the pollex are present, but found either separated or fused (De Iuliis and Cartelle 1999). Digit I is absent in M. americanum. On the whole, digit I of Thalassocnus distinctly differs from that of the other nothrotheriids, in which it is much longer and more slender, and hence approaches the reduced first digit of megatheriids.

The ungual process of the ungual phalanx is short, but robust and stout. It departs from that of other sloths in having the shape of a right triangle in profile (Fig. 33c). Indeed the dorsal length of the bone is approximately twice as great as the dorsopalmar depth at the proximal end. The ungual process of the first digit is therefore the only one that is rectilinear, not being palmarly curved as that of the other digits. In T. natans the proximal articular facet is 
small, subcircular, gently concave, and does not reach the dorsal and palmar edges of the bone, being restricted to the center of the proximal face. In T. littoralis and T. carolomartini (no data for the two other species), the proximal facet is more oval, more concave, and almost covers the entire proximal end of the bone. In Nothrotheriops (and to a lesser extent in Nothrotherium) there is a proximal process overhanging the facet dorsally. This process is absent in Thalassocnus. On some specimens, two well-fused small sesamoids are found palmar to the proximal facet. The ungual process has a dorsopalmar constriction approximately at midlength. Distal to this constriction, the ungual process becomes somewhat more robust and porous. In all specimens well enough preserved, the medial side of the ungual process is marked by a foramen extended proximally by a shallow sulcus. The palmar surface of the ungual crest (bony shelf for the horny claw), which is thickened and perforated by two small foramina, is the location of the insertion of the digital flexor muscle (inferred from Myrmecophaga; Pouchet 1867). The medial side of the ungual crest is either marked by a dorsopalmarly-directed crest or thickened relative to the lateral side.

\section{Second Metacarpal}

The second metacarpal is the smallest, not counting the MCC (Fig. 34a-d). The proportions of the second metacarpal (as well as the metacarpals lateral to it) are highly divergent in the various species of Thalassocnus (Fig. 35a-e). A distinct gradient can be observed, the length of the Mc II (compared to the dorsopalmar depth at midshaft) clearly decreasing from T. antiquus to T. yaucensis (Table 23). It can be noted that other Megatheria display diverse proportions as well. The distal end of the second metacarpal is wider mediolaterally and deeper dorsopalmarly than the proximal end. The proximal articular surface for the trapezoid is excavated and forms an elongate depression occupying the entire dorsopalmar length of the proximal end, with the medial and lateral sides forming narrow crests (Fig. 34c). This departs from the concavo-convex facet of the Nothrotheriini. This excavation is deeper and wider in T. littoralis, T. carolomartini, and T. yaucensis than in the earlier species of the genus, the medial and lateral crests hence being more elevated in the later species. Even on MNHN.F.SAS2 (referred to a very young individual of $T$. littoralis), the proximal facet is proportionally deeper and wider than that of the holotype of T. natans. A small nonarticular notch is found on the median part of the dorsal edge of the proximal end. This notch is larger in $T$. carolomartini and T. yaucensis. The articular surface for the MCC is formed by two confluent and concave surfaces and complements that described for the complex. In T. antiquus and T. natans, the two facets are more separated (their junction is less developed distally). The whole facet is less concave and extends less distally than in the later species of the genus. Distal to this facet there is a well-marked fossa (at the level of the fossa described earlier on the 
MCC when the metacarpus is articulated), probably accommodating an important interosseous metacarpal ligament between the first and second metacarpals. When articulated, the MCC and Mc II diverge distally, as in the Nothrotheriini.

The lateral side of the proximal end projects laterally to form a small process (lateroproximal process; Fig. 35a) that overlaps the third metacarpal when they are articulated. The lateral side of this process distally forms the facet for the third metacarpal. In T. antiquus and T. natans, the proximal border of this process forms a facet slightly offset medially and marked approximately at mid-depth by a conspicuous convexity. This facet is for the magnum. In T. littoralis, this facet differs only by the weaker development of the convexity. In T. carolomartini and T. yaucensis, the whole lateroproximal process is clearly expanded, resulting proximally in a larger facet for the magnum (which is also flatter, especially in T. yaucensis) and distally in a more convex facet for the Mc III.

Distal to the facet for the Mc III, the bone features, up to the midshaft, a roughened and slightly elevated surface, which is dorsopalmarly deep proximally and shallows distally (Fig. 34b). This condition probably reflects a partial synostosis with the similar, but excavated, surface found on the medial side of the Mc III. This condition is unlikely the result of arthritis, since it is widespread among specimens and since specimens MNHN.F.SAS2 and MUSM 1034 interpreted as young individuals (of $T$. littoralis and T. yaucensis respectively) are affected by this condition. A similar condition is described in M. americanum (Owen 1858: 270) and Prepotherium (Scott 19031904: 340). It was also observed, but to a lesser extent, in mature specimens of Nothrotherium, and is relatively little developed in Nothrotheriops. The dorsal surface of the shaft shows a triangular roughened surface extending along the distal two-thirds of the bone, probably for the extensor carpi radialis muscle. Pouchet (1867) mentions that this muscle inserts on the Mc III in Myrmecophaga. In Canis Linnaeus, 1758 and Homo Linnaeus, 1758, the muscle inserts on both Mc II and Mc III, but more proximally.

The distal carina is large and well developed (Fig. 34d). It is offset laterally, so the medial articular surface forms a large flat shelf. The lateral articular surface is a small narrow shelf. The dorsal edge of the carina starts at the dorsal edge of the shaft but extends onto the palmar surface. The carina is broadly curved dorsopalmarly and less so mediolaterally. An enhanced flexion capability of this metacarpophalangeal joint was therefore present in Thalassocnus, as was apparently also the case in the Nothrotheriini. However, little mediolateral deviation was possible at this joint. The carina is slightly wider and blunter in T. carolomartini and T. yaucensis than in the earlier species of the genus. This carina, and with it all the distal half of the bone, are affected, when seen distally, by a strong torsion that is clockwise when on the left side, i.e., the palmar side faces mediopalmarly. This implies that the 
whole second digit is rotated, its morphological palmar side thus facing (at least partially) medially (Fig. 17). The distal carina forms an angle of approximately $20^{\circ}$ with the vertical plane (dorsopalmar) in T. antiquus (Fig. 35f) and T. natans (Fig. 35g), which is more rotated than in Hapalops, and approaches the condition seen in the Nothrotheriini. The torsion of the digit affects more markedly the later species of the genus. In T. littoralis, the angle between the distal carina and the vertical plane is around $30^{\circ}$, so the distal articular facet medial to the carina extends dorsally on the entire mediolateral width of the bone (Fig. 35h). In T. carolomartini (Fig. 35i) and T. yaucensis (Fig. $35 \mathrm{j}$ ), this angle is $35-40^{\circ}$, hence the dorsal end of the carina is clearly directed more laterally. The ventral side of the shaft shows, just proximal to the distal articular facet and medial to the distal carina, a marked fossa for a medial sesamoid. This fossa is deeper in the species later than T. natans. The lateral (palmar) sesamoid is fused to the MC II on the holotype of T. antiquus (Fig. 35f). Both medial and lateral sesamoids are preserved on the left manus pertaining to the specimen SMNK-PAL 3815 (T. carolomartini). The medial one is larger and partly fused to the palmar edge of the median carina (Fig. 35i). It is elongated distally and it overhangs palmarly the articulation medial to the carina. In the right manus of the same specimen, no sesamoids are preserved, but the medial part of the shaft lateral to the palmar continuation of the carina features a conspicuous tuberosity. Most of the specimens referred to $T$. littoralis and the holotypes of T. natans and T. yaucensis lack a small part of the palmar continuation of the distal carina. This is probably due to the former presence of the medial sesamoid fused to this part of the bone. This medial displacement of the lateral palmar sesamoid is probably due to the torsion of the digit. Based on a larger (and grooved) medial palmar sesamoid, the medial tendon of the interosseous muscle in Mionothropus was interpreted as larger and correlated to the inferred in-turned posture of the manus (De Iuliis et al. 2011).

\section{Digit Two}

As mentioned above, the torsion affecting the distal half of the Mc II implies that, when articulated, the morphological palmar side of the phalanges faces (at least partially) medially. But in the following description the bone will be oriented as in the general mammalian condition (i.e., not affected by the torsion). The proximal phalanx is shortened proximodistally as in sloths in general (Fig. 36a-c). The proximal articular surface has a deep groove for the distal carina of the Mc II. This groove is, corresponding to the carina, slightly wider and smoother in $T$. carolomartini and T. yaucensis than in the earlier species of the genus. Medial to the proximal groove is a welldeveloped articular surface for the part of the distal facet of the Mc II medial to the carina. It covers the palmar twothirds of the height of the bone. On either side of the median groove, the palmar edge of the bone shows a small, flat 
facet for a palmar sesamoid. The lateral facet is larger than the medial; the former is facing proximopalmarly, while the latter is facing proximally. The distal surface has prominent medial and lateral extensions separated by a deep groove bearing the articular surface for the second phalanx. These medial and lateral extensions are not regularly convex but somewhat pointed distally, i.e., the dorsal half forms a flattened facet facing distodorsally, and the palmar half forms a flattened facet facing distopalmarly. The dorsal part of this groove is marked by a shallow fossa for the proximodorsal process of the second phalanx. These two features reflect the small amplitude of the flexion-extension of this joint in Thalassocnus. A similar condition is present in the Nothrotheriini.

The second phalanx is elongate and is about three times longer than the proximal phalanx (Fig. 36d-f). The proximal articular surface displays, as in other sloths, a prominent median carina separating two slightly excavated articular surfaces. This carina shows in profile a strongly concave proximal edge. In other words, its dorsal and palmar ends form processes directed proximally that lodge dorsal and palmar to the groove of the distal articular surface of the proximal phalanx. As in the Nothrotheriini and M. americanum, the dorsopalmar depth of the shaft decreases distally up to the distal trochlea. Just proximal to the distal trochlea the shaft, on both the medial and lateral sides, is a low ridge with a roughened surface that is directed distodorsally. This marks the insertion of the lumbricales muscles (inferred from Myrmecophaga; Pouchet 1867). The distal end has a prominent fossa on the dorsal surface for the reception of the overhanging process of the ungual phalanx. Several specimens referred to $T$. littoralis feature a deepened fossa when compared to the earlier species of the genus; T. carolomartini also features a deep fossa; the only specimen preserving this bone and referred to T. yaucensis is interpreted as a young individual (MUSM 1034), and features a very deep fossa. A deeper fossa is therefore found in the species later than T. natans. The fossa is incipient in Nothrotherium and relatively shallow in Nothrotheriops. The distal articular surface for the ungual phalanx forms a trochlea that starts on the dorsal surface and continues onto the palmar surface to form about three-quarters of a circle. The width of the trochlea is less than that of the shaft, hence differing from that of the Nothrotheriini in which it is equal or greater. The lateral condyle is slightly larger than the medial one, as described in Nothrotheriops (Paula Couto 1974). But the illustration of Stock (1925: fig. 24a) does not depict such a condition, or at least not one as marked as in Thalassocnus. This condition is also absent in Nothrotherium. In M. americanum the lateral condyle is slightly larger. In T. antiquus and T. littoralis (no data for T. natans), the lateral condyle only protrudes dorsally from the level of the dorsal edge of the medial one, while in T. carolomartini and T. yaucensis it is more developed dorsally and palmarly. This completes distally the medial rotation of the digit, allowing the ungual phalanx to be positioned medial to the other phalanges when flexed. Where the distal articular surface terminates on 
the palmar side of the bone there is another deep fossa to receive the proximopalmar process of the ungual phalanx. As for the dorsal fossa, the ventral one is deeper in the late species of Thalassocnus, which allows more extensive flexion. During maximum flexion, the minimum angle between the long axes of the second and ungual phalanges is approximately $70^{\circ}$ on Nothrotheriops and M. americanum and $85^{\circ}$ in Nothrotherium. This angle is $75^{\circ}$ in $T$. antiquus and $70^{\circ}$ in $T$. littoralis (no data for T. natans), while the value in T. carolomartini and T. yaucensis is only $60^{\circ}$ for the same angle.

It should be mentioned that PPI 246, an isolated phalanx found at the Aguada de Lomas locality in the horizon (or close to it) of the holotype of T. antiquus, is reminiscent of Thalassocnus. However, it differs from other specimens in being more gracile, having the proximal facet less concave, and the distal dorsal and palmar fossae very shallow.

The ungual phalanx of digit II of the species of Thalassocnus later than T. antiquus (no data for T. natans) is remarkable by the dorsopalmar flattening of its ungual process (Fig. 36g, h). In T. antiquus (Fig. 37a) the semicircular shape in cross-section is reminiscent of that seen in other nothrotheriids (M. americanum also displays a process that is rounded dorsally and flat palmarly, but differs by being flattened dorsopalmarly). However, $T$. antiquus departs from other nothrotheriids in having an ungual phalanx that is wider (relative to the depth of the horizontal ramus of the mandible; Table 24). The later species of the genus display a relatively broader process (Figs. $36 \mathrm{~h}, 37 \mathrm{~b}$, c; Table 24). The ungual process of the second digit differs from that of the other digits in being curved palmarly, the distal tip being palmar relative to the level of the subungual surface. However, conspicuous intraspecific variation was observed in the curvature and palmar extension of this process. The shape of this process ranges from being strongly curved (forming almost a quarter of a circle; Fig. 37d) and dorsopalmarly deep (part of ungual process palmar to subungual process almost as deep as depth at proximal end; Table 25) to an almost rectilinear process weakly protruding palmarly (Fig. 37e). Intermediary conditions are also observed (Figs. 36h, 37f). Notable differences in the morphology of this process were found in T. littoralis (MNHN.F.SAS53 and MUSM 2054 for instance) and in T. yaucensis (MUSM 37 and MUSM 1034; Fig. 37e, f). The lateral and medial sides of the ungual process are marked, in their proximal half, by a sulcus ending distally at a small foramen. The proximal articular surface of the ungual phalanx features a median carina, concave dorsopalmarly, which joins dorsally a welldeveloped overhanging process, and palmarly a less-developed proximopalmar process. The palmar surface of the ungual crest is marked proximally by two oval foramina (positioned medially and laterally). The distal part of this surface is roughened, which identifies the insertion of the flexor digitorum profundus muscle. Some specimens 
additionally feature two irregular and shallow concavities. None of the specimens shows a well-developed subungual process, which is also the case in the Nothrotheriini (although Stock 1925 figured an ungual phalanx with a prominent one).

\section{Third Metacarpal}

The third metacarpal has a more rectangular outline when viewed dorsally than the second (Fig. 38a-d). Relative to its depth at midshaft, the Mc III of T. antiquus is much longer than that of the later species of the genus; the proportions of T. natans fall in the range found in T. littoralis; the metacarpal is shorter in the later species, especially T. yaucensis (Table 26). Other Megatheria display various proportions, but the extremely stout ones of $T$. yaucensis are only reached (and even exceeded) by M. americanum. The mediolateral width and dorsopalmar depth of both the proximal and distal ends are similar. The proximal end of the bone is formed by four confluent facets separated by ridges (Fig. 38d). The lateralmost facet of the proximal epiphysis, for the Mc IV, is slightly convex; proximal to it is the facet for the unciform. These facets intersect at an acute angle and are supported by a square process (lateroproximal process) that overlaps the fourth metacarpal when in articulation (Fig. 38a). The facet for the unciform is directed lateroproximally except for a small dorsal triangular portion. In T. antiquus and T. natans, this portion is directed lateroproximally (and very slightly dorsally), but more proximally (and hence less laterally) in $T$. littoralis, and even more proximally in T. carolomartini. An offset from the rest of the facet is therefore more conspicuous in the latter species. In T. yaucensis, this part of the facet for the unciform is reduced in concordance with the morphology of the latter bone (described above), but the bone features the offset found in the species later than T. natans. The next medial articular surface, for the magnum, is in T. antiquus, T. natans, and T. littoralis deeply excavated along its dorsal edge; its lateral slope is also carried by the lateroproximal process. This facet is broadly confluent with the facet for the second metacarpal and is separated from it by a ridge, weak palmarly but increasing its proximal extension dorsally to form a small but prominent medioproximal process (Fig. 38a). This process is reduced (and sometimes almost absent) in T. carolomartini, in which the facets for the magnum and Mc II are separated by a lower ridge on the entire dorsopalmar depth of the bone. The medialmost facet, for the Mc II, appears to be intraspecifically variable, since it may be semicircular and regularly concave dorsopalmarly, or more developed distally and more concave for its dorsal half.

The dorsopalmar depth of the shaft is less than that of either end and the palmar edge of the bone is concave when viewed from the side. On the holotype of $T$. natans, a prominent ridge extends the length of the dorsal surface 
from the medioproximal process to connect with the dorsal surface of the distal carina. There is some interspecific (and interindividual) variation in the development of this ridge, which is probably where the extensor carpi radialis muscle inserted (inferred from Tamandua; Taylor 1978). As described for the other intermetacarpal articulations, synostosis scars are present on the proximal half of the shaft.

The distal carina extends from the dorsal edge of the shaft and continues a short distance onto the palmar surface (Fig. 38b). Hence the carina occupies the entire dorsopalmar depth of the bone, as in other nothrotheriids and Hapalops, and differs from that of M. americanum in which it is confined to the dorsal half of the bone. Unlike the second metacarpal, the carina on the third metacarpal is straight both dorsopalmarly and mediolaterally, and its palmar edge is at a right angle to the distal part. Some specimens of T. carolomartini and T. yaucensis differ from the earlier species of the genus in having the dorsal half of this carina broadened and the palmar half deviated laterally.

This implies a slightly more rotated digit in T. carolomartini and T. yaucensis (but not a difference in the proportions of the second digit, see above). The articular surface for the proximal phalanx medial to the carina is large and extends the entire dorsopalmar depth of the distal end, while the lateral surface is small and confined to the palmar edge. In normal position, therefore, very restricted flexion-extension and only medial deviation of digit three were possible in Thalassocnus.

The holotype of T. antiquus features a well-developed, partly-fused lateral (palmar) sesamoid. Some elements of MNHN.F.SAS2, a very immature individual, were found articulated. The distopalmar edge of its Mc III bears two sesamoids, which are partly fused to the metacarpal. The lateral one is located lateral to the median carina. The medial one is found palmar to the carina. All other specimens referred to T. littoralis and the holotype of $T$. natans lack a small part of the palmar continuation of the distal carina. This is probably due to the former presence of the medial sesamoid fused to this part of the bone. A large facet for the lateral (palmar) sesamoid is found on SMNKPAL 3815 (T. carolomartini; Fig. 38c) and on the holotype of T. yaucensis.

\section{Digit Three}

All the species of Thalassocnus except the two latest ones are unique among nothrotheriids in featuring coossified proximal and second phalanges of digit three of the manus (Fig. 39a, b). While no sign of their former separation is visible on the dorsal surface, most specimens display a small fissure indicating the junction of the two bones on the ventral surface. This fusion of the two bones is well represented in the studied sample, and is present in all specimens of T. antiquus, T. natans, and T. littoralis and in both manus of SMNK-PAL 3815 (T. carolomartini). 
The fusion of these two bones also occurs in both M. americanum and Eremotherium laurillardi (De Iuliis and Cartelle, 1994). In M. americanum, the fissure indicative of fusion is visible on the dorsal face of the bone, but not on its palmar face. However, MNHN.F.SAO51, a specimen that is probably referrable to T. carolomartini, seems to be a free proximal phalanx of the third digit. Moreover, MUSM 1995, a specimen also referred to T. carolomartini that features an undetermined bone pathology (arthritis?) on one manus, displays, on both the left and right manus, free phalanges of the third digit. In T. yaucensis, the bones do not seem to be co-ossified, since a short second phalanx (from both right and left manus) is preserved in the holotype, and is probably that of third digit. Furthermore, MUSM 1035, which is referred to a young individual of T. yaucensis, has on both manus separated proximal and second phalanges of the third digit. The proximal articular surface of this complex (or of the first phalanx if not co-ossified) is similar to that of the proximal phalanx of the second digit, i.e., a median groove with the medial edge enlarged for the complementary distal articular surface of the Mc III. But this metacarpophalangeal articulation differs from that of the second digit by allowing almost no flexion/extension (the carina is straight dorsopalmarly) but a little more medial deviation of the phalanx. The proximal articular surface also differs from that of the second digit in having slightly larger facets for the sesamoids. The lateral facet faces proximopalmarly, while the medial facet faces also proximopalmarly, but slightly laterally as well. On the specimen with non-co-ossified proximal and second phalanges, the two bones have a 'classical' trochleated articulation, which permits but a few degrees of flexion/extension. The distal end (of the complex or of the second phalanx) proximal to the trochlea features, as does the second phalanx of the second digit, deep dorsal and palmar fossae for the ungual phalanx. Compared to that of the second digit, the dorsal fossa is deeper and the palmar fossa is shallower and narrower. Thanks to a deeper palmar fossa, a more extensive flexion can be reached in T. carolomartini than in the earlier species of the genus (approximately $10^{\circ}$ of difference). The flexion appears even more extensive in T. yaucensis. Medial and lateral ridges of roughened surface for the lumbricales muscles are also present. The shape of the distal trochlea is similar to that of the second phalanx of the second digit, but a notable difference from the other nothrotheriids is in the size of this trochlea. In the Nothrotheriini, as well as in Mionothropus and M. americanum, the distal trochlea is large, being as wide or wider than the shaft. In Thalassocnus, the transversally-constricted trochlea is narrower than the shaft. Consistent with this feature, the ungual phalanx is also transversally narrow.

The ungual phalanx is slightly shorter than that of digit two but deeper dorsopalmarly. It is characterized by a conspicuous mediolateral constriction (Fig. 39c, d). The dorsal half of the proximal end is offset medially, which implies that, when articulated and fully flexed on the preceding phalanx, the whole phalanx is deviated medially. The 
overhanging process is more developed than that of the second digit and extends farther proximally than the proximopalmar process. The dorsal surface of the overhanging process offers a large and rugose area of insertion for the extensor digitorum muscle (inferred from Myrmecophaga; Pouchet 1867). The median ridge of the proximal articular surface is more elevated than that of the second digit, but is also deeply concave in profile. There is on all specimens a small fossa medial to the proximal articular surface that is located at mid-depth. The ungual process is deeper than wide and its cross-section forms an isosceles triangle, the shortest side being the palmar one. The lateral and medial sides of the ungual process are, like the equivalent phalanx of the second digit, marked by a sulcus ending distally in a small foramen. The proximal half to two-thirds of the ungual process, probably entirely circled by the ungual crest (the crest is never entirely preserved, consisting of a very fine lamina of bone), shows a rounded dorsal edge. Distally the dorsal edge is sharper and shallowly fissured (a similar condition is found in Tamandua for instance). The ungual crest of the palmar surface is half the length of the bone. At its midpoint it is perforated by two large foramina. As in the ungual phalanx of digit two, there is no well-developed subungual process. The area of insertion for the flexor digitorum profundus muscle is indicated by a rugose, slightly elevated surface (almost absent on some specimens referred to T. carolomartini and T. yaucensis).

\section{Fourth Metacarpal}

The fourth metacarpal is about one-fifth longer than the third metacarpal (Fig. 40a-c). Its mediolateral width at midshaft is slightly less than that of the third metacarpal. The general proportions of the Mc IV pertaining to the holotypes of T. antiquus and T. natans fall into the range of specimens referred to T. littoralis (Table 27). However, the metacarpal is markedly shorter (relative to its depth at midshaft) in T. carolomartini when compared to the earlier species of the genus; it is even shorter in T. yaucensis. Other nothrotheriids display a Mc IV that is even more slender that that of the early species of Thalassocnus. Conversely, M. americanum has a stout fourth metacarpal, but it does not reach the shortness observed in T. carolomartini or T. yaucensis. The proximal end has a single articular surface for the unciform, continuous with those of the adjoining metacarpals (Fig. 40c). This proximal surface is semicircular, its medial border being straight, and the lateral being rounded. It is concave dorsally and convex palmarly. This facet broadly adjoins with that for the third metacarpal at a slightly obtuse angle. At mid-depth the junction of these two facets is marked, in most specimens referred to T. littoralis, by a small fossa, probably for the interosseous metacarpal ligament. T. carolomartini has a larger fossa which, when articulated with the unciform and Mc III, faces the similar large fossae present on the latter bones. This fossa is absent on the holotype of T. antiquus 
and on T. yaucensis (holotype and single referred specimen). Dorsal to the contact between the facets for the unciform and Mc III is a process (proximodorsal process), the size of which varies individually. The facet for the Mc III is gently concave. Laterally the facet for the unciform also broadly connects with the articular surface for the fifth metacarpal roughly at a right angle. The latter surface is gently convex in its proximal half; it becomes concave less far distally in T. antiquus, T. natans, and T. littoralis, and is almost flat in T. carolomartini and T. yaucensis.

As described for the other intermetacarpal joints, synostosis scars are present on the proximal half of the shaft (Fig. 40b). MUSM 2073, referred to T. yaucensis, differs conspicuously from the others specimens by featuring, distal to the facet for the Mc III, a well-elevated triangular process, becoming distally a fine crest (only partly preserved) that almost reaches the distal end of the bone (Fig. 41a). An extremely large fossa is therefore formed on the palmar side of the metacarpal. The dorsal surface has a median crest that starts at mid-length of the shaft and continues distally to a small tuberosity just proximal to the carina. Well elevated and sharp in some specimens, this crest is lower and more rounded in others. The most conspicuous crest is found on MUSM 2073 (which is also the largest Mc IV recovered). However, on this specimen it starts almost on the proximal edge of the bone (Fig. $41 \mathrm{a}$ ). The mediolateral widths of the proximal and distal ends are similar, but the dorsopalmar depth of the distal end is greater than that of the proximal. The relative depth of the distal end also shows some intraspecific variation, which is best exemplified by the two specimens referred to T. yaucensis. On the holotype, which is relatively small and was previously interpreted as a female (Muizon et al. 2004), the distal end is only slightly (23\%) deeper than the rest of the bone (Fig. 41b), while on MUSM 2073 (putatively a large male), the difference is much more conspicuous (42\%), implying a much larger fourth digit (Fig. 41a).

A tuberosity is found on the lateral side of the distal end of the shaft, just proximal to the distal carina. A similarly located tuberosity is found in M. americanum.

As on the third metacarpal, the distal carina is straight, with a small continuation onto the palmar surface at a right angle to the main part. The carina is slightly oblique and directed lateropalmarly. The carina is also wider, blunter, and less elevated distally than those of the other metacarpals that feature a distal carina, as already described for Nothrotheriops (Paula Couto 1974) and observed in Nothrotherium. There is no articular surface on the lateral side of the carina, as in Nothrotheriops (Paula Couto 1974) and M. americanum (Owen 1858), which contrasts with the condition of Nothrotherium. As for the same joint of digit three, only restricted extension-flexion and medial deviation were therefore possible in Thalassocnus. The articular surface medial to the carina is small and confined to the palmar half of the bone. The palmar continuation of this surface forms a well-developed flat facet. This large 
medial, palmar and distal facet was the location of a large sesamoid, since the two bones were found associated on SMNK-PAL 3815 (T. carolomartini; Fig. 40b). The sesamoid is large and bears a conspicuous fossa on its palmar side, opposite to a dorsal, gently concave facet. A similar sesamoid is described in Mionothropus for the three central digits (De Iuliis et al. 2011).

\section{Digit Four}

The proximal phalanx is much shorter proximodistally than that of digit II (Fig. 42a, b). It also differs from the latter in its proximal groove that is shallower and rounder (as a consequence of the different distal carinae of the metacarpals), as in the Nothrotheriini. Like that of digit II, the proximal facet is extended by a medial shelf that is restricted to the palmar two-thirds of the bone. The palmar continuation of this facet is a small flat facet, which is continuous with it on most of the specimens. This small facet, directed mediopalmarly, is probably for a sesamoid. The lateral side of the groove also shows a small facet for a palmar sesamoid, but directed palmarly. The distal end, trochleated, features condyles that are not far extended distally; the medial condyle is less extended distally than the lateral one. Flexion-extension movements were possible, but limited to approximately $35^{\circ}$. The distopalmar edge of the bone is shallowly cleft.

The second phalanx is also shorter than that of the second digit (Fig. 42c-e). The proximodorsal process is more developed than that of digit II. The two concave facets forming the proximal articular surface are shallower than that of digit II, and asymmetrical (as a consequence of the different morphology of the distal condyles of the preceding phalanx). The dorsal surface of the shaft is marked by a shallow fossa, for the overhanging process of the ungual phalanx, which is displaced medially (relative to the mid-width of the bone; Fig. 42c). Very little or no extension was possible at this joint. A ventral fossa is present, also displaced medially (but less so; Fig. 42d). In distal view, the lateral condyle extends slightly palmarly but further dorsally than the medial one. Such a condition is present to a lesser extent in the Nothrotheriini (Stock 1925: fig. 24c). The distal condyles are much less developed in M. americanum.

The ungual phalanx is smaller than those of the digits medial to it (Figs. 42f, g, 43a, b). The ungual process is remarkable in being distinctly curved medially on all the specimens (Figs. 42f, 43a). This process is weakly curved palmarly (Figs. 42g, 43b). The overhanging process is less developed in T. littoralis than in T. antiquus and T. natans; it is even smaller in T. carolomartini (no data for T. yaucensis). The holotype of T. natans features, at the proximopalmar edge of the bone, a round sesamoid partly fused to the phalanx. 
Fifth Metacarpal

The length of the fifth metacarpal is about the same as the fourth, as in the Nothrotheriini (Fig. 44a-d).

However, this metacarpal is more heavily built and stockier than that of the Nothrotheriini and is more reminiscent of that of Hapalops and megatheriids. In general proportions, the $\mathrm{Mc} \mathrm{V}$ is shorter (relative to its depth at midshaft) in $T$. carolomartini (Fig. 45b, e) compared to T. littoralis (Fig. 45a, d) or T. antiquus; even stouter proportions are found in T. yaucensis (Fig. 45c, f; Table 28; no data for T. natans). While the proportions of this bone in Nothrotherium and Mionothropus are more slender than in any specimen of Thalassocnus, those of Nothrotheriops and M. americanum approach (but do not reach) the stout proportions of T. yaucensis. The proximal tip of this metacarpal is rarely preserved in Thalassocnus; this is unfortunately the case for the holotypes of both T. antiquus and T. natans. Only four specimens referred to T. littoralis are well enough preserved to be informative for this area. On three specimens referred to this species, the proximal end bears a large articular surface composed of two facets, which form an obtuse angle (Fig. 45g). The more proximal facet, disposed lateropalmar to the other, is for the cuneiform. It forms a right angle with the proximodistal axis of the bone, but faces medioproximally when the bone is in articulation. However, the other specimen referred to T. littoralis shows a different morphology, in which the bone is not as developed proximally and lacks the facet for the cuneiform. On SMNK-PAL 3815 (T. carolomartini), the facet for the cuneiform is smaller (Fig. 45h), but other specimens referred to T. carolomartini display a more developed facet. On the holotype of T. yaucensis, the left Mc V bears a similarly reduced facet, whereas the right side shows no facet; the other specimen representing this species (MUSM 347, the largest specimen) does not preserve the Mc V but based on the morphology of its cuneiform, this facet would have been extremely reduced (or even absent). It therefore appears that the relative development of this facet is subject to intraspecific variation. More specimens are required to determine if this variation applies only to the late species or the whole genus. This peculiar articulation shows that the Mc V could have been markedly laterally-deviated, since the contact with the cuneiform only occurs at that position. The second proximal facet, for the unciform, faces medially. Its size also appears to be subject to variation (Fig. 45g, h). It is continuous with the facet for the Mc IV. As already mentioned, the proximal Mc V is unknown in T. antiquus and T. natans, but it presumably had a different morphology than that of the later species of the genus, possibly more like that of other Megatheria, since there is no supplementary articular facet for the Mc V on the cuneiform. The proximal end is expanded relative to the distal end. There is an enlargement of the lateral side into a tuberosity for the insertion of the extensor carpi ulnaris muscle (inferred from Myrmecophaga; Pouchet, 1867). In 
T. carolomartini (Fig. 45e) and T. yaucensis (Fig. 45f), this tuberosity is smaller than that of T. littoralis (Fig. 45d; no data for the other species), in which it is well elevated and surrounded by marked fossae. There is a second small tuberosity on the ventral surface of the proximal end, probably for the interosseous muscle. The articulation for the fourth metacarpal on the medial side is in T. littoralis a gently concave oval surface. Corresponding to the facet of the Mc IV, T. carolomartini and T. yaucensis feature a facet that is flatter than that of T. littoralis. When articulateds these two metacarpals diverge distally, which differs from the condition of the three central metacarpals.

Between the lateroproximal tuberosity described above and the dorsal side of the distal end, the entire length of the shaft has a rugose surface. Its development varies individually, and it is even absent on the holotype of $T$. yaucensis. This rugosity may have served for the insertion of a muscle that laterally-deviated the fifth metacarpal, homologous or not with the opponens digiti minimi muscle. Just proximal to the distal end, the lateral side of the shaft is marked by a small tuberosity, as in M. americanum.

The distal articular surface is oblique to the axis of the shaft on the medial side of the distal end; it faces mediodistally. This facet may show different morphologies, from slightly convex to flat, and can occupy the medial two-thirds or half of the width of the distal end of the bone. This condition differs from that of the Nothrotheriini in which the facet covers the whole distal side of the bone. One specimen features well-developed palmar facets for sesamoids.

\section{Digit Five}

The phalanges of this digit are vestigial nubbins of bone (Fig. 46). There are probably only two phalanges, as in M. americanum and the Nothrotheriini but differing from Hapalops. The holotype of $T$. antiquus preserves a fragmentary bone that appears to include the two co-ossified phalanges; the distal tip, not entirely preserved, seems to be pointed distally (Fig. 46a). On MUSM 1995 (referred to T. carolomartini), the phalanges are unfused (Fig. 46b, c). Corresponding to the distal facet of the $\mathrm{Mc} \mathrm{V}$, the morphology of the proximal facet of the proximal phalanx may vary. The proximopalmar edge of the proximal phalanx shows two convexities, the locations of the sesamoids. The distal facet (when not co-ossified with the second phalanx), located on the medial side of the bone, is concave and Vshaped, i.e., deeper dorsopalmarly at its medial border. It may feature a minute fossa on its medial side. A third phalanx could have been present, but if so it would have been extremely reduced. Even though the other nothrotheriids also have two vestigial phalanges (De Iuliis et al. 2011), they are not as reduced as in Thalassocnus, 
since they are, at least for the proximal phalanx, approximately as deep and as wide as the distal end of the Mc V. Megatherium americanum displays a proportionally closer condition to that of Thalassocnus.

\section{Sesamoids}

Few sesamoids were recovered. Except for the falciform, they are described with the corresponding articulation.

\section{Falciform sesamoid}

As in other sloths and Xenarthra in general, the manus displays a well-developed falciform (or palmar) sesamoid, located in the common tendon of the flexor digitorum profundus muscle at the level of the palm (Rose and Emry 1993). It is a dorsopalmarly-compressed bone with an ovoid outline in dorsal or palmar view. It is slightly excavated on the palmar side and features a rugose surface on the dorsal side. A similar sesamoid is found in all other nothrotheriids (De Iuliis et al. 2011) and Megatherium. For specimens with roughly the same diameter, the (dorsopalmar) thickness of the falciform is greater in species later than T. antiquus (Table 29; no data for T. natans and T. yaucensis). However, this observation has to be nuanced by the fact that a great variability of size, shape and thickness is found in Nothrotheriops.

\section{DISCUSSION}

All sloths have long, powerful, and mobile forelimbs with large claws (Coombs 1983). On the whole this general disposition is found in the earliest species of Thalassocnus. However, when the whole genus is compared to other sloths, some differences are found, some of which have functional significance. Moreover, some intrageneric differences are also found, and are on the whole consistent with the phylogenetic relationships already recognized (Muizon et al. 2003; Amson et al. 2014). These comparative observations, along with the corresponding functional interpretations, are summed up in Table 30.

On the whole the forelimb of Thalassocnus is shorter than in other nothrotheriids (both brachium and antebrachium are short relative to the depth of the mandible). This trait appears to be further accentuated in the late species of Thalassocnus relative to the early ones. However, in the context of all mammals, the forelimb of Thalassocnus cannot be described as short, since much shorter proportions are commonly found (e.g., talpids, lutrines, pinnipeds). The ratio of length of the forelimb to length of the thorax and lumbus of T. natans (holotype, 
MNHN.F.SAS734) is indeed higher than in most semiaquatic mammals sampled by Gingerich (2003). Ratios very close to that of T. natans can be found in Ursus maritimus Phipps, 1774 and Tapirus bairdii Gill, 1865. A very similar ratio is also found in the desmostylian Desmostylus hesperus Marsh, 1888, when considering the mean value estimated by Gingerich (2005). Additionally, major features of the forelimb that depart from the conditions seen in other nothrotheriids include the greater development of the pronator ridge, and with it the anteroposterior widening of the distal radius and widening of the proximal carpal row. The manus of Thalassocnus is also characterized by its highly specialized ungual processes and, for the late species, by the shortness of the metacarpals.

Other taxa sharing the putative ecology of Thalassocnus, namely that of an amphibious coastal grazer, are scarce, and among mammals are restricted to the extinct desmostylians, the ecology of which is also reconstructed. That is why the following functional inferences are mainly based on basic biomechanics, although particular analogies with various tetrapods are also recognized.

Relative proportions of the brachium and antebrachium

The humerus of Thalassocnus is shorter than that of other nothrotheriids, either when compared to its distal width (Fig. 5; Table 5), or when compared to the depth of the mandible (Table 6). The digging mammals sampled by Hildebrand (1985) feature a humerus in which the distal width (across the epicondyles) represents at least $30 \%$ of the proximodistal length of the bone, in contrast with the $21 \%$ scored by a non-digging form (exemplified by a raccoon). Interestingly, Thalassocnus has for the same ratio a score only slightly lower than $30 \%$. Other sampled Megatheria, except M. americanum, score close to $20 \%$. The humerus of Thalassocnus can thus be described as relatively short, as commonly observed in aquatic mammals (Osburn 1903; Howell 1930) and in digging forms (Hildebrand 1988; Elissamburu and Vizcaíno 2004; Kley and Kearney 2007). But this must be nuanced by the fact that it is also the case in M. americanum. Moreover, the shortness of the humerus of Thalassocnus is not even close to that of digging forms such as talpids, or swimming forms such as pinnipeds.

The antebrachium is also relatively short in Thalassocnus when compared to other nothrotheriids. This conclusion is based on comparison of the length of the radius to the depth of the mandible (Table 14) and comparison of the length of the radius or ulna to the length of the humerus (Table 13). Additionally, a relatively shorter radius is found in T. yaucensis (and probably T. carolomartini, but the lack of complete specimens precludes a definitive assessment) when compared to the earlier species of the genus. It can be noted that the brachial index values in Thalassocnus (Table 13) are relatively high (due to the shortness of the humerus), which is more reminiscent of the 
mean condition of the non-digging taxa included in the study of Toledo et al. (2012). However, the length of the antebrachium decreases relative to that of the brachium in the late species when compared to the early ones (Table 13), which hence become more reminiscent of diggers. A short antebrachium is also commonly recognized in aquatic forms (Osburn 1903; Howell 1930).

Shoulder joint

The slightly greater posterior development of the postscapular fossa found in the late species of Thalassocnus suggests a stronger flexion of the shoulder joint (larger area of origin of teres major and increase of its mechanical advantage; Smith and Savage 1956; Taylor 1978; Fig. 3; Table 2). Such an enlarged fossa is not found in other Megatheria. However, a much more developed fossa is found in myrmecophagids, especially Myrmecophaga (the giant anteater), which is an efficient digger. A large posterior fossa, for the origin of the teres major muscle, is commonly found in diggers (both scratch diggers and hook-and-pull diggers) and swimmers (Coombs 1983; Kley and Kearney 2007; Polly 2007); in other words, taxa that need to retract the humerus in a dense medium and/or against resistance. As already mentioned, and when compared to other nothrotheriids and Planops, the humerus in all species of Thalassocnus is short. This also increases the mechanical advantage of the flexors of the shoulder joint, as is often mentioned for digging forms (Hildebrand 1985).

The clavicle differs in the late species of Thalassocnus in the reduction of the sternal articular facet (probably articulating with the other clavicle; Fig. 4). This probably reflects the widening of the manubrium sterni found in these species (see subsequent study of the axial postcranium of Thalassocnus), which would cause the contact between the clavicles to be more tenuous, and probably allows greater amplitude of movement of the brachium, especially in the mediolateral direction (see Jenkins 1974).

The development of the humeral crests of Thalassocnus does not depart greatly from that of other nothrotheriids and hence is not reminiscent of the well-developed crests usually found in swimming (e.g., pinnipeds) or digging (e.g., talpids) forms. However, a strong flexion of the shoulder joint and abduction of the brachium in the late species of Thalassocnus can be suggested by the development of the deltoid crest, which is especially conspicuous in T. littoralis (Figs. 5c, 7c).

Elbow joint 
Both the anconeal and coronoid processes of Thalassocnus are conspicuously developed when compared to those of other Megatheria (Figs. 11, 12; Table 11). This can be correlated with the deep coronoid and olecranon fossae observed on the humerus of the species earlier than T. yaucensis (Figs. 5, 7; no data for T. carolomartini). Such processes would hamper the flexion and extension of the elbow without deep enough fossae, and probably indicate a particularly strong interlocking (or stabilization; Argot 2001) of the elbow articulation. Moreover, the radial fossa of the humerus and humeral facet of the radius in the species of Thalassocnus earlier than T. yaucensis are especially deep when compared to those of other Megatheria. This also suggests a strong interlocking of the elbow when compared to other Megatheria. Since the radial and coronoid fossae are shallower in T. yaucensis, a weaker interlocking can be inferred for the latest species of the genus. This is reflected by the less hemispherical capitulum (Fig. 5d) and shallower humeral facet of the radius found in this species.

An approximation of the range of flexion and extension of the elbow joint can be drawn from measurements of articulated humerus and ulna. The maximum angle between the shafts of the humerus and ulna in Thalassocnus (T. natans, MNHN.F.SAS734; T. littoralis, MNHN MNHN.F.SAS53 and 54), reached during maximum extension, is approximately $160-170^{\circ}$ while in the Nothrotheriini this angle is only about $115-120^{\circ}$. The minimum angle, reached during maximum flexion, in T. natans and T. littoralis is approximately $110-120^{\circ}$ while angles of $70-80^{\circ}$ can be reached in the Nothrotheriini. Extensive extension and limited flexion of the elbow joint, in other words, a more extended elbow, is hence inferred in Thalassocnus when compared to the Nothrotheriini.

Radioulnar joints and interosseous ligaments

The process bearing the radial notch on the ulna of Thalassocnus is remarkable for its lateral expansion. This, together with the laterally oriented radial facet, increases the articular surface for the circumference of the radius. This feature suggests great range of pronation-supination and/or a stronger proximal radioulnar articulation.

The crests for the interosseous ligament found on the ulna and radius are usually well developed in Thalassocnus. This indicates that the interosseous membrane was probably well developed as well. However, this appears to be a common feature in Megatheria. Thalassocnus littoralis, T. carolomartini, and T. yaucensis, especially the two latest species, display a larger articular circumference of the head of the ulna and of the ulnar notch of the radius than the earlier species. This suggests a more stable distal radioulnar articulation in the latest species.

While the antebrachium of all species of Thalassocnus was probably well stabilized thanks to the morphology of the proximal and distal radioulnar joints and the well-developed interosseous membrane, the latest 
species of Thalassocnus, especially T. carolomartini and T. yaucensis, appear to have had a more stable antebrachium than the early species of the genus. Some flippered mammals tend to stiffen the radioulnar joint and eventually lose mobility at this joint, as shown by the locked elbow joint of extant cetaceans and the fusion of the radius and ulna in all but the earliest sirenians. A strong interosseous ligament is mentioned by Howell (1929: 30) for Phoca Linnaeus, 1758 (and some possible variation for Zalophus Gill, 1866).

The strongly interlocked joint inferred for the wrist of Thalassocnus (see below) indicates a need of stabilized distal forelimb. However, it is clear that pronation-supination amplitude was great in Thalassocnus. It is hence probable that the function of the forelimb of Thalassocnus required stable and mobile radioulnar joints.

Radial muscle insertions versus general shape of antebrachium and carpus

The modifications of the antebrachium of Thalassocnus are probably those that depart the most from the megathere condition. While the pronator ridge is only developed very proximally and probably represents a large area of attachment for the supinator muscle in $T$. antiquus and $T$. natans compared to that of other nothrotheriids, all specimens referred to later species of the genus show a ridge that is more developed anteriorly and more laterally concave, forming a wider and deeper area of muscular insertion (Fig. 13; Tables 16, 17). The medial side of the ridge could also have offered in these late species a wider area for the flexor digitorum profundus muscle to attach. However, this area is never marked in Thalassocnus by conspicuous muscle scars such as can be seen in the Nothrotheriini. It therefore appears that this enlarged fossa is not correlated in Thalassocnus with a more developed origin of the flexor digitorum muscle. The thick anterior edge of the pronator crest itself suggests a stronger pronator teres muscle in T. yaucensis when compared to the earlier species of the genus (no data for T. carolomartini). Moreover, the development of the pronator ridge increases the mechanical advantage of the pronator teres muscle by displacing the insertion of the muscle away from the rotation axis of the radius, as argued for Tamandua by Taylor (1978). A first hypothesis of functional significance of the distinctive morphology of the radius would hence postulate more developed pronator and supinator muscles in the late species of Thalassocnus, implying in these species more powerful movements of pronation and supination.

It can also be considered that the modification of the morphology of the radius and ulna in Thalassocnus, especially T. yaucensis, does not reflect a different myology, but rather simply the modification of the general shape of the antebrachium. In Hapalops, other Megatheria, and the early species of Thalassocnus, the morphology of the radius and ulna is more 'rod-like' (Fig. 47a, b), while in the late species, especially T. yaucensis, these bones become 
shorter (when compared to the humeral length or mandibular depth, Tables 13 and 14, respectively), the radius is widened anteroposteriorly and flattened transversely (Table 18; Fig. 47c-e), and the ulna is stouter in T. yaucensis (Table 10). Moreover, in the two latest species of Thalassocnus, T. carolomartini and T. yaucensis, a wider proximal carpal row can be found (e.g., wider scaphoid and lunar; Figs. 20, 22; Tables 20, 21). Adequate measurements could not be performed on the cuneiform (due to the possible presence of a facet for $\mathrm{Mc} \mathrm{V}$ ), but the shape of the unciform of T. yaucensis is much wider proximally than distally (in dorsal view; Fig. 31c), which also favors such an assumption. The widened carpus of the late species of Thalassocnus apparently accompanies the wide distal radius also found in these species, which gives a distinctive outline to this area of the forelimb. On the whole the outline of the antebrachium of the late species of Thalassocnus, especially T. yaucensis, tends towards that of pinnipeds (Fig. 47f, g), sirenians, especially Trichechus Linnaeus, 1758 (Fig. 47h) and desmostylians (exemplified here with Paleoparadoxia Reinhart, 1959; Fig. 47i). It must be borne in mind that in the Sirenia the whole antebrachium is integrated into the flipper (Osburn 1903). As pointed out by Reidenberg (2007), the external form of the flipper depends on that of the skeleton (contrasting with the case of the caudal flukes). While the forelimb of Thalassocnus was most certainly not as transformed into a flipper as that of sirenians (or pinnipeds), a flattening and widening of the antebrachium, and widening of the proximal carpal row as seen in the latest species of the genus, may have provided a more suitable shape (paddle-like?) for its aquatic function. In this hypothesis, the conservation of a clawed manus in Thalassocnus is probably relevant to a function other than locomotion, as is argued with the manus of Enhydra Fleming, 1822 (which is not modified into a flipper as in other aquatic mammals, possibly due to its importance in feeding; Estes 1989).

Finally, a third hypothesis would consist in a combination of the first two hypotheses. One can suppose that in the earliest species of Thalassocnus, the expanded pronator ridge is related to muscle development, and that in the latest species of the genus, the more developed ridge accompanied by widening of distal radius and carpus is related to the acquisition of a differently shaped forelimb. This would constitute an exaptation.

Wrist joint and metacarpus dimensions

The posterodistal process of the radius of Thalassocnus (Fig. 13), which extends farther distally compared to that of other nothrotheriids, offers a deeply concave articulation with strong interlocking for the wrist, especially in the flexion/extension direction. This is also favored, in T. carolomartini and T. yaucensis, by the notch of the extensor carpi radialis muscle that forms in these species a shallow concavity on the lateral side of the bone distally 
and also by the absence of a sulcus on the distal articular surface that together extend the surface area of articulation with the carpus.

The three species of Thalassocnus later than T. natans display on the dorsal side of the lunar a radial facet that is restricted to the proximal half of the bone (Fig. 22c), in contrast to the condition in the early species (Fig. 22a, b). While such a condition is found in other Megatheria, this suggests a more extended position for the wrist joint in the late species of Thalassocnus.

The morphology of both Mc III and Mc IV suggests an intraspecific variability in the development of the insertion of the extensor carpi radialis muscle, and therefore variability in the power of extension of the wrist (Fig. 41). The smaller tuberosity for the insertion of the extensor carpi ulnaris muscle on the Mc V found in the late species implies a weaker extension and/or ulnar deviation of the wrist (Fig. 45d-f).

A stout metacarpus (proximodistally shorter metacarpals compared to their dorsopalmar depth; Figs. 35a-e, 45a-f; Tables 23, 26-28) is found in the late species of Thalassocnus, especially T. carolomartini and T. yaucensis. Even though some other Megatheria have relatively stout metacarpals (e.g., M. americanum), the two latest species of Thalassocnus are clearly derived in the extremely stout proportions seen in all their metacarpals. A stout metacarpus is incompatible with the enlargement of the autopode usually seen in aquatic tetrapods (Osburn 1903; Howell 1930). Short metacarpals and digits are often seen in diggers, since it increases the mechanical advantage of the flexors of the digits (Coombs 1983; Hildebrand 1988; Kley and Kearney 2007). The digits, however, do not appear to be affected by any shortening. The short metacarpus of the late species of Thalassocnus increases the mechanical advantage of the flexors of the wrist and digits and hence allows stronger flexion (Hildebrand 1988). This is corroborated by the conspicuous scars for one origin of the flexor digitorum profundus muscle on the ulna of Thalassocnus (Fig. 11c-e) compared to that of other megatheres. Also, the relatively thicker falciform found in the late species T. littoralis and T. carolomartini (no data for T. natans and T. yaucensis; Table 29) seems to corroborate these conclusions as well. However, more specimens are required to ascertain interspecific differences in the falciform, since, as already mentioned, great variation of its size and shape was observed in Nothrotheriops. A stout metacarpus is also seen in desmostylians, although their metacarpals are roughly twice as long as their metatarsals (Domning 2002).

Digits and fifth metacarpal 
The shape of the ungual processes and hence of the claws reflects their function, as is characteristic of digging mammals (Gambaryan 2002). When compared to those of other sloths, the ungual processes of the four medial digits of Thalassocnus are highly specialized, each one characterized by a very distinctive shape (the fifth digit is reduced and clawless as is the case in other Megatheria). This suggests particular functions for each claw, but deciphering precisely these functions seems hardly achievable without modern analogues. A few hypotheses can however be proposed.

The first ungual process is stout and pointed distally (Figs. 18, 33; which is, along with the absence of the proximal phalanx of the first digit, surprisingly reminiscent of Iguanodon Mantell, 1825). Interpreting this structure functionally without a modern form displaying a similar condition would be hardly justifiable.

The second ungual process of Thalassocnus, especially in its late species, is broad, convex dorsally and flat palmarly, and with sharp medial and lateral edges (Table 24; Figs. 36g, h, 37). In addition to its remarkable ungual process, digit II of Thalassocnus, especially in the late species, is affected by torsion, reaching a maximum in $T$. carolomartini and T. yaucensis (Figs. 17,35). In the latest species, the ungual phalanx is completely inverted when articulated (i.e., lateral side facing palmarly). It can be noted that in the scelidotheriines, the Mc V (and to a lesser extent the Mc IV) is also affected by torsion (Cuenca Anaya 1995). However, the scelidotherine condition had probably a minor impact on the function of the digit, since it is much reduced. The corresponding metacarpophalangeal joint allows extension-flexion as well as a small degree of mediolateral deviation (the distal carina of the Mc II is broadly curved dorsopalmarly and also mediolaterally, which is not the case in other digits), a mobility probably related to the function of the ungual process. In the earlier species of Thalassocnus, the dorsal and ventral fossae of the second phalanx allow amplitude of extension and flexion of the ungual relative to the second phalanx comparable to that of other Megatheria. But this joint in T. carolomartini and T. yaucensis suggests more extensive movements, especially of flexion. Once again, interpreting such peculiar morphology without modern analogs appears presumptuous.

The third ungual process is characterized by its mediolateral constriction (Fig. 39c, d). Such morphology is associated with a cutting function in digging forms (Gabarian 1960 in Hildebrand 1985). The ungual is also characterized by being shallowly fissured at its distal tip. Such structure, not observed in the other digits of Thalassocnus, is also found in digging forms (and sometimes much more conspicuously, e.g., the completely cleft ungual processes in Manis javanica Desmarest, 1822) and apparently strengthens the horny claw borne by the process (Hildebrand 1985). The Mc III is characterized by a straight distal carina that is extended far distally (Fig. 
38a-c), and the proximal side of the proximal phalanx is correspondingly deeply grooved. Such morphology, not found in the other metacarpophalangeal joints of Thalassocnus, is generally associated with prevention of dislocation (in a mediolateral direction or under torsion), which is required in digging forms such as anteaters (Kley and Kearney 2007). Moreover, all species of Thalassocnus except T. yaucensis differ from other nothrotheriids in having coossified proximal and second phalanges of this digit. Hildebrand (1985) argued that the first and second phalanges of mammals digging with the manus tend to be articulated by an immovable joint. According to this author, coossification of these phalanges is also frequent in digging forms. Priodontes Cuvier, 1825 for instance features coossified first and second phalanges. However, one must bear in mind that co-ossified proximal and second phalanges of the third digit are not unique to Thalassocnus, since they are also found in megatheriids. Finally, hyperextension of the distal interphalangeal articulation is apparently prevented by the well-developed overhanging process of the third ungual phalanx (which is the best developed of all digits; Fig. 39d). The morphology of the third metacarpal and digit of Thalassocnus is hence compatible with a digging function, and more particularly loosening firm material. The presence of such putative adaptations on one digit only suggests that the digging area was very restricted. However, it is usual, for instance in xenarthrans, for the third digit to be the strongest (e.g., myrmecophagids, Priodontes).

The fourth ungual process is bent medially (Figs. 42f, g, 43). Such morphology may be related to the need for keeping the claw off the ground, since the distal end of the Mc IV was probably weight-bearing (see comments on terrestrial function below). However, other Megatheria that also supported a part of their weight on this region do not share such a peculiarity. It is hence hard to give much credit to this interpretation.

The peculiar articulation of the $\mathrm{Mc} \mathrm{V}$ with the lateral side of the cuneiform found in $T$. littoralis and $T$. carolomartini (Figs. 24b-d, 45G, H) allows great lateral deviation of this metacarpal. Interestingly, this contact, not common in sloths or mammals in general, is found in sirenians and in desmostylians (as mentioned below). One can naturally wonder about the presence of tissue enclosing the digits, as this is the case in flippered mammals. In extant flippered mammals, the claws or nails tend to be reduced (e.g., monachines) or absent (e.g., Dugong Lacépède, 1799; Husar 1978), and the metacarpals and digits tend to be flattened dorsopalmarly. Since none of these tendencies is found in Thalassocnus, there is a priori no reason to infer for the genus the acquisition of some kind of webbing. However, one must bear in mind that extant sloths feature digits that are syndactylous up to the distal interphalangeal joints (Mendel 1985). According to the extant phylogenetic brackets approach (Witmer 1995), this feature was present in all extinct sloths. However, it is associated with the loss of at least two digits, and might belong to the numerous convergences purported between the two extant genera of sloths (Billet et al. 2013), which are highly 
specialized for suspensory posture and locomotion (Nyakatura 2012). Moreover, the putatively different function of each of the four medial digits of Thalassocnus, as argued earlier in the text, would suggest independence of movement of each digit, which is not in favor of the syndactylous hypothesis. While the osteology of the manus of Thalassocnus is definitely not that of a flippered mammal, the laterally-deviated $\mathrm{Mc} \mathrm{V}$ may have helped to increase the surface of the manus (which is otherwise reduced, especially in the late species of the genus, as a consequence of the shortness of the metacarpus).

Comments on the terrestrial function of the forelimb

The forelimb of Thalassocnus is on the whole conservative and reflects the gross morphology of terrestrial Megatheria. A question of functional anatomy of Megatheria still pending today is the importance of the forelimb in weight-bearing. This question is associated with the erect posture that the extinct sloths could apparently assume, as argued by various authors (see the discussion of this matter by Argot 2008). In terrestrial "ground sloths," the manus is either considered plantigrade, inverted (i.e., the weight is borne by the lateral (ulnar) border), or vertical (i.e., as in Myrmecophaga, the weight is borne by the flexed ungual phalanx; or practicing knuckle-walking, Tito and De Iuliis 2003; Pujos et al. 2012; and references therein). The manus of Thalassocnus features parallel metacarpals displaying synostosis scars, tuberosities on the lateral side of the distal end of the shafts of the Mc IV and V, which probably functioned for weight-bearing (as already hypothesized by Tito and De Iuliis 2003), and a very reduced fifth digit. This is on the whole more reminiscent of the manus of M. americanum than that of other nothrotheriids. This is especially true for the earliest species of Thalassocnus, since the latest species, particularly T. carolomartini and T. yaucensis, show derived features departing from the plesiomorphic megathere condition (however, the semicircular shape of the cross-section of the ungual process of the digit II is in Thalassocnus, especially T. antiquus, more reminiscent of that of other nothrotheriids). Moreover, the relatively stout humerus (short when compared to its width across the epicondyles) of Thalassocnus is also more reminiscent of M. americanum. The terrestrial function of the forelimb was hence probably similar in Thalassocnus (at least the earliest species) and M. americanum. This terrestrial function, although not resolved here, is likely to have permitted, at least temporarily, the bearing of a fraction of the weight of the animal on land.

Hypothesis of aquatic functions of the forelimb 
The osteosclerotic and pachyostotic ribs and osteosclerotic limbs of Thalassocnus, especially in the late species, indicate a need for hydrostatic regulation (Amson et al. 2014). Analogously to the sea cows (Sirenia), Thalassocnus was taking advantage of its dense skeleton to be stable and negatively or neutrally buoyant and hence to facilitate grazing on coastal subtidal vegetation. This specifies the type of aquatic adaptation that likely affects Thalassocnus, which hence corresponds to the aquatic megaherbivore adaptive zone sensu Domning (2001). Most living mammals are able to swim by quadrupedal paddling (Fish 2001), including those that do not feature aquatic adaptations, such as "tree sloths" for instance (Howell 1930). More particularly, mammals that show few or no limb specialization(s) swim by quadrupedal paddling (Thewissen and Taylor 2007), often referred to as a 'dog-paddle.' It is hence very likely that Thalassocnus was capable of such locomotion as well. The manus of Thalassocnus drastically differs from that of mammals swimming by underwater flight (or pectoral oscillation), i.e., otariids. Another swimming mode that was unlikely practiced by Thalassocnus is pectoral rowing. Ornithorhynchus Blumenbach, 1800 (the platypus) generates the thrust during swimming only with its forelimbs by using this swimming mode (Fish et al. 1997). It is allowed by adaptations towards humeral rotation, which include short and stout forelimbs, and specialized scapula and humerus. These adaptations are also related to the digging habits of Ornithorhynchus (see below). The manus is described as wide (Thewissen and Taylor 2007), despite the absence of clear osteological correlates (only well-developed webbing is seen). The forelimb in Thalassocnus is relatively short and stout, but it does not reach the short and stout proportions and does not suggest humeral rotation as seen in Ornithorhynchus. Therefore, more specialized swimming modes in which the forelimb of Thalassocnus is more likely to have been actively used are pectoral paddling and bottom-walking. Pectoral paddling is practiced by $U$. maritimus (the polar bear). The manus of U. maritimus is described as 'large' (Demaster and Stirling 1981) or 'widened' (Thewissen and Taylor 2007), although its osteology does not differ from that of terrestrial bears (Ursus arctos Linnaeus, 1758 for instance). Even though in the late species of Thalassocnus the metacarpus is shortened, the widened distal radius and carpus may be regarded as consistent with swimming by paddling with the forelimb. The forelimb was either used alone (pectoral paddling) or in concert with the hind limb (quadrupedal paddling). The presence of strong osteosclerosis and pachyostosis in Thalassocnus clearly suggests that the occupation of a completely submerged position on the bottom was preponderant, and also that Thalassocnus likely swam by bottomwalking (see subsequent study of the axial postcranium of Thalassocnus), also termed deep-water wading (Thewissen and Taylor 2007). It should be kept in mind that the forelimb of sirenians can be considered as involved in such a function. While sirenians display what can be called a flipper, they do not use it in pectoral paddling or oscillation 
mode of swimming, but to "walk" or "crawl" on the sea or river floor (Husar 1978; Reidenberg 2007). In the case of Thalassocnus, the adaptation increasing the mechanical advantage of the flexor muscles of the wrist and digits may be useful for gripping fixed objects on the seafloor, either to feed on them, or to stabilize the animal (as already proposed by Muizon et al. 2004b), or to propel it. An analogous behavior is seen in the walrus, since "they sometimes use their tusks to grip the sea floor or ice and push their body forward with a downward nod of the head" (Reidenberg 2007). Another analogy can be found in phocids. The manus of phocines differs from that of lobodontines in its more robust digits, more developed claws and larger sesamoids (Thewissen and Taylor 2007). The different morphology of the manus of phocines is regarded as reflecting their particular terrestrial locomotion, which involves digging their hands into the substrate and subsequently flexing the shoulder and elbow joints in order to drag the body (Thewissen and Taylor 2007). During bottom-walking locomotion, the manus of Thalassocnus, which features robust digits and large claws and was capable of strong flexion (especially in the late species of the genus), may have performed similar movements. The shape of the antebrachium, which tends toward that of Trichechus in the late species of Thalassocnus, may have provided help for equilibration and/or additional propulsion. The stabilized antebrachium, especially in T. carolomartini and T. yaucensis, would also be appropriate for such functions. Strongly interlocked elbow (but less so in T. yaucensis) and wrist joints are found in Thalassocnus. A similar feature, which was achieved by a slightly different structure in desmostylians, is interpreted as a way to prevent dislocation during paddling (Domning 2002). One can postulate that such an adaptation would also be present in the case of bottom-walking forms, as was suggested in regard to the pygmy hippopotamus (Choeropsis liberiensis Morton, 1844) and its adaptations that prevent splaying of the toes (Fisher et al. 2007).

Additionally, the morphological features (having in some cases muscular implications) of Thalassocnus are consistent with digging habits. Thalassocnus is, among other things, characterized by powerful shoulder flexion (short humerus, large postscapular fossa in the late species, powerful deltoid crest in T. littoralis, no data for $T$. carolomartini and T. yaucensis), strong abduction of the brachium (again, powerful deltoid crest), and strongly interlocked wrist. The strongly interlocked elbow of Thalassocnus (but less so in T. yaucensis, suggesting a decrease in the need for such a feature) can also be considered as consistent with digging habits, since deep coronoid and olecranon fossae are found in Orycteropus Geoffroy, 1791. However, this must be nuanced by the fact that myrmecophagids have shallow fossae. Moreover, powerful flexion of the wrist and digits (as mentioned above) is also found in Thalassocnus. The latter ability was increased in the late species of the genus. Numerous extant xenarthrans practice digging (and are even diversified to include both scratch digging in armadillos and hook-and- 
pull digging in anteaters), and similar digging adaptations of the forearm are often associated with the xenarthran morphology. For instance, a well-developed acromion process (even forming a complete arch in sloths) and dorsopalmarly-oriented keel-groove articulation of the metacarpophalangeal and interphalangeal joints can be mentioned (Kley and Kearney 2007). Several features of the hind limb and axial postcranium of Thalassocnus appear also consistent with digging habits (see subsequent studies). One can also mention that digging habits have already been hypothesized in extinct sloths, especially mylodontids (Pujos et al. 2012 and references therein). More specifically, the proportions and capacity to resist bending forces of the limb bones of Scelidotherium and Glossotherium Owen, 1840 were interpreted as consistent with digging habits (Bargo et al. 2000). The morphology of the forelimb of Santacruzian sloth, more reminiscent of that of myrmecophagids than that of suspensory sloths, was also interpreted as consistent with digging habits (Toledo et al. 2013).

Furthermore, the inclusion of roots in the diet of the closely related Nothrotheriops is documented (Lull 1929), although they appeared to have been at best a minor part of its diet (some coprolites did not reveal any trace of roots; Hansen 1978). In the slightly more distantly related mylodontids, and more particularly in the narrow-muzzled sloths, uprooting food items has been inferred (Bargo and Vizcaíno 2008). This makes more conceivable the inference, in the case of Thalassocnus (and especially the late species), of a specialization to feed on aquatic vegetation and uproot rhizomes of seagrasses, as has been suggested by Muizon et al. (2004b). The distinctive ungual phalanges of Thalassocnus may have been involved in feeding on the nutritious rhizomes of seagrasses (loosening the substratum and/or cutting rhizomes). A similar function is purported for the large bladelike tusks found in extinct dugongids (Domning and Beatty 2007; Clementz et al. 2009), and the procumbent tusks of some desmostylians (Domning 2001b). Although different from the hypothesized forelimb function of Thalassocnus, it can be mentioned that manatees have been observed using their flippers to manipulate food and bringing it to the oral cavity (Marshall et al. 2003). However, feeding in extant sirenians is mainly accomplished by their orofacial specializations (Marshall et al. 2003). It is hence argued here that Thalassocnus was specialized for aquatic life and digging, as is the case in the extant Ornithorhynchus, and as is inferred in other extinct forms such as Castorocauda Ji et al., 2006. Although not significantly used in a trophic activity, the forelimb of Ornithorhynchus is short, stout, displays large claws, and is involved in underwater digging, since camping and resting burrows tend to have their entrances below the water level (Pasitschniak-Arts and Marinelli 1998). Another analogy can be found in the loggerhead turtle (Caretta caretta Linnaeus, 1758), which is known to dig out its prey from sediments (Preen 1996). Interestingly, this behavior in the latter taxon was also correlated with increased bone density (Maffucci et al. 2013), one of the main features of the 
postcranium of Thalassocnus. In the case of Thalassocnus, the digging behavior was related to feeding on marine vegetation, as in extant sirenians, but it would have included some kind of digging activity with the forelimb, possibly similar to that observed in the extant anteaters when foraging on ant nests and termite mounds.

Comparison with desmostylians

Several characteristics of the forelimb of Thalassocnus are reminiscent of some of ones seen in desmostylians that have also been interpreted as aquatic adaptations (Inuzuka 2000). These are listed in Table 31. Compact internal microstructure of ribs and long bones was already mentioned as a common trait of the two taxa (Amson et al. 2014). The putatively similar ecology of Thalassocnus and Desmostylia, already mentioned by Domning (2002), is reflected in the similarity of the forelimb gross anatomy of the two groups. The gross anatomy of the hind limb and axial postcranium are also similar in several respects (see subsequent studies of the hind limb and axial postcranium of Thalassocnus).

The forelimb in desmostylians is interpreted as being involved in active swimming (pectoral paddling) as well as in bottom-walking (Shikama 1966; Inuzuka 2000; Domning 2002; Gingerich 2005; Barnes 2013). The forelimb is described as showing no obvious aquatic adaptations (Domning 2002), although a paddle-like manus (Shikama 1966) and a general similarity of the humerus to that of pinnipeds (Barnes 2013) are mentioned for some taxa. At least some desmostylians feature well-characterized osteosclerosis and pachyostosis, which suggest that bottom-walking was part of their repertoire of locomotor modes (Hayashi et al. 2013). Therefore, it is likely that the forelimb of (at least some) desmostylians was involved, as in Thalassocnus, in paddling and bottom-walking. However, the function of the forelimb of Thalassocnus clearly differs from that of desmostylians, in that it was probably important in obtaining food, which has never been suggested for the forelimb of desmostylians.

\section{CONCLUSION}

While the major features of the terrestrial megathere forelimb are found in Thalassocnus, some characteristics of the genus with functional implications are clearly autapomorphic. These characteristics are often more conspicuous when in the late species of Thalassocnus are compared than in the early ones. This corroborates the increasing adaptation of the genus to a particular ecology, already argued to be marine herbivory (Muizon et al. 2004b). This ecology also called for buoyancy and trim control, by means of osteosclerosis and pachyostosis (Amson et al. 2014). It is likely that the forelimb of Thalassocnus was involved in swimming modes that included 
quadrupedal paddling (and possibly pectoral paddling) and bottom-walking. Bottom-walking was most likely used, as it is seen in extant sirenians during grazing on the bottom, except that in Thalassocnus the well-developed hind limb was most likely involved as well. Several characteristics of Thalassocnus are also found in desmostylians, which reflects their putatively close ecologies (as already mentioned by Muizon et al. 2004b and Domning 2002). However, the supposed function of the forelimb of Thalassocnus differs from those of desmostylians and extant sirenians, in that the limb was used to obtain food, namely by uprooting rhizomes of seagrasses. The hind limb and axial postcranium of Thalassocnus are currently under study, which will, like the present work, describe their morphology and assess their possible functions.

Sirenians are recorded from two Neogene deposits on the west coast of South America beside the Pisco Formation,. One is located in northern Peru (Montera Formation, early to middle Miocene; Muizon and Domning 1985 ) and the other in Chile (Bahia Inglesa Formation, late Miocene; Bianucci et al. 2006). In the Pisco Formation, two specimens have been referred to sirenians. One is a mandible from the lowermost beds of the locality of Aguada de Lomas corresponding to a horizon stratigraphically between the El Jahuay level and the Aguada de Lomas level (Lambert and Muizon 2013), it is thus earlier than the earliest species of Thalassocnus, T. antiquus. The other is an isolated rib referred to an unnamed dugongid gen. et sp. indet. (Muizon and Domning 1985). The latter is in fact a rib of a late species of Thalassocnus (either T. carolomartini or T. yaucensis; Amson et al. in press). It thus appears that Thalassocnus was the sole occupant of the aquatic megaherbivore adaptive zone on the coast of Peru from ca. $8 \mathrm{Myr}$ up to its extinction.

Domning (2001) and Vélez-Juarbe (2014) have argued that the evolution of sirenians and seagrasses are tightly linked. The latter author even uses the fossil record of sirenians to infer the past distribution of seagrasses on the western coast of South America (among other localities). A possible cause of extinction of Thalassocnus would be the inability of the genus to cope with the cooling of Pacific waters along the coast of Peru and/or the demise of some seagrasses from the Western Hemisphere during the Cenozoic, both arguably caused by the closureof the Central American Seaway (Ivany et al. 1990). Although this is highly conjectural, one can hypothesize that this was aggravated by the fact that the latest species of Thalassocnus were highly specialized for seagrass foraging and consumption (Muizon et al. 2004b). 


\section{ACKNOWLEDGEMENTS}

We are indebted to Rodolfo Salas-Gismondi (MUSM), Samuel McLeod and Vanessa Rhue (both LACM), Castor Cartelle (MCL), and Géraldine Veron (MNHN), who allowed access to the collections under their care. Rodolfo Salas-Gismondi (MUSM) and Mario Urbina (MUSM) are thanked for collecting numerous specimens of Thalassocnus. François Pujos (CCT-CONICET-Mendoza) and Rodolfo Salas-Gismondi (MUSM) are acknowledged for the assistance they brought regarding general xenarthrans questions. We thank Colas Bouillet (MNHN), Batz Le Dimet (MNHN), Philippe Richir (MNHN), and Renaud Vacant (CNRS) for preparing and/or helping prepare some of the fossils included in this study. Finally, Christian Lemzaouda and Philippe Loubry (CNRS) are thanked for taking some of the photographs that illustrate this publication. Finally, we thank the two anonymous reviewers and the editor, John Wible, for their numerous comments and suggestions that conspicuously improved the quality of both the content and form of the manuscript.

\section{REFERENCES}

Amson E, Muizon C de (2014) A new durophagous phocid (Mammalia: Carnivora) from the late Neogene of Peru and considerations on monachine seals phylogeny. J Syst Palaeontol 12:523-548. doi:

$10.1080 / 14772019.2013 .799610$

Amson E, Muizon C de, Laurin M, Argot C, Buffrénil V de (2014) Gradual adaptation of bone structure to aquatic lifestyle in extinct sloths from Peru. Proc R Soc B 281:20140192. doi: 10.1098/rspb.2014.0192

Amson E, Muizon C de, Domning DP, Argot C, Buffrénil V de (in press) Bone histology as a clue for resolving the puzzle of a dugong rib in the Pisco Formation, Peru. J Vertebr Paleontol.

Argot C (2001) Functional-adaptive anatomy of the forelimb in the Didelphidae, and the paleobiology of the Paleocene marsupials Mayulestes ferox and Pucadelphys andinus. J Morphol 247:51-79. doi: 10.1002/10974687(200101)247:1<51::AID-JMOR1003>3.0.CO;2-\#

Argot C (2008) Changing views in paleontology: the story of a giant (Megatherium, Xenarthra). In: Sargis EJ, Dagosto M (eds) Mammalian Evolutionary Morphology. Springer, Dordrecht, pp 37-50 
Bargo MS, Vizcaíno SF (2008) Paleobiology of Pleistocene ground sloths (Xenarthra, Tardigrada): biomechanics, morphogeometry and ecomorphology applied to the masticatory apparatus. Ameghiniana 45:175-196

Bargo MS, Vizcaíno SF, Archuby FM, Blanco RE (2000) Limb bone proportions, strength and digging in some Lujanian (Late Pleistocene-Early Holocene) mylodontid ground sloths (Mammalia, Xenarthra). J Vertebr Paleontol 20:601-610

Barnes LG (2013) A new genus and species of late Miocene paleoparadoxiid (Mammalia, Desmostylia) from California. Contrib Sci 521:51-114

Barone R (1966) Anatomie comparée des Mammifères domestiques, Tome 1, Ostéologie. Imprimerie des BeauxArts, Lyon

Bianucci G, Sorbi S, Suárez ME, Landini W (2006) The southernmost sirenian record in the eastern Pacific Ocean, from the late Miocene of Chile. Comptes Rendus Palevol 5:945-952. doi: 10.1016/j.crpv.2006.06.001

Billet G, Germain D, Ruf I, Muizon C de, Hautier L (2013) The inner ear of Megatherium and the evolution of the vestibular system in sloths. J Anat 223:557-567. doi: 10.1111/joa.12114

Canto J, Salas-Gismondi R, Cozzuol M, Yáñez J (2008) The aquatic sloth Thalassocnus (Mammalia, Xenarthra) from the late Miocene of North-Central Chile: biogeographic and ecological implications. J Vertebr Paleontol 28:918-922. doi: 10.1671/0272-4634(2008)28[918:TASTMX]2.0.CO;2

Cartelle C, Bohorquez GA (1982) Eremotherium laurillardi Lund 1842. Parte I. Deteminação específica e dimorfismo sexual. Iheringia, Séria Géologica, Porto Alegre 7:45-63

Cartelle C, Fonseca JS (1983) Contribuição ao melhor conhecimento da pequena preguiça terrícola Nothrotherium maquinense (Lund) Lydekker, 1889. Lundiana 2:127-181

Clementz MT, Sorbi S, Domning DP (2009) Evidence of Cenozoic environmental and ecological change from stable isotope analysis of sirenian remains from the Tethys-Mediterranean region. Geology 37:307-310. doi: 10.1130/G25533A.1 
Coombs MC (1983) Large mammalian clawed herbivores: a comparative study. Trans Am Philos Soc New Ser 73:196

Cuenca Anaya J (1995) El Aparato Locomotor de los Escelidoterios (Edentata, Mammalia) y su Paleobiologia. Ajuntament de Valencia, Valencia

Davis DD (1964) The giant panda: a morphological study of evolutionary mechanisms. Fieldiana, Zool Mem 3:1-339

De Esteban-Trivigno S, Mendoza M, De Renzi M (2008) Body mass estimation in xenarthra: a predictive equation suitable for all quadrupedal terrestrial placentals? J Morphol 269:1276-93. doi: 10.1002/jmor.10659

De Iuliis G (2003) Toward a morphofunctional understanding of the humerus of Megatheriinae: the identity and homology of some diaphyseal humeral features (Mammalia, Xenarthra, Megatheriidae). Senckenberg Biol 83:69-78

De Iuliis G, Cartelle C (1994) The medial carpal and metacarpal elements of Eremotherium and Megatherium (Xenarthra: Mammalia). J Vertebr Paleontol 13:525-533

De Iuliis G, Cartelle C (1999) A new giant megatheriine ground sloth (Mammalia: Xenarthra: Megatheriidae) from the late Blancan to early Irvingtonian of Florida. Zool J Linn Soc 127:495-515

De Iuliis G, Gaudin TJ, Vicars MJ (2011) A new genus and species of nothrotheriid sloth (Xenarthra, Tardigrada, Nothrotheriidae) from the Late Miocene (Huayquerian) of Peru. Palaeontology 54:171-205. doi: $10.1111 / \mathrm{j} .1475-4983.2010 .01001 . \mathrm{x}$

Demaster DP, Stirling I (1981) Ursus maritimus. Mammal Species 145:1-7. doi: 10.2307/3503828

Domning DP (2001a) Sirenians, seagrasses, and Cenozoic ecological change in the Caribbean. Palaeogeogr Palaeoclimatol Palaeoecol 166:27-50. doi: 10.1016/S0031-0182(00)00200-5

Domning DP (2001b) Evolution of the Sirenia and Desmostylia. In: Mazin J, Buffrénil V de (eds) Secondary Adaptation of Tetrapods to Life Water. Verlag Dr Friedrich Pfeil, München, pp 151-168

Domning DP (2002) The terrestrial posture of desmostylians. Smithson Contrib Paleobiol 1959:99-111 
Domning DP, Aguilera OA (2008) Fossil Sirenia of the West Atlantic and Caribbean region. VIII. Nanosiren garciae, gen. et sp. nov. and Nanosiren sanchezi, sp. nov. J Vertebr Paleontol 28:479-500. doi: 10.1671/0272$4634(2008) 28$

Domning DP, Beatty BL (2007) Use of tusks in feeding by dugongid sirenians: observations and tests of hypotheses. Anat Rec 290:523-38. doi: 10.1002/ar.20540

Ehret DJ, Macfadden BJ, Jones DS, DeVries TJ, Foster DA, Salas-Gismondi R (2012) Origin of the white shark Carcharodon (Lamniformes: Lamnidae) based on recalibration of the Upper Neogene Pisco Formation of Peru. Palaeontology 55:1139-1153. doi: 10.1111/j.1475-4983.2012.01201.x

Elissamburu A, Vizcaíno SF (2004) Limb proportions and adaptations in caviomorph rodents (Rodentia: Caviomorpha). J Zool 262:145-159. doi: 10.1017/S0952836903004485

Estes JA (1989) Adaptations for aquatic living by carnivores. In: Gittleman JL (ed) Carnivore Behavior, Ecology, and Evolution. Cornell University Press, Ithaca, pp 242-282

Fariña RA, Vizcaíno SF (2003) Slow moving or browsers? A note on nomenclature. Senckenb Biol 83:3-4.

Fish FE (2001) A mechanism for evolutionary transition in swimming mode by mammals. In: Mazin J-M, Buffrénil de V (eds) Secondary Adaptation of Tetrapods to Life in Water. Verlag Dr Friedrich Pfeil, München, pp 261287

Fish FE, Baudinette RV, Frappell PB, Sarre MP (1997) Energetics of swimming by the platypus Ornithorhynchus anatinus: metabolic effort associated with rowing. J Exp Biol 200:2647-2652.

Fisher RE, Scott KM, Naples VL (2007) Forelimb myology of the pygmy hippopotamus (Choeropsis liberiensis). Anat Rec 290:673-93. doi: 10.1002/ar.20531

Fujiwara S (2009) Olecranon orientation as an indicator of elbow joint angle in the stance phase, and estimation of forelimb posture in extinct quadruped animals. J Morphol 270:1107-21. doi: 10.1002/jmor.10748

Gambaryan PP (2002) Ways of adaptive changes in claws of digging mammals [abstract in English of article in Russian]. Zoologicheskii Zhurnal 81:978-990 
Gaudin TJ (2004) Phylogenetic relationships among sloths (Mammalia, Xenarthra, Tardigrada): the craniodental evidence. Zool J Linn Soc 140:255-305. doi: 10.1111/j.1096-3642.2003.00100.x

Gaudin TJ, McDonald HG (2008) Morphology-based investigations of the phylogenetic relationships among extant and fossil xenarthrans. In: Vizcaino SF, Loughry WJ (eds) The Biology of the Xenarthra. University Press of Florida, Gainesville, pp 24-36

Gingerich PD (2003) Land-to-sea transition in early whales: evolution of Eocene Archaeoceti (Cetacea) in relation to skeletal proportions and locomotion of living semiaquatic mammals. Paleobiology 29:429-454. doi: 10.1666/0094-8373(2003)029<0429:LTIEWE >2.0.CO;2

Gingerich PD (2005) Aquatic adaptation and swimming mode inferred from skeletal proportions in the Miocene desmostylian Desmostylus. J Mamm Evol 12:183-194. doi: 10.1007/s10914-005-5719-1

Hansen RM (1978) Shasta ground sloth food habits, Rampart Cave, Arizona. Paleobiology 4:302-319

Hayashi S, Houssaye A, Nakajima Y, Chiba K, Ando T, Sawamura H, Inuzuka N, Kaneko N, Osaki T (2013) Bone inner structure suggests increasing aquatic adaptations in Desmostylia (Mammalia, Afrotheria). PLoS One 8:e59146. doi: 10.1371/journal.pone.0059146

Hildebrand M (1985) Digging of quadrupeds. In: Hildebrand M (ed) Functional Vertebrate Morphology. Cambridge University Press, Cambridge, pp 89-109

Hildebrand M (1988) Analysis of Vertebrate Structure. 3rd edn. John Wiley \& Sons, Inc., New York

Hoffstetter R (1968) Un gisement de vertébrés tertiaires à Sacaco (Sud-Pérou), témoin néogène d'une migration de faunes australes au long de la côte occidentale sud-américaine. Comptes rendus hebdomadaires des séances l'Académie des Sciences Série D 267:1273-1276

Hoffstetter R (1961) Description d'un squelette de Planops (Gravigrade du Miocène de Patagonie). Mammalia 25:196

Howell AB (1929) Contribution to the comparative anatomy of the eared and earless seals (genera Zalophus and Phoca). Proc US Natl Museum 73:1-142 
Howell AB (1930) Aquatic Mammals: Their Adaptations to Life in the Water. Charles C. Thomas, Springfield

Husar SL (1978) Dugong dugon. Mammal Species 88:1-7

Inuzuka N (2000) Aquatic adaptations in desmostylians. Hist Biol 14:97-113

Ivany LC, Portell RW, Jones DS (1990) Animal-plant relationships and paleobiogeography of an Eocene seagrass community from Florida. Palaios 5:244-258

Jenkins FA Jr (1974) The movement of the shoulder in claviculate and aclaviculate mammals. J Morphol 144:71-84

Ji Q, Luo Z-X, Yuan C-X, Tabrum AR (2006) A swimming mammaliaform from the Middle Jurassic and ecomorphological diversification of early mammals. Science 311:1123-1127. doi: 10.1126/science.1123026

Kley NJ, Kearney M (2007) Adaptations for digging and burrowing. In: Hall BK (ed) Fins into Limbs: Evolution, Development, and Transformation. University of Chicago Press, Chicago, pp 284-309

Lambert O, Muizon C de (2013) A new long-snouted species of the Miocene pontoporiid dolphin Brachydelphis and a review of the Mio-Pliocene marine mammal levels in the Sacaco Basin, Peru. J Vertebr Paleontol 33:709-721

Lara-Ruiz P, Chiarello AG (2005) Life-history traits and sexual dimorphism of the Atlantic forest maned sloth Bradypus torquatus (Xenarthra: Bradypodidae). J Zool 267:63. doi: 10.1017/S0952836905007259

Lessertisseur J, Saban R (1967) Squelette appendiculaire. In: Grassé P-P (ed) Traité de Zoologie. Tome 16. Masson et Cie, Paris, pp 709-1076

Lull RS (1929) A remarkable ground sloth. Mem Peabody Museum Yale Univ 3:1-39. doi: 10.1002/asna.19292372003

Maffucci F, Annona G, de Girolamo P, Bologna M A, Meomartino L, Montesano A, Bentivegna F, Hochscheid S (2013) Bone density in the loggerhead turtle: functional implications for stage specific aquatic habits. J Zool 291:243-248. doi: 10.1111/jzo.12060 
Marshall CD, Maeda H, Iwata M, Furuta M, Asano S, Rosas F, Reep RL (2003) Orofacial morphology and feeding behaviour of the dugong, Amazonian, West African and Antillean manatees (Mammalia: Sirenia): functional morphology of the muscular-vibrissal complex. J Zool 259:245-260. doi: 10.1017/S0952836902003205

McDonald HG, Muizon C de (2002) The cranial anatomy of Thalassocnus (Xenarthra, Mammalia), a derived nothrothere from the Neogene of the Pisco Formation (Peru). J Vertebr Paleontol 22:349-365

Mendel FC (1985) Use of hands and feet of three-toed sloths (Bradypus variegatus) during climbing and terrestrial locomotion. J Mammal 66:359-366

Miller RA (1935) Functional adaptations in the forelimb of the sloths. J Mammal 16:38-51

Muizon C de, DeVries TJ (1985) Geology and paleontology of late Cenozoic marine deposits in the Sacaco area (Peru). Geol Rundschau 74:547-563

Muizon C de, Domning DP (1985) The first records of fossil sirenians in the southeastern Pacific Ocean. Bull Mus natl Hist nat Sec C, 4ème sér 7:189-213

Muizon C de, McDonald HG (1995) An aquatic sloth from the Pliocene of Peru. Nature 375:224-227. doi: $10.1038 / 375224 \mathrm{a} 0$

Muizon C de, McDonald HG, Salas R, Urbina M (2004a) The youngest species of the aquatic sloth Thalassocnus and a reassessment of the relationships of the nothrothere sloths (Mammalia: Xenarthra). J Vertebr Paleontol 24:287-397. doi: 10.1671/2429a

Muizon C de, McDonald HG, Salas R, Urbina M (2003) A new early species of the aquatic sloth Thalassocnus (Mammalia, Xenarthra) from the ate Miocene of Peru. J Vertebr Paleontol 23:886-894. doi: 10.1671/2361-13

Muizon C de, McDonald HG, Salas R, Urbina M (2004b) The evolution of feeding adaptations of the aquatic sloth Thalassocnus. J Vertebr Paleontol 24:398-410. doi: 10.1671/2429b

Nyakatura JA (2012) The convergent evolution of suspensory posture and locomotion in tree sloths. J Mammal Evol 19:225-234. doi: 10.1007/s10914-011-9174-x 
Nyakatura JA, Fischer MS (2011) Functional morphology of the muscular sling at the pectoral girdle in tree sloths: convergent morphological solutions to new functional demands? J Anat 219:360-74. doi: 10.1111/j.14697580.2011.01394.x

Osburn RC (1903) Adaptation to aquatic, arboreal, fossorial and cursorial habits in mammals. I. Aquatic adaptations. Am Nat 37:651-665

Owen R (1858) On the Megatherium (Megatherium americanum, Cuvier and Blumenbach). Part IV. Bones of the anterior extremities. Phil Trans R Soc London 148:261-278

Pasitschniak-Arts M, Marinelli L (1998) Ornithorhynchus anatinus. Mammal Species 585:1-9

Paula Couto C de (1974) The manus of Nothrotheriops shastense (Sinclair, 1905). Anais do XXVIII Congresso Brasileiro de Geologia 2:165-176

Polly PD (2007) Limbs in mammalian evolution. In: Hall BK (ed) Fins into Limbs: Evolution, Development, and Transformation. University of Chicago Press, Chicago, pp 245-268

Pouchet G (1867) Mémoires sur le Grand Fourmilier. G. Masson, Paris

Preen A (1996) Infaunal mining: a novel foraging method of loggerhead turtles. J Herpetol 30:94-96

Pujos F, De Iuliis G, Argot C, Werdelin L (2007) A peculiar climbing Megalonychidae from the Pleistocene of Peru and its implication for sloth history. Zool J Linn Soc 149:179-235

Pujos F, Gaudin TJ, De Iuliis G, Cartelle C (2012) Recent advances on variability, morpho-functional adaptations, dental terminology, and evolution of sloths. J Mammal Evol 19:159-169. doi: 10.1007/s10914-012-9189-y

Pyenson ND, Gutstein CS, Parham JF, Little H, Metallo A, Roux P Le, Carren C, Rossi V, Valenzuela-Toro AM, Velez-Juarbe J, Santelli CM, Rogers DR, Cozzuol MA, Suárez ME (2014) Repeated mass strandings of Miocene marine mammals from Atacama Region of Chile point to sudden death at sea. Proc R Soc B 281: 20133316. doi: 10.1098/rspb.2013.3316

Reidenberg JS (2007) Anatomical adaptations of aquatic mammals. Anat Rec 290:507-513. doi: 10.1002/ar.20541 
Reinhardt J (1878) Kæmpedovendyr-Slægten Coelodon. Danske Videnskabernes Selskab Skrifter, Naturvidenskabelig og Mathematisk Afdeling Serie 5 12:255-349

Rose KD, Emry RJ (1993) Relationships of Xenarthra, Pholidota, and fossil "edentates": the morphological evidence. In: Szalay FS, Novacek MJ, McKenna MC (eds) Mammal Phylogeny: Placentals. Springer-Verlag, New York, pp $81-102$

Salas R, Pujos F, Muizon C de (2005) Ossified meniscus and cyamo-fabella in some fossil sloths: a morphofunctional interpretation. Geobios 38:389-394. doi: 10.1016/j.geobios.2003.11.009

Scott WB (1903-1904) Mammalia of the Santa Cruz beds. Reports of the Princeton University Expedition to Patagonia, 1896-1899 5:1-490. doi: 10.1525/mua.2006.29.2.153

Shikama T (1966) Postcranial skeletons of Japanese Desmostylia: limb bones and sternum of Desmostylus and Paleoparadoxia, with considerations on their evolution. Palaeontol Soc Japan Spec Pap 12:202

Smith JM, Savage RJG (1956) Some locomotory adaptations in mammals. Zool J Linn Soc 42:603-622

Stock C (1925) Cenozoic gravigrade edentates of western North America, with special reference to the Pleistocene Megalonychinae and Mylodontidae of Rancho La Brea. Carnegie Inst Wash Publ 331:1-206

Taylor BK (1978) The anatomy of the forelimb in the anteater (Tamandua) and its functional implications. J Morphol $157: 347-368$

Thewissen JGM, Taylor MA (2007) Aquatic adaptations in the limbs of amniotes. In: Hall BK (ed) Fins into Limbs: Evolution, Development, and Transformation. University of Chicago Press, Chicago, pp 310-322

Tito G, De Iuliis G (2003) Morphofunctional aspects and palaeobiology of the manus in the giant ground sloth Eremotherium Spillmann 1948. Senckenb Biol 83:79-94

Toledo N, Bargo MS, Cassini GH, Vizcaíno SF (2012) The forelimb of early Miocene sloths (Mammalia, Xenarthra, Folivora): morphometrics and functional implications for substrate preferences. J Mammal Evol 19:185-198. doi: $10.1007 / \mathrm{s} 10914-012-9185-2$ 
Toledo N, Bargo MS, Vizcaíno SF (2013) Muscular reconstruction and functional morphology of the forelimb of early Miocene sloths (Xenarthra, Folivora) of Patagonia. Anat Rec 296:305-325. doi: 10.1002/ar.22627

Vélez-Juarbe J (2014) Ghost of seagrasses past: using sirenians as a proxy for historical distribution of seagrasses. Palaeogeogr Palaeoclimatol Palaeoecol 400:41-49. doi: 10.1016/j.palaeo.2013.05.012

Witmer LM (1995) The extant phylogenetic bracket and the importance of reconstructing soft tissues in fossils. In: Thomason J (ed) Functional Morpholology Vertebrate Paleontology. Cambridge University Press, Cambridge, pp 19-33 
Figure Captions

Fig. 1 Map of central South America, with a focus on the Pisco basin. The outcrops of the Pisco Formation are represented with vertical stripes. The Pan-American Highway is figured as a dashed line [Intended for single column width]

Fig. 2 Articulated left forelimb of T. natans (holotype, MNHN.F.SAS734) in lateral view. Reconstructed elements in solid brown

[Intended for single column width]

Fig. 3 Scapula of Thalassocnus in lateral view: a, T. natans (holotype, MNHN.F.SAS734, right); b, T. antiquus; (holotype, MUSM 228, left inverted); c, T. littoralis (MUSM 223, right); and d, T. yaucensis (MUSM 2056, left inverted)

[Intended for double column width]

Fig. 4 Clavicle of Thalassocnus in posterior view: a, T. natans (holotype, MNHN.F.SAS734, right); and b, T. littoralis (MNHN.F.SAS1647, unknown laterality)

[Intended for single column width]

Fig. 5 Humerus of Thalassocnus in anterior view: a, T. antiquus (holotype, MUSM 228, left inverted); b, T. natans (holotype, MNHN.F.SAS734, right and left); c, T. littoralis (MNHN.F.SAS53, right); and d, $T$. yaucensis (holotype, MUSM 37, left distal epiphysis inverted)

[Intended for double column width]

Fig. 6 Humerus of Thalassocnus in lateral view: a, T. antiquus (holotype, MUSM 228, left); b, T. natans (holotype, MNHN.F.SAS734, right and proximal half of left); and c, T. littoralis (MNHN.F.SAS53, right inverted)

[Intended for double column width] 
Fig. 7 Humerus of Thalassocnus in posterior view: a, T. antiquus (holotype, MUSM 228, left inverted); b, T. natans (holotype, MNHN.F.SAS734, right and proximal half of left); and c, T. littoralis (MNHN.F.SAS53, right)

[Intended for double column width]

Fig. 8 Humerus of Thalassocnus in medial view: a, T. antiquus (holotype, MUSM 228, left inverted); b, T. natans (holotype, MNHN.F.SAS734, right and left); and $\mathbf{c}$, T. littoralis (MNHN.F.SAS53, right) [Intended for double column width]

Fig. 9 Ulna of Thalassocnus in anterior view: a, T. natans (holotype, MNHN.F.SAS734, left); b, T. littoralis (MNHN.F.SAS1620, right inverted); c, T. carolomartini (MUSM 1995, right inverted); and d, T. yaucensis (holotype, MUSM 37, left)

[Intended for double column width]

Fig. 10 Ulna of Thalassocnus in posterior view: a, T. natans (holotype, MNHN.F.SAS734, left); b, T. littoralis (MNHN.F.SAS1620, right inverted); and c, T. yaucensis (holotype, MUSM 37, left) [Intended for double column width]

Fig. 11 Ulna of Thalassocnus in medial view: a, T. antiquus (holotype, MUSM 228, left); b, T. natans (holotype, MNHN.F.SAS734, left); c, T. littoralis (MNHN.F.SAS1620, right inverted); d, $T$. carolomartini (MUSM 1995, right inverted); and e, T. yaucensis (holotype, MUSM 37, left) [Intended for double column width]

Fig. 12 Ulna of Thalassocnus in lateral view: a, T. antiquus (holotype, MUSM 228, left); b, T. natans (holotype, MNHN.F.SAS734, left); c, T. littoralis (MNHN.F.SAS1620, right inverted); d, $T$. carolomartini (MUSM 1995, right inverted); and e, T. yaucensis (holotype, MUSM 37, left) [Intended for double column width] 
Fig. 13 Radius of Thalassocnus in lateral view: a, T. antiquus (holotype, MUSM 228, left inverted); b, T. natans (holotype, MNHN.F.SAS734, right); c, T. littoralis (MUSM 223, right); d, T. carolomartini (MUSM 1995, right); and e, T. yaucensis (holotype, MUSM 37, left inverted) [Intended for double column width]

Fig. 14 Radius of Thalassocnus in medial view: a, T. antiquus (holotype, MUSM 228, left inverted); b, T. natans (holotype, MNHN.F.SAS734, right); c, T. littoralis (MUSM 223, right); d, T. carolomartini (MUSM 1995, right); and e, T. yaucensis (holotype, MUSM 37, left inverted) [Intended for double column width]

Fig. 15 Radius of Thalassocnus in anterior view: a, T. natans (holotype, MNHN.F.SAS734, right); b, T. littoralis (MNHN.F.SAS802, right); c, T. carolomartini (MUSM 1995, right); and d, T. yaucensis (holotype, MUSM 37, left inverted) [Intended for double column width]

Fig. 16 Radius of Thalassocnus in posterior view: a, T. natans (holotype, MNHN.F.SAS734, right); b, T. littoralis (MNHN.F.SAS802, right); c, T. carolomartini (MUSM 1995, right); and d, T. yaucensis (holotype, MUSM 37, left inverted) [Intended for double column width]

Fig. 17 Left manus of T. carolomartini (SMNK-PAL 3814) in dorsal view. The ungual phalanx of the second digit is semi-flexed. The Mc V is in neutral position, and hence does not contact the cuneiform; such contact occurs during lateral deviation of the metacarpal. Abbreviations: D., digit; Mc, metacarpal; ph., phalanx [Intended for double column width]

Fig. 18 Right manus of T. natans (holotype, MNHN.F.SAS734): a, dorsal view (bones are placed in articulated position); $\mathbf{b}$, proximal view of each carpals of the proximal row; and $\mathbf{c}$, medial view of each element of the metacarpus and digits preserved. Abbreviations: D., digit; Mc, metacarpal; ph., phalanx 
[Intended for double column width]

Fig. 19 Left scaphoid of T. carolomartini (SMNK-PAL 3814): a, dorsal; b, medial; c, lateral; d, proximal; and e, distal views. Abbreviation: f. (fs for plural), facet

[Intended for double column width]

Fig. 20 Scaphoid of Thalassocnus in lateral view: a, T. antiquus (holotype, MUSM 228, left); b, T. natans (holotype, MNHN.F.SAS734, right inverted); c, T. carolomartini (SMNK-PAL 3814, left); and d, T. yaucensis (MUSM 347, right inverted). Abbreviation: f., facet

[Intended for double column width]

Fig. 21 Left lunar of T. carolomartini (SMNK-PAL 3814): a, dorsal; b, medial; and c, lateral views. Abbreviation: f., facet

[Intended for single column width]

Fig. 22 Lunar of Thalassocnus in dorsal view: a, T. antiquus (holotype, MUSM 228, left); b, T. natans (holotype, MNHN.F.SAS734, right inverted); c, T. carolomartini (MUSM 1995, right inverted). Abbreviation: f., facet

[Intended for double column width]

Fig. 23 Left cuneiform of $T$. carolomartini (SMNK-PAL 3814): a, dorsal; b, palmar; and $\mathbf{c}$, medial views. Abbreviation: f., facet

[Intended for single column width]

Fig. 24 Cuneiform of Thalassocnus in dorsal view. a, T. natans (holotype, MNHN.F.SAS734, right inverted); b, T. littoralis MNHN.F.SAS156, right inverted); c, T. carolomartini (SMNK-PAL 3814, left); and d, T. carolomartini (MUSM 156, right inverted). Abbreviation: f., facet [Intended for double column width] 
Fig. 25 Left pisiform of Thalassocnus in lateral view: a, T. littoralis (MNHN.F.SAS53); and b, $T$. carolomartini (SMNK-PAL 3814). Abbreviation: f., facet

[Intended for single column width]

Fig. 26 Left trapezoid of T. carolomartini (SMNK-PAL 3814): a, lateral; b, proximal; and c, distal views. Abbreviation: f. (fs for plural), facet

[Intended for single column width]

Fig. 27 Left trapezoid of Thalassocnus in distal view: a, T. antiquus (holotype, MUSM 228); and b, T. carolomartini (SMNK-PAL 3814) Abbreviation: f., facet

[Intended for single column width]

Fig. 28 Left magnum of $T$. carolomartini (SMNK-PAL 3814): a, dorsal; b, medial; c, lateral; and d, distal views.

Abbreviation: f., facet

[Intended for double column width]

Fig. 29 Magnum of Thalassocnus: Medial view of a, T. antiquus (holotype, MUSM 228, left); and b, T. carolomartini (SMNK-PAL 3814, left). Distal view of c, T. littoralis (MNHN.F.SAS1605, right inverted); and d, $T$. carolomartini (SMNK-PAL 3814, left). Abbreviation: f. (fs for plural), facet

[Intended for double column width]

Fig. 30 Left unciform of T. carolomartini (SMNK-PAL 3814): a, dorsal; b, lateral; c, proximal; and d, distal views. Abbreviation: f., facet

[Intended for double column width]

Fig. 31 Unciform of Thalassocnus: Dorsal view of a, T. antiquus (holotype, MUSM 228, left); b, T. carolomartini (SMNK-PAL 3814, left); and c, T. yaucensis (MUSM 347, left). Lateral view of d, $T$. antiquus (holotype, MUSM 228, left); e, T. littoralis (MUSM 223, right inverted); and f, T. carolomartini (SMNK-PAL 3814, left). Abbreviation: f., facet 
[Intended for double column width]

Fig. 32 Left trapezium-first metacarpal complex of T. carolomartini (SMNK-PAL 3814): a, dorsal; b, medial; and c, lateral views. Abbreviation: f., facet

[Intended for single column width]

Fig. 33 Left first digit of T. carolomartini (SMNK-PAL 3814): a, dorsal; b, palmar; and c, lateral views. Abbreviation: f., facet

[Intended for single column width]

Fig. 34 Left second metacarpal of $T$. carolomartini (SMNK-PAL 3814): a, dorsal; b, lateral; c, proximal; and $\mathbf{d}$, distal views. Abbreviation: f., facet

[Intended for double column width]

Fig. 35 Second metacarpal of Thalassocnus. Dorsal (a-e) and distal (f-j) views of T. antiquus (a, $\mathbf{f}$, holotype, MUSM 228, left); T. natans (b, g, holotype, MNHN.F.SAS734, right inverted); T. littoralis (c, h, MUSM 223, right inverted); T. carolomartini (d, i, SMNK-PAL 3814, left); and T. yaucensis (e, j, holotype, MUSM 37, right inverted). Abbreviation: f., facet

[Intended for double column width]

Fig. 36 Left second digit of T. carolomartini (SMNK-PAL 3814). Proximal phalanx in a, dorsal; b, lateral; and $\mathbf{c}$, distal views. Second phalanx in $\mathbf{d}$, dorsal; $\mathbf{e}$, ventral; and $\mathbf{f}$, lateral views. Ungual phalanx in $\mathbf{g}$, dorsal; and $\mathbf{h}$, lateral views

[Intended for single column width]

Fig. 37 Left ungual phalanx of the second digit of Thalassocnus. Dorsal (a-c) and lateral (d-f) views of $T$. antiquus (a, d, holotype, MUSM 228); and two specimens of T. yaucensis (b, e, holotype, MUSM 37; c, f, MUSM 1034). The distal part of the ungual process of the holotype of T. yaucensis (b) was slightly reoriented (at the level of the black line), due to a fracture. Abbreviation: f., facet 
[Intended for double column width]

Fig. 38 Left third metacarpal of T. carolomartini (SMNK-PAL 3814): a, dorsal; b, medial; c, lateral; and d, proximal views. Abbreviation: f., facet

[Intended for double column width]

Fig. 39 Left third digit of T. carolomartini (SMNK-PAL 3814). Co-ossified proximal and second phalanges in a, dorsal; and $\mathbf{b}$, lateral views. Ungual phalanx in $\mathbf{c}$, dorsal; and $\mathbf{d}$, lateral views [Intended for single column width]

Fig. 40 Left fourth metacarpal of T. carolomartini (SMNK-PAL 3814): a, dorsal; b, lateral; and c, proximal views Abbreviations: f., facet

[Intended for double column width]

Fig. 41 Fourth metacarpal of T. yaucensis in medial view. a, MUSM 2073 (right, inverted); and b, the holotype (MUSM 37, left). Abbreviation: f., facet

[Intended for single column width]

Fig. 42 Left fourth digit of $T$. carolomartini (SMNK-PAL 3814). Proximal phalanx in a, dorsal; and $\mathbf{b}$, lateral views. Second phalanx in $\mathbf{c}$, dorsal; $\mathbf{d}$, palmar; and $\mathbf{e}$, lateral views. Ungual phalanx in $\mathbf{f}$, dorsal (right inverted); and g, lateral views. Abbreviation: f., facet [Intended for single column width]

Fig. 43 Right ungual phalanx of fourth digit of T. natans (holotype, MNHN.F.SAS734): a, dorsal; and b, lateral view. Abbreviation: f., facet

[Intended for single column width]

Fig. 44 Left fifth metacarpal of T. carolomartini (SMNK-PAL 3814): a, dorsal; b, palmar; c, lateral; and d, proximal views. Abbreviation: f., facet 
[Intended for double column width]

Fig. 45 Fifth metacarpal of Thalassocnus: Palmar (a-c) and lateral (d-f) views of T. littoralis (a, d; MUSM 223, left); T. carolomartini (b, e; SMNK-PAL 3814, left); and T. yaucensis (c, f; holotype, MUSM 37, left). Proximal view of $\mathbf{g}$, T. littoralis (MNHN.F.SAS156, right, inverted); and $\mathbf{h}$, T. carolomartini (SMNK-PAL 3814, left). Abbreviation: f., facet

[Intended for single column width]

Fig. 46 Left fifth digit of Thalassocnus: a, lateral view of co-ossified proximal and second phalanges of $T$. antiquus (holotype, MUSM 228). Distal view of b, proximal phalanx; and $\mathbf{c}$, second phalanx of $T$. carolomartini (MUSM 1995). Abbreviation: f., facet

[Intended for single column width]

Fig. 47 Comparison of the antebrachia of several species of Thalassocnus and other marine mammals. The outlined right radius and ulna are seen laterally, during supination and are not to scale. a, Nothrotherium (MCL 1020); b, T. natans (holotype, MNHN.F.SAS734); c, T. littoralis (MNHN.F.SAS56); d, T. carolomartini (MUSM 1995); e, T. yaucensis (holotype, MUSM 37, inverted); f, Zalophus; g, Phoca; h, Trichechus; i, Paleoparadoxia. $\mathbf{f - h}$ are modified from Howell (1930), i is modified from Fujiwara (2009) [Intended for double column width] 
Tables

Table 1. Measurements (in millimeters) of the scapula of Thalassocnus.

\begin{tabular}{|c|c|c|c|c|c|}
\hline & T. antiquus & T. natans & T. littoralis & T. carolomartini & T. yaucensis \\
\hline $\begin{array}{l}\text { Length of primary } \\
\text { spine, from anterior } \\
\text { extremity of coracoid } \\
\text { to vertebral border }\end{array}$ & - & 234.4 & 228.5 (MUSM 223) & - & $\begin{array}{c}141^{*} \\
\text { (MUSM } \\
1034)\end{array}$ \\
\hline $\begin{array}{l}\text { Length of secondary } \\
\text { spine, from posterior } \\
\text { border of glenoid } \\
\text { fossa to posterodorsal } \\
\text { angle }\end{array}$ & - & 182.4 & $\begin{array}{c}174 \text { (MUSM 223); } 186.0 \\
\text { (MNHN.F.SAS1647) }\end{array}$ & - & $\begin{array}{c}151^{*} \\
\text { (MUSM } \\
1034)\end{array}$ \\
\hline $\begin{array}{l}\text { Greatest AP length of } \\
\text { infraspinous fossa }\end{array}$ & - & 78 & $\begin{array}{l}76 \text { (MUSM 223); } 79 \\
\text { (MNHN.F.SAS1647) }\end{array}$ & - & - \\
\hline $\begin{array}{l}\text { Greatest AP length of } \\
\text { postscapular fossa }\end{array}$ & - & 19 & $\begin{array}{l}20 \text { (MUSM 223); } 24 \\
\text { (MNHN.F.SAS1647) }\end{array}$ & - & - \\
\hline $\begin{array}{l}\text { Greatest AP length of } \\
\text { glenoid fossa }\end{array}$ & - & 50.9 & $\begin{array}{l}47.0 \text { (MNHN.F.SAS10); } \\
51.7 \text { (MNHN.F.SAS53); } \\
\text { 51.8 (MNHN.F.SAS64); } \\
\text { 56.4 (MUSM 223); 57.8 } \\
\text { (MNHN.F.SAS1647) }\end{array}$ & $\begin{array}{c}58^{*} \\
\text { (MNHN.F.SAO207) }\end{array}$ & $\begin{array}{c}61^{*} \\
\text { (MUSM } \\
2056)\end{array}$ \\
\hline $\begin{array}{l}\text { Greatest ML width of } \\
\text { glenoid fossa }\end{array}$ & - & 33.8 & $\begin{array}{l}28.8 \text { (MNHN.F.SAS10); } \\
31.1 \text { (MNHN.F.SAS53); } \\
31.9 \text { (MNHN.F.SAS64); } \\
\text { 35.4 (MUSM 223); 35.1 } \\
\text { (MNHN.F.SAS1647) }\end{array}$ & $\begin{array}{c}29.5 \\
\text { (MNHN.F.SAO207) }\end{array}$ & $\begin{array}{c}40.4 \\
\text { (MUSM } \\
2056)\end{array}$ \\
\hline $\begin{array}{l}\text { Greatest DV depth of } \\
\text { glenoid fossa }\end{array}$ & - & 15 & $\begin{array}{l}14 \text { (MNHN.F.SAS10); } \\
14 \text { (MNHN.F.SAS53); } \\
15 \text { (MNHN.F.SAS64); } \\
18 \text { (MNHN.F.SAS1647) }\end{array}$ & $\begin{array}{c}11 \\
\text { (MNHN.F.SAO207) }\end{array}$ & \\
\hline $\begin{array}{l}\text { Length (parallel to the } \\
\text { primary spine) of } \\
\text { coraco-scapular } \\
\text { foramen }\end{array}$ & - & 21.9 & $\begin{array}{l}\text { 18.7 (MUSM 223); } 21.6 \\
\text { (MNHN.F.SAS1647) }\end{array}$ & - & - \\
\hline
\end{tabular}

Footnotes: If no specimen number is given after a measurement, it is that of the holotype of the species. *, estimate; AP, anteroposterior; DV, dorsoventral; ML, mediolateral.

Table 2. Development of the postscapular fossa.

\begin{tabular}{lccccc}
\hline Taxon & Specimen number & $\begin{array}{c}\text { Maximum AP } \\
\text { length of } \\
\text { postscapular fossa } \\
\text { (Ps) }\end{array}$ & $\begin{array}{c}\text { Maximum AP } \\
\text { length of } \\
\text { infraspinous } \\
\text { fossa (Is) }\end{array}$ & Ps/Is & $\begin{array}{c}\text { Species value (mean if } \\
\text { several specimens) }\end{array}$ \\
\hline T. natans & MNHN.F.SAS734 & 19 & 78 & 0.24 & 0.24 \\
T. littoralis & MUSM 223 & 20 & 76 & 0.26 & 0.28 \\
T. littoralis & MNHN.F.SAS1647 & 24 & 79 & 0.30 & \\
\hline
\end{tabular}

Footnotes: AP, anteroposterior. 
Table 3. Measurements (in millimeters) of the clavicle of Thalassocnus.

\begin{tabular}{lccccc}
\hline & T. antiquus & T. natans & T. littoralis & T. carolomartini & T. yaucensis \\
\hline Greatest length & - & 101.5 & 110.0 (MUSM 223) & - & - \\
Sternal end, AP width & - & 29.7 & - & - & - \\
Sternal end, DV width & - & 26.1 & - & - & 29.2 \\
$\begin{array}{l}\text { Acromial end, AP } \\
\text { width }\end{array}$ & - & 22.1 & 24.3 (MUSM 223) & - \\
$\begin{array}{l}\text { Acromial end, DV } \\
\text { width }\end{array}$ & - & 17.0 & 16.1 (MUSM 223) & - & - \\
Midshaft, AP width & & 14.8 & 13.2 (MUSM 223) & - & - \\
Midshaft, DV width & - & 11.0 & 12.4 (MUSM 223) & - & - \\
\hline
\end{tabular}

Footnotes: If no specimen number is given after a measurement, it is that of the holotype of the species. AP, anteroposterior; DV, dorsoventral.

Table 4. Measurements (in millimeters) of the humerus of Thalassocnus.

\begin{tabular}{|c|c|c|c|c|c|}
\hline & T. antiquus & T. natans & T. littoralis & T. carolomartini & T. yaucensis \\
\hline $\begin{array}{l}\text { Greatest PD length } \\
\text { (between proximal end } \\
\text { of head and median } \\
\text { part of condyle) }\end{array}$ & 245.0 & 255.4 & $\begin{array}{c}279.3 \\
\text { (MNHN.F.SAS44); } \\
243.9 \\
\text { (MNHN.F.SAS45); } \\
243.2 \\
\text { (MNHN.F.SAS53); } \\
227.1 \\
\text { (MNHN.F.SAS54); } \\
229.0 \\
\text { (MNHN.F.SAS256); } \\
284 * \text { (MUSM 223); }\end{array}$ & 297.0 (MUSM 1995) & - \\
\hline Head, AP depth & 45.3 & 47.7 & $\begin{array}{c}52.7 \text { (MNHN.F.SAS44); } \\
47.0 \text { (MNHN.F.SAS45); } \\
47.2 \text { (MNHN.F.SAS53); } \\
44.8 \text { (MNHN.F.SAS54); } \\
40.8 \\
\text { (MNHN.F.SAS256); } \\
\text { 49.7 } \\
\text { (MNHN.F.SAS1605); } \\
\text { 51.4 (MUSM 223); }\end{array}$ & $\begin{array}{c}48.9 \\
\text { (MNHN.F.SAO13); } \\
57.3 \\
\text { (MNHN.F.SAO201); } \\
\text { 59.1 (MUSM 1995) }\end{array}$ & $\begin{array}{c}59.9 \\
\text { (MUSM 347) }\end{array}$ \\
\hline Head, ML width & 43.4 & 45.4 & $\begin{array}{c}50.6 \text { (MNHN.F.SAS44); } \\
\text { 43.5 (MNHN.F.SAS45); } \\
\text { 46.1 (MNHN.F.SAS53); } \\
\text { 43.1 (MNHN.F.SAS54); } \\
\text { 38.2 } \\
\text { (MNHN.F.SAS256); } \\
\text { 44.6 (1605); 48.4 } \\
\text { (MUSM 223); }\end{array}$ & $\begin{array}{c}43 \\
\text { (MNHN.F.SAO13)*; } \\
44.6 \\
\text { (MNHN.F.SAO201); } \\
\text { 53.5 (MUSM 1995) }\end{array}$ & $\begin{array}{c}55.7 \\
\text { (MUSM 347) }\end{array}$ \\
\hline
\end{tabular}




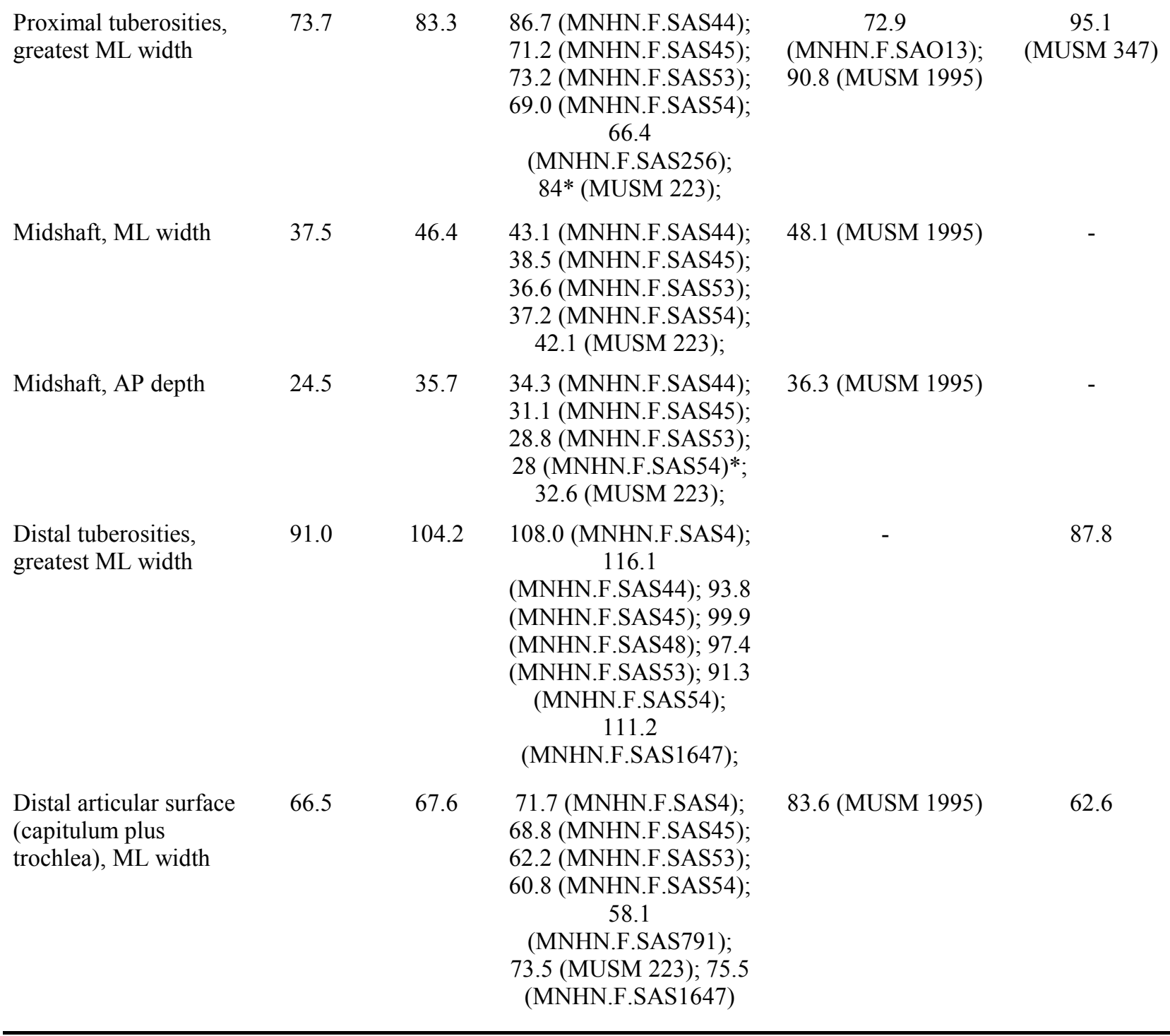

Footnotes: If no specimen number is given after a measurement, it is that of the holotype of the species; *, estimate. $\mathrm{AP}$, anteroposterior; ML, mediolateral; $\mathrm{PD}$, proximodistal.

Table 5. Proximodistal length of the humerus compared to the width of the distal articular surface in Thalassocnus and other Megatheria.

\begin{tabular}{lccccc}
\hline Taxon & Specimen number & PD length (L) & $\begin{array}{c}\text { ML width of } \\
\text { distal articular } \\
\text { surface }(\mathrm{W})\end{array}$ & L/W & $\begin{array}{c}\text { Species value } \\
\text { (mean if } \\
\text { several } \\
\text { specimens) }\end{array}$ \\
\hline T. antiquus & MUSM 228 & 245.0 & 66.5 & 3.68 & 3.68 \\
T. natans & MNHN.F.SAS734 & 255.4 & 67.6 & 3.78 & 3.78 \\
T. littoralis & MNHN.F.SAS45 & 243.9 & 68.8 & 3.55 & 3.76 \\
& MNHN.F.SAS53 & 243.2 & 62.2 & 3.91 & \\
& MNHN.F.SAS54 & 227.1 & 60.8 & 3.74 & \\
& MUSM 223 & 284.0 & 73.5 & 3.86 &
\end{tabular}




\begin{tabular}{lccccc} 
T. carolomartini & MUSM 1995 & 297.0 & 83.6 & 3.55 & 3.55 \\
Nothrotheriops & LACM 21604 & 402.3 & 90.6 & 4.44 & 4.44 \\
Nothrotherium & MCL 1020 & 248.7 & 48.9 & 5.09 & 5.09 \\
Mionothropus & LACM & 319.5 & 67.1 & 4.76 & 4.76 \\
Planops & 4609/117533 & & & & \\
Megatherium & BMNH M.9207 & 324 & 75.5 & 4.29 & 4.29 \\
\hline
\end{tabular}

Footnotes: ML, mediolateral; PD, proximodistal.

Table 6. Proximodistal length of the humerus compared to the depth of the horizontal ramus of the mandible in Thalassocnus and other nothrotheriids.

\begin{tabular}{lcccc}
\hline Taxon & Specimen number & $\begin{array}{c}\text { PD length of humerus } \\
(\mathrm{Lh})\end{array}$ & $\begin{array}{c}\text { Maximum depth of } \\
\text { horizontal ramus } \\
\text { of mandible (Md) }\end{array}$ & Lh/Md \\
\hline T. antiquus & MUSM 228 & 245.0 & 42.5 & 5.76 \\
T. natans & MNHN.F.SAS734 & 255.4 & 44.8 & 5.70 \\
Nothrotherium & MCL 1020 & 248.7 & 32.4 & 7.68 \\
Mionothropus & LACM & 319.5 & 45.1 & 7.08 \\
& 4609/117533 & & & \\
\hline
\end{tabular}

Footnotes: PD, proximodistal.

Table 7. Humeral size (width at proximal tuberosities) compared to that of the mandible (maximum depth of horizontal ramus) in Thalassocnus.

\begin{tabular}{lcccc}
\hline Taxon & Specimen number & $\begin{array}{c}\text { Maximum depth of } \\
\text { horizontal ramus of } \\
\text { mandible (Md) }\end{array}$ & $\begin{array}{c}\text { ML Width at } \\
\text { humeral proximal } \\
\text { tuberosities (Hw) }\end{array}$ & Hw/Md \\
\hline T. antiquus & MUSM 228 & 42.5 & 73.7 & 1.73 \\
T. natans & MNHN.F.SAS734 & 44.8 & 83.3 & 1.86 \\
T. littoralis & MUSM 223 & 45.4 & $84^{*}$ & 1.85 \\
T. yaucensis & MUSM 347 & 51.5 & 95.1 & 1.85 \\
\hline
\end{tabular}

Footnotes: *, estimate. ML, mediolateral.

Table 8. Humeral size (proximodistal length) compared to that of the seventeenth thoracic vertebra in Thalassocnus.

\begin{tabular}{|c|c|c|c|c|c|c|c|c|}
\hline Taxon & $\begin{array}{c}\text { Specimen } \\
\text { number }\end{array}$ & $\begin{array}{c}\mathrm{CC} \\
\text { length } \\
\text { of T7 } \\
\text { (LT7) }\end{array}$ & $\begin{array}{l}\text { humeral } \\
\text { PD length } \\
(\mathrm{Hl})\end{array}$ & $\mathrm{LT} 7 / \mathrm{Hl}$ & $\begin{array}{c}\text { Transverse } \\
\text { width of } \\
\text { T7 (WT7) }\end{array}$ & WT7/Hl & $\begin{array}{c}\text { DV } \\
\text { height } \\
\text { of T7 } \\
\text { (HT7) }\end{array}$ & $\mathrm{HT} 7 / \mathrm{Hl}$ \\
\hline & MNHN.F.SAS & & & & & & & \\
\hline T. natans & 734 & 32.6 & 255.4 & 0.13 & 30.3 & 0.12 & 27.2 & 0.11 \\
\hline T. littoralis & MUSM 223 & 31.5 & 284.0 & 0.11 & 30.6 & 0.11 & 25.3 & 0.09 \\
\hline T. carolomartini & MUSM 1995 & 36.0 & 297.0 & 0.12 & 37.4 & 0.13 & 31.7 & 0.11 \\
\hline
\end{tabular}

Footnotes: CC, craniocaudal; DV, dorsoventral; PD, proximodistal.

Table 9. Measurements (in millimeters) of the ulna of Thalassocnus. 


\begin{tabular}{|c|c|c|c|c|c|}
\hline & T. antiquus & T. natans & T. littoralis & T. carolomartini & T. yaucensis \\
\hline $\begin{array}{l}\text { Greatest length } \\
\text { (proximodistal) }\end{array}$ & - & 333.0 & $\begin{array}{c}297 * \\
\text { (MNHN.F.SAS61); } \\
\text { 318.0 (MNHN.F.SAS } \\
\text { 1620); 333.8 (MUSM } \\
\text { 223); }\end{array}$ & 353.6 (MUSM 1995) & 300.5 \\
\hline $\begin{array}{l}\text { Olecranon length } \\
\text { (from proximal end to } \\
\text { level of proximal most } \\
\text { anconeal process) }\end{array}$ & - & 35.9 & $\begin{array}{c}31.4 \text { (MNHN.F.SAS53); } \\
\text { 27.9 (MNHN.F.SAS54); } \\
\text { 32.7 (MNHN.F.SAS56); } \\
\text { 30.4 (MNHN.F.SAS57); } \\
\text { 35.1 (MNHN.F.SAS58); } \\
\text { 28.7 (MNHN.F.SAS61); } \\
\text { 26.5 (MNHN.F.SAS64); } \\
23 * \\
\text { (MNHN.F.SAS256); } \\
29.8 \\
\text { (MNHN.F.SAS491); } \\
37.3 \\
\text { (MNHN.F.SAS762); } \\
33.5 \\
\text { (MNHN.F.SAS1620); } \\
33.2 \\
\text { (MNHN.F.SAS1632); } \\
\text { 32.4 (MUSM 223); } \\
\text { (MUSM 2057); 30.5 } \\
\text { (MUSM 2057) }\end{array}$ & 36.7 (MUSM 1995); & $\begin{array}{c}34.8 ; 49.5 \\
\text { (MUSM 347) }\end{array}$ \\
\hline $\begin{array}{l}\text { AP depth at proximal } \\
\text { apex of anconeal } \\
\text { process }\end{array}$ & - & 49.5 & $\begin{array}{c}47.7 \text { (MNHN.F.SAS49); } \\
48.7 \text { (MNHN.F.SAS53); } \\
44.9 \text { (MNHN.F.SAS54); } \\
49.7 \text { (MNHN.F.SAS56); } \\
46.0 \text { (MNHN.F.SAS57); } \\
\text { 52.1 (MNHN.F.SAS58); } \\
\text { 39.4 (MNHN.F.SAS61); } \\
48^{*} \\
\text { (MNHN.F.SAS491); } \\
51.3 \\
\text { (MNHN.F.SAS1620); } \\
\text { 33.2 } \\
\text { (MNHN.F.SAS1632); } \\
\text { 60.0 (MUSM 223); 46.6 } \\
\text { (MUSM 2057) }\end{array}$ & - & $\begin{array}{c}50.5 ; 69.3 \\
\text { (MUSM 347) }\end{array}$ \\
\hline $\begin{array}{l}\text { AP depth at proximal } \\
\text { apex of coronoid } \\
\text { process }\end{array}$ & - & 59.0 & $\begin{array}{c}54.8 \text { (MNHN.F.SAS53); } \\
47 * \text { (MNHN.F.SAS54); } \\
50.8 \text { (MNHN.F.SAS56); } \\
43 * \text { (MNHN.F.SAS57); } \\
\text { 48.9 (MNHN.F.SAS61); } \\
\text { 51.0 } \\
\text { (MNHN.F.SAS256); } \\
33.2 \\
\text { (MNHN.F.SAS1632); } \\
\text { 64.3 (MUSM 223); 57.2 } \\
\text { (MUSM 2057) }\end{array}$ & 70.5 (MUSM 1995); & 61.5 \\
\hline
\end{tabular}


ML width, between medial apex of sigmoid notch and lateral apex of radial notch

Midshaft, ML width

Midshaft, AP depth

ML width at articular circumference

AP depth at articular circumference

Carpal articular surface, ML width

Carpal articular surface, ML depth
44.4 46* (MNHN.F.SAS49);

38.7 (MNHN.F.SAS53);

41* (MNHN.F.SAS56);

$51 *$

(MNHN.F.SAS1620);

55.9 (MUSM 223);

$17.0^{* *} \quad 21.3$

$20.8^{* *}$
(MNHN.F.SAS53); $17.4 * *$

(MNHN.F.SAS54); $18.1^{* *}$

(MNHN.F.SAS56); $19.0 * *$

(MNHN.F.SAS57); $15.8 * *$

(MNHN.F.SAS61); $16.7 * *$

(MNHN.F.SAS256); 18.5

(MNHN.F.SAS1620);

19.3 (MUSM 223);

\begin{tabular}{|c|c|c|c|c|}
\hline $26.2 * *$ & 28.9 & $\begin{array}{c}\text { 25.2**(MNHN.F.SAS53 } \\
\text { ); } 22.1^{* *} \\
\text { (MNHN.F.SAS54); 22.1 } \\
\text { ** (MNHN.F.SAS56); } \\
\text { 23.6** } \\
\text { (MNHN.F.SAS57); } \\
\text { 21.4** } \\
\text { (MNHN.F.SAS61); } \\
\text { 25.4** } \\
\text { (MNHN.F.SAS256); } \\
\text { 27.4 } \\
\text { (MNHN.F.SAS1620); } \\
\text { 32.6 (MUSM 223); }\end{array}$ & 32.6 (MUSM 1995); & $\begin{array}{c}\text { 36.8; 25.1** } \\
\text { (MUSM 1034) }\end{array}$ \\
\hline 23.7 & 25.9 & $\begin{array}{c}26.6 \\
\text { (MNHN.F.SAS1620); } \\
21.8 \text { (MUSM 223); }\end{array}$ & $\begin{array}{c}26.7 \text { (MUSM 1995); } \\
31.3 \text { (MUSM 156) }\end{array}$ & 26.6 \\
\hline 26.7 & 26.1 & $\begin{array}{c}27.3 \\
\text { (MNHN.F.SAS1620); } \\
27.2 \text { (MUSM 223); }\end{array}$ & $\begin{array}{c}31.2 \text { (MUSM 1995); } \\
37.2 \text { (MUSM 156) }\end{array}$ & 32.1 \\
\hline 16.8 & 15.2 & $\begin{array}{c}15.5 \\
\text { (MNHN.F.SAS1620); } \\
25.2 \text { (MUSM 223); }\end{array}$ & $\begin{array}{c}25.8 \text { (MUSM 1995); } \\
26.3 \text { (MUSM 156) }\end{array}$ & $\begin{array}{c}16.3 ; 13.1 \\
\text { (MUSM 1034) }\end{array}$ \\
\hline 19.8 & 20.3 & $\begin{array}{c}19.3 \\
\text { (MNHN.F.SAS1620); } \\
\text { 22.8 (MUSM 223); }\end{array}$ & $\begin{array}{c}19.8 \text { (MUSM 1995); } \\
12.7 \text { (MUSM 156) }\end{array}$ & $\begin{array}{c}\text { 17.5; } 15.1 \\
\text { (MUSM 1034) }\end{array}$ \\
\hline
\end{tabular}

Footnotes: If no specimen number is given after a measurement, it is that of the holotype of the species; *, estimate; **, measurement at estimated midshaft. AP, anteroposterior; ML, mediolateral.

Table 10. Proportions of the ulna in Thalassocnus and other nothrotheriids. 


\begin{tabular}{lcccc}
\hline & & (D) & (L) & \\
\hline T. natans & MNHN.F.SAS734 & 28.9 & 333.0 & 0.09 \\
T. littoralis & MNHN.F.SAS61 & 21.4 & 297.0 & 0.07 \\
& MNHN.F.SAS1620 & 27.4 & 318.0 & 0.09 \\
T. carolomartini & MUSM 1995 & 32.6 & 353.6 & 0.09 \\
T. yaucensis & MUSM 37 & 36.8 & 300.5 & 0.12 \\
Nothrotheriops & LACM 21598 & 41.7 & 402.5 & 0.10 \\
Nothrotherium & MCL 1020 & 18.4 & 252.8 & 0.07 \\
Mionothropus & LACM & 33.3 & 337.2 & 0.10 \\
& 4609/117533 & & & \\
\hline
\end{tabular}

Footnotes: AP, anteroposterior; PD, proximodistal.

Table 11. Development of the anconeal and coronoid processes in Thalassocnus and other nothrotheriids.

\begin{tabular}{|c|c|c|c|c|c|c|c|c|}
\hline Taxon & $\begin{array}{c}\text { Specimen } \\
\text { number }\end{array}$ & $\begin{array}{l}\text { AP depth at } \\
\text { midshaft } \\
(\mathrm{Dm})\end{array}$ & $\begin{array}{l}\text { AP depth at } \\
\text { anconeal } \\
\text { process } \\
\text { (Da) }\end{array}$ & $\begin{array}{l}\text { AP depth at } \\
\text { coronoid } \\
\text { process } \\
\text { (Dc) } \\
\end{array}$ & $\mathrm{Da} / \mathrm{Dm}$ & $\begin{array}{l}\text { Species } \\
\text { value of } \\
\mathrm{Da} / \mathrm{Dm} \\
\text { (mean if } \\
\text { several } \\
\text { specimens) }\end{array}$ & $\begin{array}{l}\mathrm{Dc} / \\
\mathrm{Dm}\end{array}$ & $\begin{array}{c}\text { Species } \\
\text { value of } \\
\text { Dc/Dm } \\
\text { (mean if } \\
\text { several } \\
\text { specimens) }\end{array}$ \\
\hline \multirow{10}{*}{$\begin{array}{l}\text { T. natans } \\
\text { ?T. natans, ?T. } \\
\text { littoralis } \\
\text { T. littoralis }\end{array}$} & $\begin{array}{c}\text { MNHN.F. } \\
\text { SAS734 } \\
\text { MNHN.F. }\end{array}$ & 28.9 & 49.5 & 59.0 & 1.71 & 1.71 & 2.04 & 2.04 \\
\hline & SAS57 & 23.6 & 46.0 & - & 1.95 & & - & - \\
\hline & $\begin{array}{c}\text { MNHN.F. } \\
\text { SAS53 }\end{array}$ & 252 & 487 & 54.8 & 193 & 1.96 & 2.17 & 2.14 \\
\hline & MNHN.F. & & & & & & & \\
\hline & $\begin{array}{c}\text { SAS54 } \\
\text { MNHN.F. }\end{array}$ & 22.1 & 44.9 & 47.0 & 2.03 & & 2.13 & \\
\hline & $\begin{array}{c}\text { SAS56 } \\
\text { MNHN.F. }\end{array}$ & 22.1 & 49.7 & 50.8 & 2.25 & & 2.30 & \\
\hline & $\begin{array}{c}\text { SAS61 } \\
\text { MNHN.F. }\end{array}$ & 21.4 & 39.4 & 48.9 & 1.84 & & 2.29 & \\
\hline & $\begin{array}{c}\text { SAS256 } \\
\text { MNHN.F. }\end{array}$ & 25.4 & - & 51.0 & - & & 2.01 & \\
\hline & $\begin{array}{c}\text { SAS1620 } \\
\text { MUSM }\end{array}$ & 27.4 & 51.3 & - & 1.87 & & - & \\
\hline & $\begin{array}{c}223 \\
\text { MUSM }\end{array}$ & 32.6 & 60.0 & 64.3 & 1.84 & & 1.97 & \\
\hline T. carolomartini & $\begin{array}{c}1995 \\
\text { MUSM }\end{array}$ & 32.6 & - & 70.5 & - & - & 2.16 & 2.16 \\
\hline T. yaucensis & $\begin{array}{c}37 \\
\text { LACM }\end{array}$ & 36.8 & 50.5 & 61.5 & 1.37 & 1.37 & 1.67 & 1.67 \\
\hline Nothrotheriops & $\begin{array}{l}21598 \\
\text { MCL }\end{array}$ & 41.7 & 49.6 & 81.5 & 1.19 & 1.19 & 1.95 & 1.95 \\
\hline Nothrotherium & $\begin{array}{c}1020 \\
\text { LACM } \\
4609 / 117\end{array}$ & 18.4 & 26.9 & 40.2 & 1.46 & 1.46 & 2.18 & 2.18 \\
\hline Mionothropus & 533 & 33.3 & 45.4 & 62.0 & 1.36 & 1.36 & 1.86 & 1.86 \\
\hline
\end{tabular}

Footnotes: AP, anteroposterior.

Table 12. Development of carpal facet of the ulna in Thalassocnus and other nothrotheriids. 


\begin{tabular}{lcccc}
\hline Taxon & Specimen number & $\begin{array}{c}\text { AP depth at midshaft } \\
(\mathrm{Dm})\end{array}$ & $\begin{array}{c}\text { Carpal facet, AP } \\
\text { depth (Dc) }\end{array}$ & Dc/Dm \\
\hline T. antiquus & MUSM 228 & 26.2 & 19.8 & 0.76 \\
T. natans & MNHN.F.SAS734 & 28.9 & 20.3 & 0.70 \\
T. littoralis & MNHN.F.SAS1620 & 27.4 & 19.3 & 0.70 \\
& MUSM 223 & 32.6 & 22.8 & 0.70 \\
T. carolomartini & MUSM 1995 & 32.6 & 19.8 & 0.61 \\
T. yaucensis & MUSM 37 & 36.8 & 17.5 & 0.48 \\
Nothrotheriops & LACM 21598 & 41.7 & 35.1 & 0.84 \\
Nothrotherium & MCL 1020 & 18.4 & 16.1 & 0.88 \\
Mionothropus & LACM & 33.3 & 28.5 & 0.86 \\
& 4609/117533 & & & \\
\hline
\end{tabular}

Footnotes: AP, anteroposterior.

Table 13. Length of the ulna and radius relative to the humerus in Thalassocnus and other nothrotheriids.

\begin{tabular}{lcccccc}
\hline Taxon & Specimen number & $\begin{array}{c}\text { PD length of } \\
\text { humerus (Lh) }\end{array}$ & $\begin{array}{c}\text { PD length of } \\
\text { ulna (Lu) }\end{array}$ & $\begin{array}{c}\text { PD length of } \\
\text { radius (Lr) }\end{array}$ & Lu/Lh & Lr/Lh \\
\hline T. antiquus & MUSM 228 & 245.0 & - & 267.0 & - & 1.09 \\
T. natans & MNHN.F.SAS734 & 255.4 & 333.0 & 284.8 & 1.30 & 1.12 \\
T. littoralis & MUSM 223 & 284.0 & 333.8 & 292.5 & 1.18 & 1.03 \\
T. carolomartini & MUSM 1995 & 297.0 & 353.6 & 302.0 & 1.19 & 1.02 \\
Nothrotheriops & YPM 13198 & 387 & 379 & 340 & 0.98 & 0.88 \\
Nothrotherium & MCL 1020 & 248.7 & 252.8 & 239.5 & 1.02 & 0.96 \\
Mionothropus & LACM & 319.5 & 337.2 & 308 & 1.06 & 0.96 \\
& 4609/117533 & & & & & \\
\hline
\end{tabular}

Footnotes: Measurements of Nothrotheriops are from Lull (1929); PD, proximodistal. The ratio of length of radius over that of humerus ( $\mathrm{Lr} / \mathrm{Lh})$ approximates the brachial index sensu Toledo et al. (2012).

Table 14. Proximodistal length of the radius compared to the depth of the horizontal ramus of the mandible in Thalassocnus and other nothrotheriids.

\begin{tabular}{lcccc}
\hline Taxon & Specimen number & $\begin{array}{c}\text { PD length of radius } \\
(\mathrm{Lr})\end{array}$ & $\begin{array}{c}\text { Maximum depth of } \\
\text { horizontal ramus } \\
\text { of mandible (Md) }\end{array}$ & $\mathrm{Lr} / \mathrm{Md}$ \\
\hline T. antiquus & MUSM 228 & 267.0 & 42.5 & 6.28 \\
T. natans & MNHN.F.SAS734 & 284.8 & 44.8 & 6.36 \\
T. littoralis & MUSM 223 & 292.5 & 45.4 & 6.44 \\
T. yaucensis & MUSM 37 & 250.5 & 46.4 & 5.40 \\
Nothrotherium & MCL 1020 & 239.5 & 32.4 & 7.39 \\
Mionothropus & LACM & 308 & 45.1 & 6.83 \\
& 4609/117533 & & & \\
\hline
\end{tabular}

Footnotes: PD, proximodistal.

Table 15. Measurements (in millimeters) of the radius of Thalassocnus. 


\begin{tabular}{|c|c|c|c|c|c|}
\hline & T. antiquus & T. natans & T. littoralis & T. carolomartini & T. yaucensis \\
\hline Greatest PD length & 267.0 & $\begin{array}{c}284.8 ; \\
264.0 \\
\text { (MUSM } \\
2059)\end{array}$ & $\begin{array}{c}260^{*} \\
\text { (MNHN.F.SAS53); } \\
268.5 \\
\text { (MNHN.F.SAS56); } \\
261.8 \\
\text { (MNHN.F.SAS801); } \\
259.0 \\
\text { (MNHN.F.SAS802); } \\
279.0 \\
\text { (MNHN.F.SAS1605); } \\
\text { 292.5 (MUSM 223); } \\
250.2 \text { (MUSM 443) }\end{array}$ & 302.0 (MUSM 1995) & 250.5 \\
\hline Head, AP depth & 34.6 & $\begin{array}{c}36.2 ; 34.5 \\
\text { (MUSM } \\
2059)\end{array}$ & $\begin{array}{c}36.3 \text { (MNHN.F.SAS53); } \\
33.4 \text { (MNHN.F.SAS56); } \\
31.5 \text { (MNHN.F.SAS57); } \\
36.2 \\
\text { (MNHN.F.SAS801); } \\
33.5 \\
\text { (MNHN.F.SAS802); } \\
\text { 40.6 (MUSM 223); 33.8 } \\
\text { (MUSM 443) }\end{array}$ & 42.9 (MUSM 1995) & $\begin{array}{c}\text { 33.3; } 44.3 \\
\text { (MUSM 347) }\end{array}$ \\
\hline Head, ML width & $27 *$ & $\begin{array}{c}33.4 ; 32.1 \\
\text { (MUSM } \\
\text { 2059) }\end{array}$ & $\begin{array}{c}28.2 \text { (MNHN.F.SAS53); } \\
30.0 \text { (MNHN.F.SAS56); } \\
28.2 \text { (MNHN.F.SAS57); } \\
30.2 \\
\text { (MNHN.F.SAS801); } \\
\text { 25.6 } \\
\text { (MNHN.F.SAS802); } \\
\text { 39.7 (MUSM 223); 32.6 } \\
\text { (MUSM 443) }\end{array}$ & - & $\begin{array}{c}33.0 ; 39.2 \\
\text { (MUSM 347) }\end{array}$ \\
\hline Neck, AP depth & 24.8 & $\begin{array}{c}30.8 ; 24.4 \\
\text { (MUSM } \\
2059)\end{array}$ & $\begin{array}{c}26.3 \text { (MNHN.F.SAS53); } \\
\text { 21.8 (MNHN.F.SAS56); } \\
24.6 \text { (MNHN.F.SAS57); } \\
24.5 \\
\text { (MNHN.F.SAS499); } \\
25.6 \\
\text { (MNHN.F.SAS801); } \\
28.7 \\
\text { (MNHN.F.SAS802); } \\
25.5 \\
\text { (MNHN.F.SAS1605); } \\
\text { 26.9 (MUSM 223); 21.5 } \\
\text { (MUSM 443) }\end{array}$ & 33.4 (MUSM 1995) & $\begin{array}{c}26.7 ; 36.6 \\
\text { (MUSM 347); } \\
26.8 \text { (MUSM } \\
1034 \text { ) }\end{array}$ \\
\hline
\end{tabular}




\begin{tabular}{|c|c|c|c|c|c|}
\hline Midshaft, AP depth & 34.1 & $\begin{array}{l}37 * ; 34.9 \\
\text { (MUSM } \\
2059 \text { ) }\end{array}$ & $\begin{array}{c}34.5 \text { (MNHN.F.SAS53); } \\
37.7 \text { (MNHN.F.SAS56); } \\
31.9 \text { (MNHN.F.SAS57); } \\
41.0 \\
\text { (MNHN.F.SAS801); } \\
33.9 \\
\text { (MNHN.F.SAS802); } \\
\text { 42.0 (MUSM 223); } 42.9 \\
\text { (MUSM 443) }\end{array}$ & 49.5 (MUSM 1995) & $\begin{array}{c}49.4 ; 44.4^{* *} \\
(\text { MUSM 1034) }\end{array}$ \\
\hline Midshaft, ML width & 17.9 & $\begin{array}{l}21.1 ; 17.8 \\
\text { (MUSM } \\
2059 \text { ) }\end{array}$ & $\begin{array}{c}18.6 \text { (MNHN.F.SAS53); } \\
\text { 17.3 (MNHN.F.SAS56); } \\
\text { 17.8 (MNHN.F.SAS57); } \\
26.5 \\
\text { (MNHN.F.SAS499); } \\
16.5 \\
\text { (MNHN.F.SAS801); } \\
\text { 15.2 } \\
\text { (MNHN.F.SAS802); } \\
\text { 20.3 (MUSM 223); } 17.1 \\
\text { (MUSM 443) }\end{array}$ & 23.2 (MUSM 1995) & $\begin{array}{l}17.3 ; 14.8^{* *} \\
\text { (MUSM 1034) }\end{array}$ \\
\hline $\begin{array}{l}\text { ML width just } \\
\text { proximal to distal } \\
\text { epiphysis }\end{array}$ & - & $\begin{array}{l}30.2 ; 26.8 \\
\text { (MUSM } \\
2059 \text { ) }\end{array}$ & $\begin{array}{c}20.9 \text { (MNHN.F.SAS56); } \\
21.6 \text { (MNHN.F.SAS56); } \\
24.3 \text { (MNHN.F.SAS57); } \\
\text { 14.6 } \\
\text { (MNHN.F.SAS499); } \\
\text { 18.9 } \\
\text { (MNHN.F.SAS802); } \\
\text { 32.7 (MUSM 223); 28.3 } \\
\text { (MUSM 443) }\end{array}$ & $\begin{array}{c}26.7 \text { (MUSM 1995); } \\
34.7 \text { (MUSM 156) }\end{array}$ & $\begin{array}{c}30.0 ; 23.8 \\
\text { (MUSM 1034) }\end{array}$ \\
\hline $\begin{array}{l}\text { Articular facet for } \\
\text { manus, AP depth }\end{array}$ & $51 *$ & $\begin{array}{l}51.5 ; 47.1 \\
\text { (MUSM } \\
2059 \text { ) }\end{array}$ & $\begin{array}{c}\text { 56* (MNHN.F.SAS53); } \\
\text { 47.6 (MNHN.F.SAS56); } \\
48.4 \text { (MNHN.F.SAS63); } \\
47.5 \\
\text { (MNHN.F.SAS801); } \\
46.3 \\
\text { (MNHN.F.SAS802); } \\
\text { 50.2 (MUSM 223) }\end{array}$ & $\begin{array}{l}\text { 62.6 (MUSM 1995); } \\
64.5 \text { (MUSM 156) }\end{array}$ & $\begin{array}{c}50.3 ; 65^{*} \\
\text { (MUSM 347); } \\
49.3 \text { (MUSM } \\
1034 \text { ) }\end{array}$ \\
\hline $\begin{array}{l}\text { Articular facet for } \\
\text { manus, greatest ML } \\
\text { width }\end{array}$ & - & $\begin{array}{l}28.1 ; 29.0 \\
\text { (MUSM } \\
2059 \text { ) }\end{array}$ & $\begin{array}{c}29.2 \text { (MNHN.F.SAS53); } \\
\text { 26.1(MNHN.F.SAS56); } \\
\text { 24.6 (MNHN.F.SAS63); } \\
26.3 \\
\text { (MNHN.F.SAS801); } \\
24.7 \\
\text { (MNHN.F.SAS802); } \\
\text { 29* (MUSM 223); } \\
\text { (MUSM 443) }\end{array}$ & $\begin{array}{c}33.3 \text { (MUSM 1995); } \\
33 * \text { (MUSM 156) }\end{array}$ & $\begin{array}{c}\text { 27.4; } 28.2 \\
\text { (MUSM 347) }\end{array}$ \\
\hline
\end{tabular}

Footnotes: If no specimen number is given after a measurement, it is that of the holotype of the species; *, estimate. $\mathrm{AP}$, anteroposterior; ML, mediolateral; PD, proximodistal.

Table 16. Development of the supinator crest in Thalassocnus and other nothrotheriids.

\begin{tabular}{llllll}
\hline Taxon & Specimen number & AP depth at & PD length $(\mathrm{L})$ & $\mathrm{D} / \mathrm{L}$ & Species value
\end{tabular}




\begin{tabular}{|c|c|c|c|c|c|}
\hline & & idshaft (D) & & & $\begin{array}{c}\text { (mean if } \\
\text { several } \\
\text { specimens) }\end{array}$ \\
\hline T. antiquus & MUSM 228 & 34.1 & 267.0 & 0.13 & 0.13 \\
\hline \multirow[t]{2}{*}{ T. natans } & MNHN.F.SAS734 & $37 *$ & 284.8 & 0.13 & 0.13 \\
\hline & MUSM 2059 & 34.9 & 264.0 & 0.13 & \\
\hline \multirow[t]{5}{*}{ T. littoralis } & MNHN.F.SAS56 & 37.7 & 268.5 & 0.14 & 0.15 \\
\hline & MNHN.F.SAS801 & 41.0 & 261.8 & 0.16 & \\
\hline & MNHN.F.SAS802 & 33.9 & 259.0 & 0.13 & \\
\hline & MUSM 223 & 42.0 & 292.5 & 0.14 & \\
\hline & MUSM 443 & 42.9 & 250.2 & 0.17 & \\
\hline T. carolomartini & MUSM 1995 & 49.5 & 302.0 & 0.16 & 0.16 \\
\hline T. yaucensis & MUSM 37 & 49.4 & 250.5 & 0.20 & 0.20 \\
\hline Nothrotheriops & LACM 119216 & 50.0 & 380.8 & 0.13 & 0.13 \\
\hline Nothrotherium & MCL 1020 & 21.5 & 239.5 & 0.09 & 0.09 \\
\hline Mionothropus & $\begin{array}{c}\text { LACM } \\
4609 / 117533\end{array}$ & 42.6 & 308 & 0.14 & 0.14 \\
\hline
\end{tabular}

Footnotes: *, estimates. AP, anteroposterior; PD, proximodistal.

Table 17. Proportions of the radius at midshaft in Thalassocnus and other nothrotheriids.

\begin{tabular}{lccccc}
\hline Taxon & Specimen number & $\begin{array}{c}\text { AP depth at } \\
\text { midshaft (D) }\end{array}$ & $\begin{array}{c}\text { ML width at } \\
\text { midshaft (W) }\end{array}$ & D/W & $\begin{array}{c}\text { Species value } \\
\text { (mean if } \\
\text { several } \\
\text { specimens) }\end{array}$ \\
\hline T. antiquus & MUSM 228 & 34.1 & 17.9 & 1.91 & 1.91 \\
T. natans & MNHN.F.SAS734 & $37^{*}$ & 21.1 & 1.75 & 1.86 \\
?T. natans, ?T. & MUSM 2059 & 34.9 & 17.8 & 1.96 & \\
littoralis & MNH.F.SAS57 & 31.9 & 17.8 & 1.79 & - \\
T. littoralis & MNHN.F.SAS56 & 34.5 & 18.6 & 1.85 & 2.05 \\
& MNHN.F.SAS802 & 33.9 & 15.2 & 2.23 & \\
T. carolomartini & MUSM 223 & 42.0 & 20.3 & 2.07 & \\
T. yaucensis & MUSM 1995 & 49.5 & 23.2 & 2.13 & 2.13 \\
Nothrotheriops & MUSM 37 & 49.4 & 17.3 & 2.86 & 2.93 \\
Nothrotherium & MUCM 119216 & 44.4 & 14.8 & 3.00 & \\
Mionothropus & MCL 1020 & 21.5 & 13.1 & 1.93 & 1.93 \\
& 4609/117533 & 42.6 & 18.7 & 2.28 & 2.28 \\
\hline
\end{tabular}

Footnotes: *, estimates. AP, anteroposterior; ML, mediolateral.

Table 18. Depth of the carpal facet of the radius compared to the width at midshaft in Thalassocnus and other nothrotheriids.

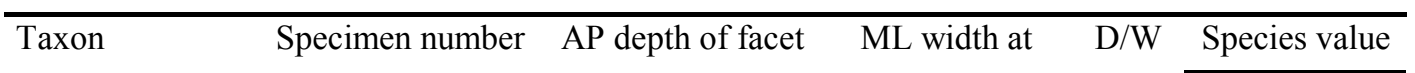




\begin{tabular}{|c|c|c|c|c|c|}
\hline & & for carpus (D) & midshaft $(\mathrm{W})$ & & $\begin{array}{c}\text { (mean if } \\
\text { several } \\
\text { specimens) }\end{array}$ \\
\hline T. antiquus & MUSM 228 & 51.0 & 17.9 & 2.85 & 2.85 \\
\hline \multirow[t]{2}{*}{ T. natans } & MNHN.F.SAS734 & 51.5 & 21.1 & 2.44 & 2.54 \\
\hline & MUSM 2059 & 47.1 & 17.8 & 2.65 & \\
\hline \multirow[t]{4}{*}{ T. littoralis } & MNHN.F.SAS56 & 47.6 & 18.6 & 2.56 & 2.53 \\
\hline & MNHN.F.SAS801 & 47.5 & 15.2 & 3.13 & \\
\hline & MNHN.F.SAS802 & 46.3 & 20.3 & 2.28 & \\
\hline & MUSM 223 & 50.2 & 23.2 & 2.16 & \\
\hline T. carolomartini & MUSM 1995 & 62.6 & 17.3 & 3.62 & 3.62 \\
\hline T. yaucensis & MUSM 37 & 50.3 & 14.8 & 3.40 & 3.40 \\
\hline Nothrotheriops & LACM 119216 & 51.6 & 25.9 & 1.99 & 1.99 \\
\hline Nothrotherium & MCL 1020 & 28.6 & 13.1 & 2.18 & 2.18 \\
\hline Mionothropus & $\begin{array}{c}\text { LACM } \\
4609 / 117533\end{array}$ & 44.8 & 18.7 & 2.40 & 2.40 \\
\hline
\end{tabular}

Footnotes: AP, anteroposterior; ML, proximodistal.

Table 19. Measurements (in millimeters) of the bones of the manus of Thalassocnus.

\begin{tabular}{|c|c|c|c|c|c|}
\hline & T. antiquus & T. natans & T. littoralis & T. carolomartini & T. yaucensis \\
\hline \multicolumn{6}{|l|}{ Scaphoid } \\
\hline $\begin{array}{l}\text { Greatest PD length } \\
\text { (at level of distal } \\
\text { process) }\end{array}$ & 23.8 & 26.3 & $\begin{array}{l}29.0 \text { (MNHN.F.SAS57); } \\
26.1 \text { (MUSM 223) }\end{array}$ & $\begin{array}{c}23.9 \text { (SMNK-PAL } \\
\text { 3815); } 27.1 \text { (MUSM } \\
\text { 1995) }\end{array}$ & $\begin{array}{l}21.1 ; 24.8 \\
\text { (MUSM 347) }\end{array}$ \\
\hline $\begin{array}{l}\text { Greatest ML width } \\
\text { (at level of articular } \\
\text { facet for Mc I) }\end{array}$ & - & - & 41.0 (MNHN.F.SAS57); & $\begin{array}{c}40.9 \text { (SMNK-PAL } \\
\text { 3815); } 47.0 \text { (MUSM } \\
\text { 1995) }\end{array}$ & $\begin{array}{c}40.4 ; 45.8 \\
\text { (MUSM 347) }\end{array}$ \\
\hline $\begin{array}{l}\text { Greatest DP depth } \\
\text { (at level of dorsal } \\
\text { process) }\end{array}$ & 22.7 & 28.9 & $\begin{array}{l}28.9 \text { (MNHN.F.SAS57); } \\
28.7 \text { (MUSM 223) }\end{array}$ & $\begin{array}{c}25.0 \text { (SMNK-PAL } \\
\text { 3815); } 32.8 \text { (MUSM } \\
\text { 156); } 30.5 \text { (MUSM } \\
1995)\end{array}$ & $\begin{array}{c}27.0 ; 35.5 \\
(\text { MUSM 347) }\end{array}$ \\
\hline \multicolumn{6}{|l|}{ Lunar } \\
\hline Greatest PD length & 27.6 & 30.6 & $\begin{array}{c}27.0 \text { (MNHN.F.SAS53); } \\
27.6 \text { (MNHN.F.SAS57); } \\
27.7 \\
\text { (MNHN.F.SAS163); } \\
31.1 \\
\text { (MNHN.F.SAS182); } \\
\text { 28.7 (MUSM 223) }\end{array}$ & $\begin{array}{c}25.2 \text { (SMNK-PAL } \\
\text { 3815); } 30.5 \text { (MUSM } \\
\text { 1995) }\end{array}$ & - \\
\hline Greatest ML width & 20.0 & 32.9 & $\begin{array}{c}33.2 \\
\text { (MNHN.F.SAS182); } \\
30.2 \text { (MUSM 223) }\end{array}$ & $\begin{array}{c}31.3 \text { (SMNK-PAL } \\
\text { 3815); } 38.1 \text { (MUSM } \\
\text { 1995) }\end{array}$ & - \\
\hline
\end{tabular}




\begin{tabular}{|c|c|c|c|c|c|}
\hline Greatest DP depth & 24.4 & 26.0 & $\begin{array}{c}23.2 \text { (MNHN.F.SAS53); } \\
22.4 \\
\text { (MNHN.F.SAS163); } \\
25.5 \\
\text { (MNHN.F.SAS1605); } \\
\text { 25.6 (MUSM 223) }\end{array}$ & $\begin{array}{c}23.2 \text { (SMNK-PAL } \\
\text { 3815); } 27.2 \text { (MUSM } \\
\text { 1995) }\end{array}$ & - \\
\hline \multicolumn{6}{|l|}{ Cuneiform } \\
\hline Greatest PD length & 26.0 & 26.2 & $\begin{array}{c}27.9 \text { (MNHN.F.SAS49); } \\
23.9 \text { (MNHN.F.SAS57); } \\
25.8 \\
\text { (MNHN.F.SAS156); } \\
26.9 \\
\text { (MNHN.F.SAS766); } \\
24.9 \\
\text { (MNHN.F.SAS1605); } \\
\text { 28.3 (MUSM 223) }\end{array}$ & $\begin{array}{c}26.4 \text { (SMNK-PAL } \\
\text { 3815). } 34.2 \text { (MUSM } \\
\text { 156); } 30.8 \text { (MUSM } \\
1995)\end{array}$ & $\begin{array}{c}31.6 \\
\text { (MUSM 347) }\end{array}$ \\
\hline Greatest ML width & $27^{*}$ & 30.0 & $\begin{array}{l}31.7 \text { (MNHN.F.SAS4); } \\
34.6 \text { (MUSM 223) }\end{array}$ & $\begin{array}{c}30.8 \text { (SMNK-PAL } \\
\text { 3815). } 40.4 \text { (MUSM } \\
\text { 156); } 41.2 \text { (MUSM } \\
1995 \text { ) }\end{array}$ & $\begin{array}{c}38.3 \\
\text { (MUSM 347) }\end{array}$ \\
\hline $\begin{array}{l}\text { Greatest dorsopalmar } \\
\text { depth }\end{array}$ & 20.0 & 21.6 & $\begin{array}{c}21.1 \text { (MNHN.F.SAS4); } \\
22.6 \text { (MNHN.F.SAS49); } \\
19.0 \text { (MNHN.F.SAS57); } \\
22.1 \\
\text { (MNHN.F.SAS766); } \\
22.2 \text { (MUSM 223) }\end{array}$ & $\begin{array}{c}20.6 \text { (SMNK-PAL } \\
\text { 3815). } 24.1 \text { (MUSM } \\
\text { 156); 23.6 (MUSM } \\
1995)\end{array}$ & $\begin{array}{c}26.6 \\
\text { (MUSM 347) }\end{array}$ \\
\hline \multicolumn{6}{|l|}{ Pisiform } \\
\hline Greatest DP depth & - & - & $\begin{array}{c}33.5 \text { (MNHN.F.SAS53); } \\
27.2 \text { (MNHN.F.SAS57); } \\
26.3 \\
\text { (MNHN.F.SAS1604); } \\
\text { 19.9 } \\
\text { (MNHN.F.SAS1605); } \\
\text { 31.2 (MUSM 223) }\end{array}$ & $\begin{array}{c}30.9 \text { (SMNK-PAL } \\
\text { 3815); } 40 * \text { (MUSM } \\
\text { 156); } 42.9 \text { (MUSM } \\
1995)\end{array}$ & 28.6 \\
\hline $\begin{array}{l}\text { Greatest PD length } \\
\text { (at dorsal edge of the } \\
\text { bone) }\end{array}$ & - & - & $\begin{array}{c}29.6 \text { (MNHN.F.SAS53); } \\
27.8 \text { (MNHN.F.SAS57); } \\
25.4 \\
\text { (MNHN.F.SAS1604); } \\
30.9 \text { (MUSM 223) }\end{array}$ & $\begin{array}{c}25.6 \text { (SMNK-PAL } \\
\text { 3815); } 36.2 \text { (MUSM } \\
\text { 1995) }\end{array}$ & 26.9 \\
\hline \multicolumn{6}{|l|}{ Trapezoid } \\
\hline $\begin{array}{l}\text { Greatest PD length at } \\
\text { dorsal end }\end{array}$ & 9.2 & - & $\begin{array}{c}9.5 \text { (MNHN.F.SAS53); } \\
11 * \text { (MNHN.F.SAS57); } \\
9.5 \\
\text { (MNHN.F.SAS1605); } \\
9.6 \text { (MUSM 223) }\end{array}$ & $\begin{array}{c}\text { 8.1 (SMNK-PAL } \\
\text { 3815); } 11.3 \text { (MUSM } \\
\text { 1995) }\end{array}$ & 12.2 \\
\hline Greatest DP depth & 23.2 & - & $\begin{array}{l}24.4 \text { (MNHN.F.SAS53); } \\
24.1 \text { (MNHN.F.SAS57); } \\
25.8 \text { (MUSM 223) }\end{array}$ & $\begin{array}{c}23.6 \text { (SMNK-PAL } \\
\text { 3815); } 28.6 \text { (MUSM } \\
\text { 1995) }\end{array}$ & 26.7 \\
\hline
\end{tabular}




\begin{tabular}{|c|c|c|c|c|c|}
\hline Greatest DP depth & 22.3 & - & $\begin{array}{c}28.2 \text { (MNHN.F.SAS57); } \\
27.1 \\
\text { (MNHN.F.SAS774); } \\
25.8 \\
\text { (MNHN.F.SAS1604); } \\
\text { 29.4 (MUSM 223) }\end{array}$ & $\begin{array}{c}28.1 \text { (SMNK-PAL } \\
\text { 3815); } 34.8 \text { (MUSM } \\
\text { 156); } 34.2 \text { (MUSM } \\
1995)\end{array}$ & 31.1 \\
\hline $\begin{array}{l}\text { Greatest PD length } \\
\text { (at proximal process) }\end{array}$ & 21.5 & - & $\begin{array}{c}20.4 \text { (MNHN.F.SAS57); } \\
18.7 \\
\text { (MNHN.F.SAS774); } \\
19.1 \\
\text { (MNHN.F.SAS1604); } \\
22.1 \\
\text { (MNHN.F.SAS1605); } \\
23.3 \text { (MUSM 223) }\end{array}$ & $\begin{array}{c}20.5 \text { (SMNK-PAL } \\
\text { 3815); } 26.3 \text { (MUSM } \\
\text { 156); } 27.2 \text { (MUSM } \\
1995)\end{array}$ & 22.5 \\
\hline \multicolumn{6}{|l|}{ Unciform } \\
\hline Greatest DP depth & 26.5 & - & $\begin{array}{c}26.9 \text { (MNHN.F.SAS9); } \\
27.1 \text { (MNHN.F.SAS53); } \\
28.4 \text { (MNHN.F.SAS57); } \\
30.9 \\
\text { (MNHN.F.SAS747); } \\
29.7 \\
\text { (MNHN.F.SAS1605); } \\
29.7 \text { (MUSM 223) }\end{array}$ & $\begin{array}{c}28.6 \text { (SMNK-PAL } \\
\text { 3815); } 34.6 \text { (MUSM } \\
\text { 156); } 34.3 \text { (MUSM } \\
1995)\end{array}$ & 34.6 \\
\hline \multicolumn{6}{|c|}{ Trapezium - Mc I complex (MCC) } \\
\hline Greatest PD length & 32.6 & - & $\begin{array}{c}35.5 \text { (MNHN.F.SAS2); } \\
33.4 \text { (MNHN.F.SAS53); } \\
34.3 \\
\text { (MNHN.F.SAS163); } \\
35.8 \text { (MUSM 223) }\end{array}$ & $\begin{array}{c}30 * \text { (SMNK-PAL } \\
3815) ; 37 * \text { (MUSM } \\
156) ; 39.6 \text { (MUSM } \\
1995)\end{array}$ & 35.2 \\
\hline $\begin{array}{l}\text { Greatest ML width } \\
\text { (at lateroproximal } \\
\text { process) }\end{array}$ & 27.7 & - & $\begin{array}{c}25.8 \text { (MNHN.F.SAS53); } \\
26.0 \\
\text { (MNHN.F.SAS163); } \\
28.1 \\
\text { (MNHN.F.SAS795); } \\
28.8 \\
\text { (MNHN.F.SAS1605); } \\
30.2 \text { (MUSM 223) }\end{array}$ & $\begin{array}{c}26.1 \text { (SMNK-PAL } \\
\text { 3815); } 31.2 \text { (MUSM } \\
\text { 1995) }\end{array}$ & 27.8 \\
\hline DP depth at midshaft & 16.2 & - & $\begin{array}{c}15.8 \text { (MNHN.F.SAS53); } \\
15.9 \\
\text { (MNHN.F.SAS163); } \\
15.2 \\
\text { (MNHN.F.SAS1605); } \\
20.3 \text { (MUSM 223) }\end{array}$ & $\begin{array}{c}15.1 \text { (SMNK-PAL } \\
\text { 3815); } 17.1 \text { (MUSM } \\
\text { 156); 19.3 (MUSM } \\
1995)\end{array}$ & 17.1 \\
\hline \multicolumn{6}{|l|}{ Ph. D. I } \\
\hline $\begin{array}{l}\text { Greatest PD length } \\
\text { (N.B. the distal tip is } \\
\text { rarely preserved) }\end{array}$ & $47^{*}$ & 55.1 & $\begin{array}{c}44.5 \text { (MNHN.F.SAS53); } \\
41.9 \\
\text { (MNHN.F.SAS1641); } \\
52 * \text { (MUSM 223) }\end{array}$ & $\begin{array}{c}43 * \text { (SMNK-PAL } \\
3815) ; 50.0 \text { (MUSM } \\
1995)\end{array}$ & - \\
\hline $\begin{array}{l}\text { Greatest ML width } \\
\text { (at proximal end) }\end{array}$ & 17.9 & 27.7 & $\begin{array}{c}22 * \text { (MNHN.F.SAS53); } \\
18.4 \\
\text { (MNHN.F.SAS1641); } \\
22.3 \text { (MUSM 223) }\end{array}$ & $\begin{array}{c}20.1 \text { (SMNK-PAL } \\
\text { 3815); } 23.1 \text { (MUSM } \\
\text { 1995) }\end{array}$ & - \\
\hline
\end{tabular}




\begin{tabular}{|c|c|c|c|c|c|}
\hline $\begin{array}{l}\text { Greatest DP depth } \\
\text { (at proximal end) }\end{array}$ & 26.8 & 31.0 & $\begin{array}{c}27.4 \text { (MNHN.F.SAS53); } \\
25.1 \\
\text { (MNHN.F.SAS1641); } \\
29.2 \text { (MUSM 223) }\end{array}$ & $\begin{array}{c}26.6 \text { (SMNK-PAL } \\
\text { 3815); } 30.9 \text { (MUSM } \\
1995)\end{array}$ & - \\
\hline \multicolumn{6}{|l|}{ Mc II } \\
\hline Greatest PD length & 62.5 & 69.0 & $\begin{array}{c}60.6 \text { (MNHN.F.SAS57); } \\
59.4 \\
\text { (MNHN.F.SAS163); } \\
64^{*} \\
\text { (MNHN.F.SAS294); } \\
66.5 \\
\text { (MNHN.F.SAS371); } \\
64^{*} \\
\text { (MNHN.F.SAS531); } \\
63^{*} \\
\text { (MNHN.F.SAS764); } \\
60.2 \\
\text { (MNHN.F.SAS1604); } \\
63^{*} \\
\text { (MNHN.F.SAS1605); } \\
68.1 \text { (MUSM 223) }\end{array}$ & $\begin{array}{c}57.1 \text { (SMNK-PAL } \\
\text { 3815); } 60 * \text { (MUSM } \\
\text { 156); } 72.5 \text { (MUSM } \\
1995)\end{array}$ & 51.7 \\
\hline $\begin{array}{l}\text { ML width at } \\
\text { midshaft }\end{array}$ & 17.0 & 22.1 & $\begin{array}{c}14.9 \text { (MNHN.F.SAS2); } \\
17.9 \text { (MNHN.F.SAS53); } \\
16.9 \\
\text { (MNHN.F.SAS163); } \\
19.0 \\
\text { (MNHN.F.SAS294); } \\
17.9 \\
\text { (MNHN.F.SAS371); } \\
13.0 \\
\text { (MNHN.F.SAS531); } \\
16.1 \\
\text { (MNHN.F.SAS764); } \\
16.4 \\
\text { (MNHN.F.SAS1604); } \\
17.3 \\
\text { (MNHN.F.SAS1605); } \\
20.2 \text { (MUSM 223) }\end{array}$ & $\begin{array}{c}19.1 \text { (SMNK-PAL } \\
3815) ; 21 * \text { (MUSM } \\
\text { 156); } 21.4 \text { (MUSM } \\
1995)\end{array}$ & 19.2 \\
\hline
\end{tabular}




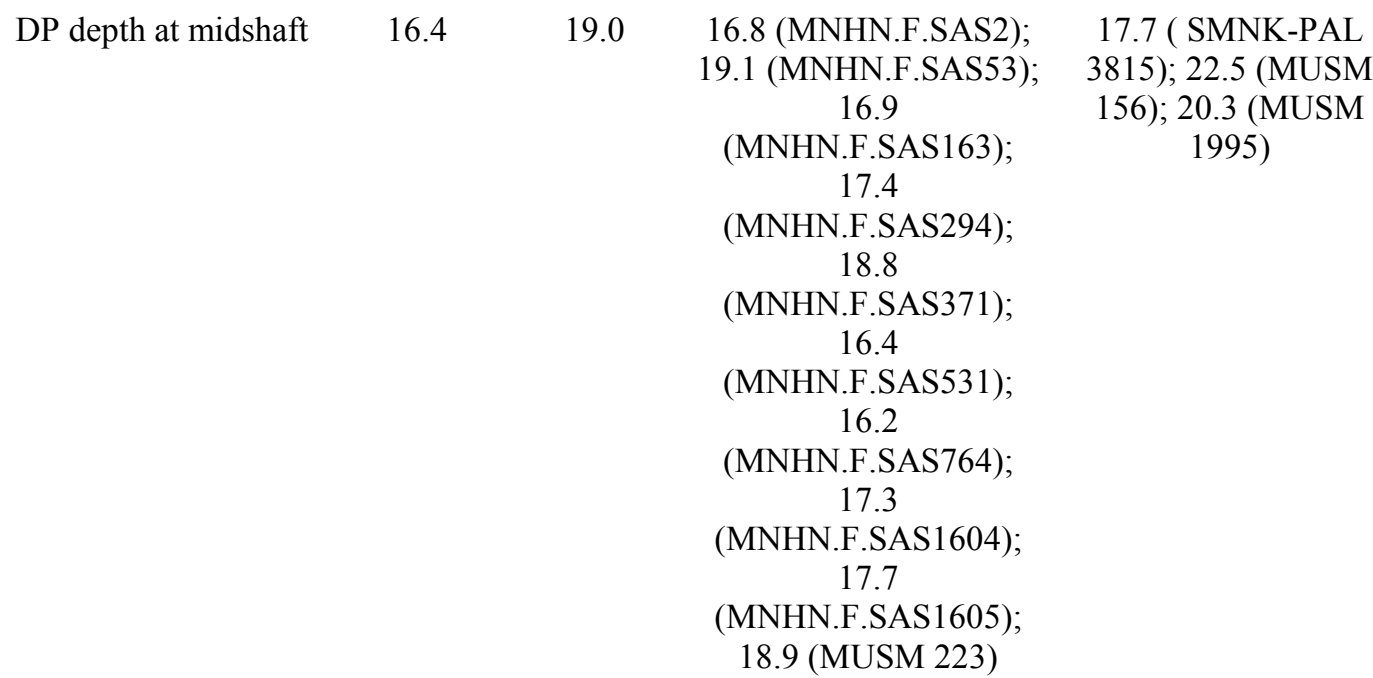

\begin{tabular}{|c|c|c|c|c|c|}
\hline Ph. 1 D. II & & & & & \\
\hline Greatest PD length & 20.7 & 23.2 & $\begin{array}{c}23.7 \text { (MNHN.F.SAS53); } \\
20.4 \\
\text { (MNHN.F.SAS786); } \\
19.5 \\
\text { (MNHN.F.SAS1604); } \\
22.0 \\
\text { (MNHN.F.SAS1605); } \\
\text { 22.6 (MUSM 223) }\end{array}$ & $\begin{array}{c}20.8 \text { (SMNK-PAL } \\
3815) ; 29 * \text { (MUSM } \\
156) ; 24.4 \text { (MUSM } \\
1995)\end{array}$ & $\begin{array}{c}\text { 20.3; } 16.2 \\
\text { (MUSM 1034) }\end{array}$ \\
\hline Greatest ML width & 25.5 & 27.1 & $\begin{array}{c}24.8 \text { (MNHN.F.SAS53); } \\
22.9 \\
\text { (MNHN.F.SAS786); } \\
22.6 \\
\text { (MNHN.F.SAS1604); } \\
26.1 \\
\text { (MNHN.F.SAS1605); } \\
27.9 \text { (MUSM 223) }\end{array}$ & $\begin{array}{c}19.2 \text { (SMNK-PAL } \\
\text { 3815); } 26.4 \text { (MUSM } \\
\text { 156); } 28.7 \text { (MUSM } \\
1995)\end{array}$ & $\begin{array}{c}25.4 ; 21.0 \\
\text { (MUSM 1034) }\end{array}$ \\
\hline Greatest DP depth & 27.6 & 32.6 & $\begin{array}{c}27.2 \text { (MNHN.F.SAS53); } \\
25.8 \\
\text { (MNHN.F.SAS786);25. } \\
9 \text { (MNHN.F.SAS1604); } \\
28.5 \\
\text { (MNHN.F.SAS1605); } \\
\text { 30.5 (MUSM 223) }\end{array}$ & $\begin{array}{c}27.0 \text { (SMNK-PAL } \\
\text { 3815); } 34.6 \text { (MUSM } \\
\text { 156); } 35.1 \text { (MUSM } \\
1995)\end{array}$ & $\begin{array}{c}29.9 ; 21.9 \\
\text { (MUSM 1034) }\end{array}$ \\
\hline
\end{tabular}




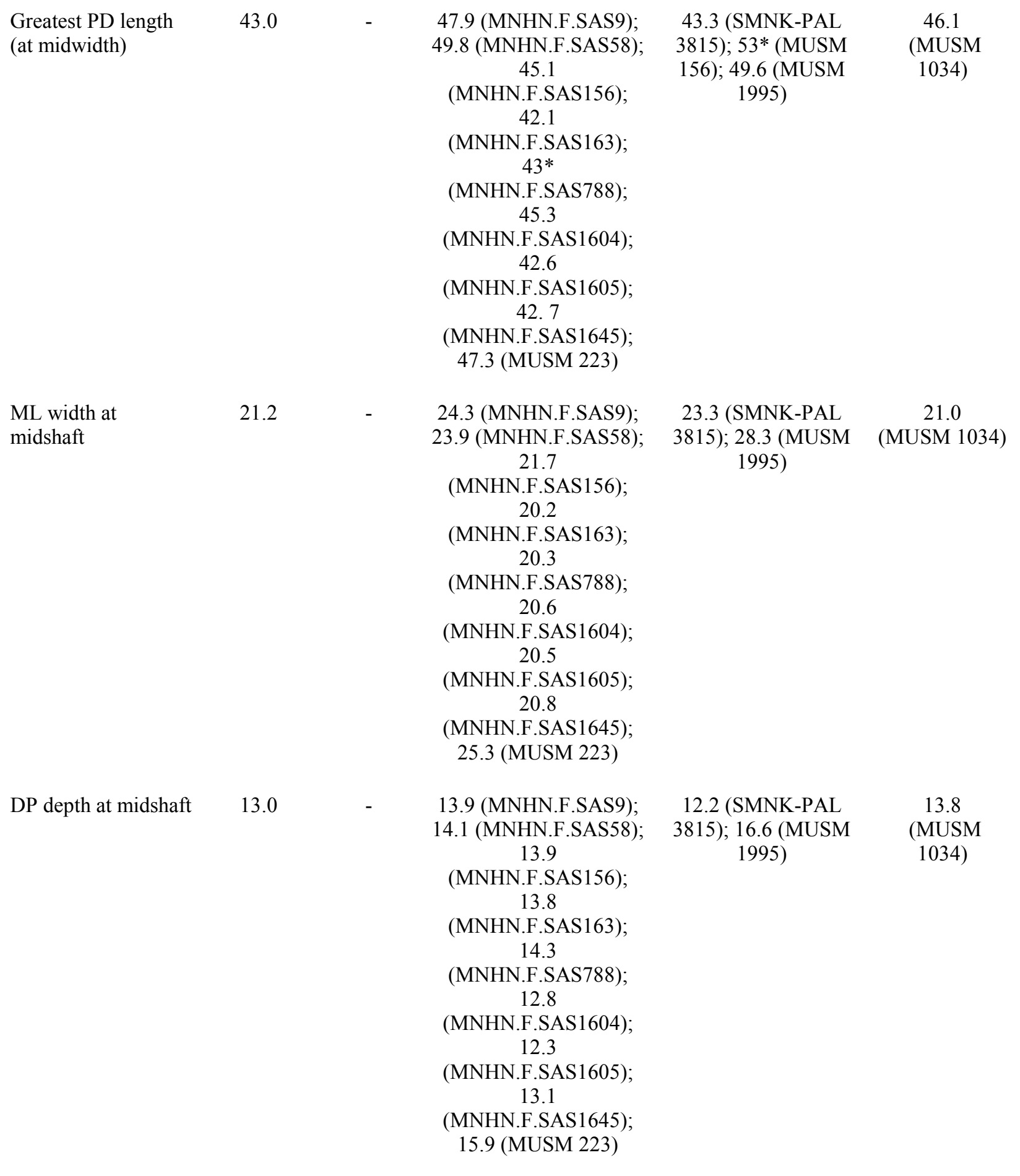

\begin{tabular}{|c|c|c|c|c|c|}
\hline Ph. 3 D. II & & & & & \\
\hline $\begin{array}{l}\text { Greatest PD length } \\
\text { (N.B. the distal tip is } \\
\text { rarely preserved) }\end{array}$ & 64.2 & - & $\begin{array}{c}\text { 77* (MNHN.F.SAS53); } \\
82 * \text { (MNHN.F.SAS } 82) ; \\
81.9 \text { (MUSM 223) }\end{array}$ & $\begin{array}{c}83.0 \text { (SMNK-PAL } \\
3815)\end{array}$ & $97 *$ \\
\hline
\end{tabular}




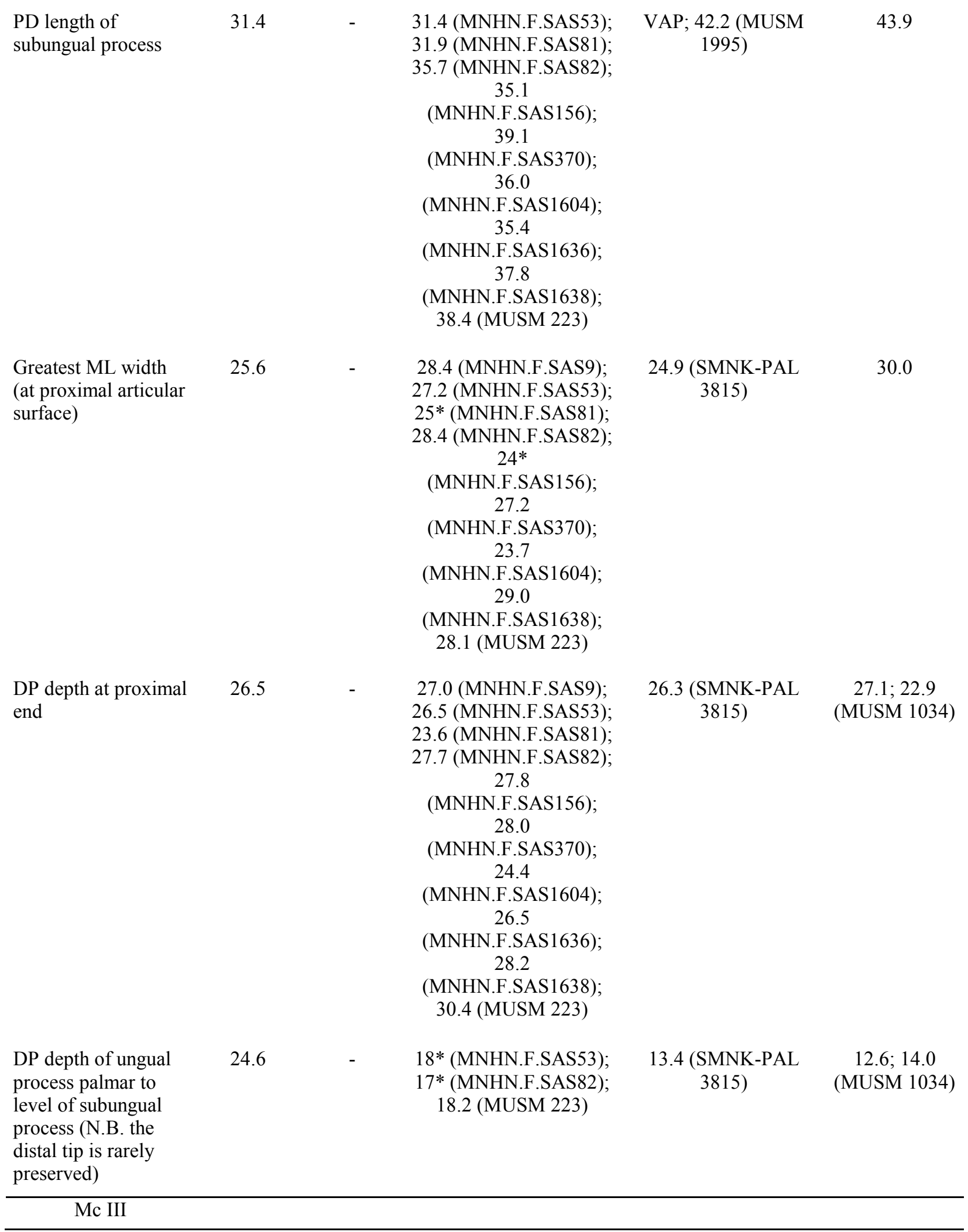




\begin{tabular}{|c|c|c|c|c|c|}
\hline $\begin{array}{l}\text { Greatest PD length } \\
\text { (at middepth) }\end{array}$ & $75^{*}$ & 77.7 & $\begin{array}{c}73.1 \text { (MNHN.F.SAS53); } \\
71.2 \\
\text { (MNHN.F.SAS156); } \\
71.7 \\
\text { (MNHN.F.SAS212); } \\
76.5 \\
\text { (MNHN.F.SAS765); } \\
72.3 \\
\text { (MNHN.F.SAS779); } \\
\text { 73.5 } \\
\text { (MNHN.F.SAS1605); } \\
\text { 77.7 (MUSM 223) }\end{array}$ & $\begin{array}{c}71.2 \text { (SMNK-PAL } \\
\text { 3815); } 78.7 \text { (MUSM } \\
\text { 156); } 81.4 \text { (MUSM } \\
1995)\end{array}$ & $\begin{array}{c}67.9 \\
\text { (MUSM 1034) }\end{array}$ \\
\hline $\begin{array}{l}\text { ML width at } \\
\text { midshaft }\end{array}$ & 17.4 & 19.3 & $\begin{array}{c}19.7 \text { (MNHN.F.SAS4); } \\
17.6 \text { (MNHN.F.SAS53); } \\
15.8 \\
\text { (MNHN.F.SAS156); } \\
16.3 \\
\text { (MNHN.F.SAS163); } \\
15.4 \\
\text { (MNHN.F.SAS212); } \\
16.2 \\
\text { (MNHN.F.SAS491); } \\
17.2 \\
\text { (MNHN.F.SAS765); } \\
16.6 \\
\text { (MNHN.F.SAS779); } \\
17.2 \\
\text { (MNHN.F.SAS1605); } \\
16.6 \\
\text { (MNHN.F.SAS1609); } \\
\text { 17.6 (MUSM 223) }\end{array}$ & $\begin{array}{c}18.9 \text { (SMNK-PAL } \\
\text { 3815); } 22.2 \text { (MUSM } \\
\text { 156); } 21.3 \text { (MUSM } \\
1995 \text { ) }\end{array}$ & $\begin{array}{c}19.1 \\
\text { (MUSM } \\
1034 \text { ) }\end{array}$ \\
\hline DP depth at midshaft & 17.6 & 22.2 & $\begin{array}{c}23.8 \text { (MNHN.F.SAS4); } \\
20.0 \text { (MNHN.F.SAS53); } \\
19.0 \\
\text { (MNHN.F.SAS163); } \\
19.6 \\
\text { (MNHN.F.SAS212); } \\
19.4 \\
\text { (MNHN.F.SAS491); } \\
20.3 \\
\text { (MNHN.F.SAS765); } \\
19.0 \\
\text { (MNHN.F.SAS779); } \\
21.4 \\
\text { (MNHN.F.SAS1605); } \\
19.6 \\
\text { (MNHN.F.SAS1609); } \\
\text { 22.3 (MUSM 223) }\end{array}$ & $\begin{array}{c}19.3 \text { (SMNK-PAL } \\
\text { 3815); 25* (MUSM } \\
\text { 156); } 22.3 \text { (MUSM } \\
1995)\end{array}$ & $\begin{array}{c}21.1 \\
\text { (MUSM 1034) }\end{array}$ \\
\hline
\end{tabular}




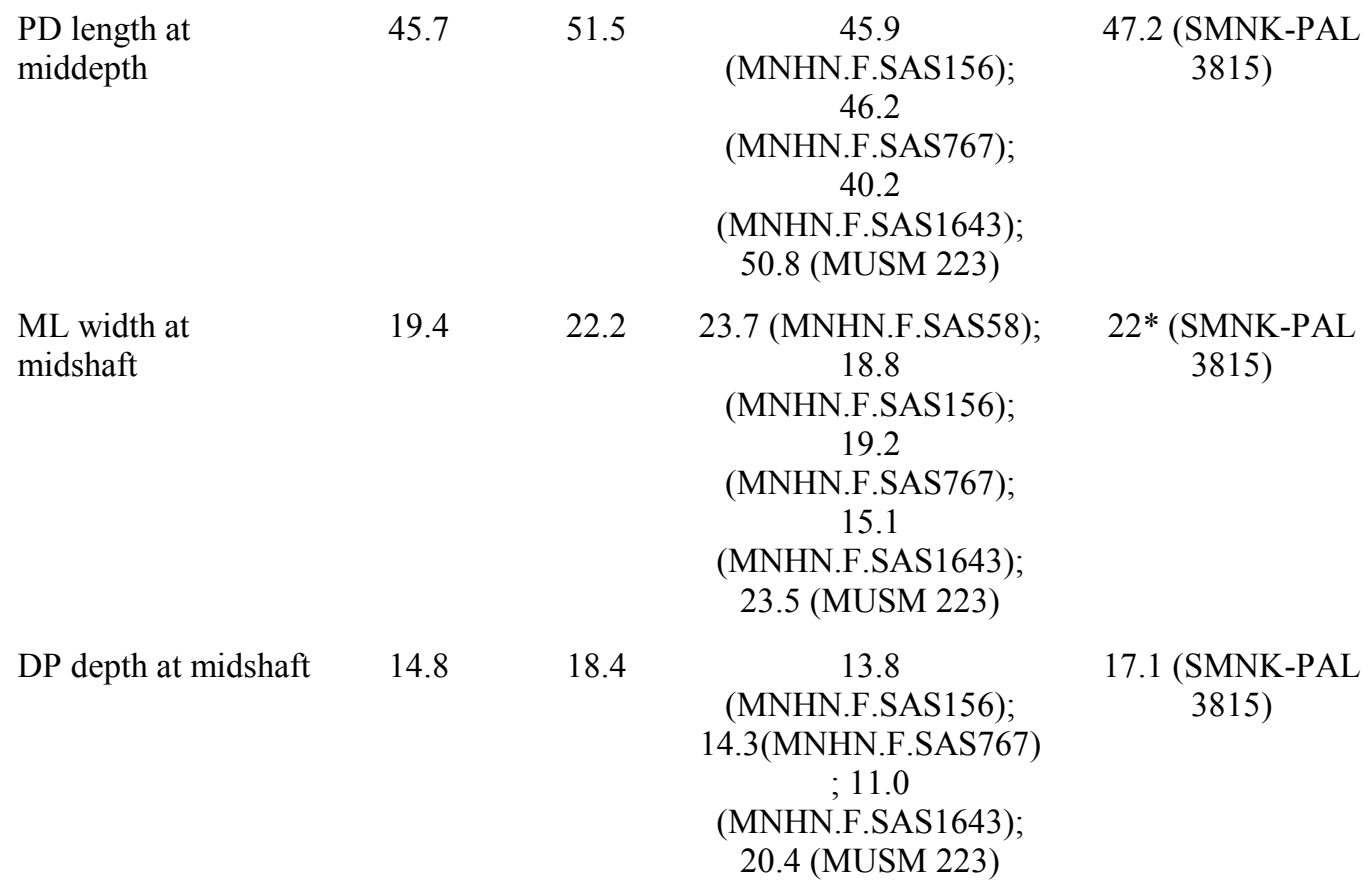

18.4

13.8

(MNHN.F.SAS156); 14.3(MNHN.F.SAS767)$$
\text { ; } 11.0
$$

(MNHN.F.SAS1643);

20.4 (MUSM 223)

\begin{tabular}{|c|c|c|c|c|c|}
\hline \multicolumn{6}{|l|}{ Ph. 1 D. III } \\
\hline Greatest PD length & N.A. & N.A. & N.A. & 20.8 (MUSM 1995); & - \\
\hline Greatest ML width & N.A. & N.A. & N.A. & 28.0 (MUSM 1995); & - \\
\hline Greatest DP depth & N.A. & N.A. & N.A. & 39.6 (MUSM 1995); & - \\
\hline \multicolumn{6}{|l|}{ Ph. 2 D. III } \\
\hline $\begin{array}{l}\text { Greatest PD length } \\
\text { (at midwidth) }\end{array}$ & N.A. & N.A. & N.A. & 42.5 (MUSM 1995); & 35.1 \\
\hline $\begin{array}{l}\text { ML width at } \\
\text { midshaft }\end{array}$ & N.A. & N.A. & N.A. & 27.5 (MUSM 1995); & 25.3 \\
\hline DP depth at midshaft & N.A. & N.A. & N.A. & 17.6 (MUSM 1995); & 17.1 \\
\hline \multicolumn{6}{|l|}{ Ph. 3 D. III } \\
\hline $\begin{array}{l}\text { Greatest PD length } \\
\text { (N.B. the distal tip is } \\
\text { rarely preserved) }\end{array}$ & $84^{*}$ & - & $\begin{array}{c}\text { 79* (MNHN.F.SAS53); } \\
74 * \\
\text { (MNHN.F.SAS156); } \\
75^{*} \\
\text { (MNHN.F.SAS1604); } \\
\text { 87* (MUSM 223) }\end{array}$ & $\begin{array}{c}78 *(\text { SMNK-PAL } \\
3815) ; 89 *(\text { MUSM } \\
1995)\end{array}$ & $\begin{array}{c}76.6 \\
\text { (MUSM 1034) }\end{array}$ \\
\hline
\end{tabular}


Greatest ML width (at proximal end)

Greatest DP depth (at proximal end)
20.7

21.4

(MNHN.F.SAS156);

21.0

(MNHN.F.SAS497); 20.2

(MNHN.F.SAS1604); 23.3

(MNHN.F.SAS1605);

23.2 (MUSM 223)

29.8

29.1 (MNHN.F.SAS53) 27.4

(MNHN.F.SAS156); 30.6

(MNHN.F.SAS497); 25.8

(MNHN.F.SAS1604); 32.5

(MNHN.F.SAS1605);

33.6 (MUSM 223)

\begin{tabular}{|c|c|c|c|c|c|}
\hline Mc IV & & & & & \\
\hline $\begin{array}{l}\text { Greatest PD length } \\
\text { (at middepth) }\end{array}$ & 84.3 & 93.3 & $\begin{array}{c}84.3 \text { (MNHN.F.SAS53); } \\
88.1 \\
\text { (MNHN.F.SAS156); } \\
73.8 \\
\text { (MNHN.F.SAS742); } \\
87.8 \\
\text { (MNHN.F.SAS763); } \\
\text { 91.1 (MUSM 223) }\end{array}$ & $\begin{array}{c}86.0 \text { (SMNK-PAL } \\
\text { 3815); } 94.5 \text { (MUSM } \\
\text { 156); } 93.3 \text { (MUSM } \\
1995)\end{array}$ & $\begin{array}{c}79.4 ; 97.2 \\
\text { (MUSM 2073) }\end{array}$ \\
\hline $\begin{array}{l}\text { ML width at } \\
\text { midshaft }\end{array}$ & 16.2 & 18.9 & $\begin{array}{c}15.5 \text { (MNHN.F.SAS53); } \\
14.5 \text { (MNHN.F.SAS54); } \\
16.2 \\
\text { (MNHN.F.SAS181); } \\
12.9 \\
\text { (MNHN.F.SAS742); } \\
16.9 \\
\text { (MNHN.F.SAS763); } \\
16.2 \\
\text { (MNHN.F.SAS1633); } \\
15.5 \text { (MUSM 223) }\end{array}$ & $\begin{array}{c}17.3 \text { (SMNK-PAL } \\
\text { 3815); } 19.0 \text { (MUSM } \\
\text { 1995) }\end{array}$ & $\begin{array}{c}18.0 ; 19.6 \\
\text { (MUSM 2073) }\end{array}$ \\
\hline DP depth at midshaft & 18.4 & 19.1 & $\begin{array}{c}20.1 \text { (MNHN.F.SAS53); } \\
19.2 \text { (MNHN.F.SAS54); } \\
19.5 \\
\text { (MNHN.F.SAS181); } \\
16.7 \\
\text { (MNHN.F.SAS742); } \\
17.1 \\
\text { (MNHN.F.SAS763); } \\
\text { 20.5 } \\
\text { (MNHN.F.SAS1633); } \\
21.2 \text { (MUSM 223) }\end{array}$ & $\begin{array}{c}21.3 \text { (SMNK-PAL } \\
\text { 3815); } 22.8 \text { (MUSM } \\
\text { 1995) }\end{array}$ & $\begin{array}{c}21.3 ; 25.2 \\
\text { (MUSM 2073) }\end{array}$ \\
\hline
\end{tabular}

19.8 (SMNK-PAL 3815); 27.1 (MUSM 1995)

18.2 (MUSM 1034)

27.7 (SMNK-PAL 27.6 3815); 34.3 (MUSM (MUSM 1034) 1995) 


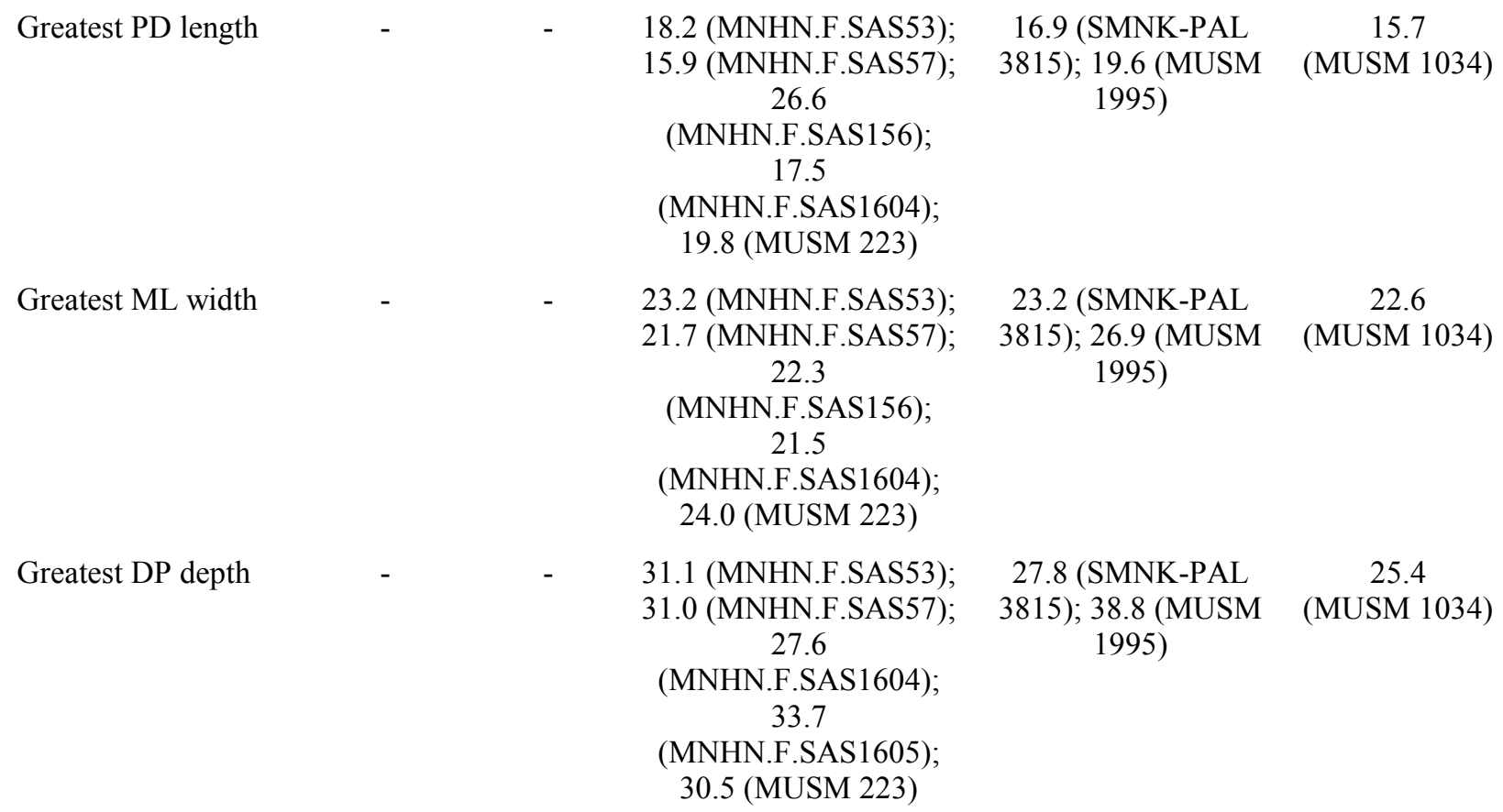

\begin{tabular}{|c|c|c|c|c|c|}
\hline Ph. 2 D. IV & & & & & \\
\hline Greatest PD length & 31.3 & 37.0 & $\begin{array}{c}33.6 \text { (MNHN.F.SAS9); } \\
32.5 \text { (MNHN.F.SAS53); } \\
32.3 \text { (MNHN.F.SAS57); } \\
33.0 \\
\text { (MNHN.F.SAS156); } \\
32.2 \\
\text { (MNHN.F.SAS485); } \\
31.7 \\
\text { (MNHN.F.SAS1604); } \\
\text { 19.5 } \\
\text { (MNHN.F.SAS1605); } \\
\text { 37.7 } \\
\text { (MNHN.F.SAS1633); } \\
\text { 35.2 (MNHN.F.SAS4); } \\
\text { 35.0 (MUSM 223) }\end{array}$ & $\begin{array}{c}29.5 \text { (SMNK-PAL } \\
\text { 3815); } 35.9 \text { (MUSM } \\
1995)\end{array}$ & $\begin{array}{c}28.9 \\
\text { (MUSM 1034) }\end{array}$ \\
\hline Greatest ML width & $16^{*}$ & 19.9 & $\begin{array}{c}18.9 \text { (MNHN.F.SAS9); } \\
19.0 \text { (MNHN.F.SAS53); } \\
17.6 \text { (MNHN.F.SAS57); } \\
18.2 \\
\text { (MNHN.F.SAS485); } \\
17.6 \\
\text { (MNHN.F.SAS1604); } \\
\text { 21.9 (MNHN.F.SAS4); } \\
20.3 \text { (MUSM 223) }\end{array}$ & $\begin{array}{c}18.1 \text { (SMNK-PAL } \\
\text { 3815); } 23.3 \text { (MUSM } \\
1995)\end{array}$ & $\begin{array}{c}16.2 \\
\text { (MUSM 1034) }\end{array}$ \\
\hline
\end{tabular}


Greatest DP depth (at proximal end)
28.3

24.2 (MNHN.F.SAS9);
24.7 (MNHN.F.SAS53);
25.0 (MNHN.F.SAS57);
24.2
(MNHN.F.SAS156);
22.3
(MNHN.F.SAS485);
24.6
(MNHN.F.SAS1604);
26.6
(MNHN.F.SAS1633);
27.2 (MNHN.F.SAS4);
25.8 (MUSM 223)

24.1 (SMNK-PAL

3815); 30.3 (MUSM 1995)
23.1 (MUSM 1034)

\begin{tabular}{|c|c|c|c|c|c|}
\hline Ph. 3 D. IV & & & & & \\
\hline $\begin{array}{l}\text { Greatest PD length } \\
\text { (N.B. the distal tip is } \\
\text { rarely preserved) }\end{array}$ & $72 *$ & $79^{*}$ & $\begin{array}{c}72 * \text { (MNHN.F.SAS53) } \\
75^{*} \text { (MUSM 223) }\end{array}$ & $\begin{array}{c}62.4 \text { (SMNK-PAL } \\
3815)\end{array}$ & $\begin{array}{c}66.7 \\
\text { (MUSM 1034) }\end{array}$ \\
\hline $\begin{array}{l}\text { ML width at } \\
\text { proximal end }\end{array}$ & 16.2 & 31.9 & $\begin{array}{c}24.1 \text { (MNHN.F.SAS53); } \\
17.7 \\
\text { (MNHN.F.SAS1604); } \\
22.4 \text { (MUSM 223) }\end{array}$ & $\begin{array}{c}19.3 \text { (SMNK-PAL } \\
3815)\end{array}$ & $\begin{array}{c}17.8 \\
\text { (MUSM 1034) }\end{array}$ \\
\hline Greatest DP depth & 24.0 & 26.6 & $\begin{array}{c}24.4 \text { (MNHN.F.SAS9); } \\
23.5 \text { (MNHN.F.SAS53); } \\
22.1 \\
\text { (MNHN.F.SAS1604); } \\
27.3 \text { (MUSM 223) }\end{array}$ & $\begin{array}{c}24.3 \text { (SMNK-PAL } \\
3815)\end{array}$ & $\begin{array}{c}21.9 \\
\text { (MUSM 1034) }\end{array}$ \\
\hline \multicolumn{6}{|l|}{$\mathrm{Mc} \mathrm{V}$} \\
\hline $\begin{array}{l}\text { Greatest PD length } \\
\text { (at lateral edge; N.B. } \\
\text { the proximal tip is } \\
\text { rarely preserved) }\end{array}$ & $74 *$ & - & $\begin{array}{c}89.0 \\
\text { (MNHN.F.SAS156); } \\
97.9 \\
\text { (MNHN.F.SAS384); } \\
80.9 \\
\text { (MNHN.F.SAS163); } \\
\text { 93.4 (MNHN.F.SAS4); } \\
\text { 92.2 (MUSM 223) }\end{array}$ & $\begin{array}{c}83.7 \text { (SMNK-PAL } \\
\text { 3815); 98* (MUSM } \\
\text { 156); } 98.8 \text { (MUSM } \\
1995)\end{array}$ & 78.7 \\
\hline $\begin{array}{l}\text { ML width at } \\
\text { midshaft }\end{array}$ & 14.3 & - & $\begin{array}{c}14.0 \text { (MNHN.F.SAS53); } \\
13.8 \\
\text { (MNHN.F.SAS156); } \\
14.5 \\
\text { (MNHN.F.SAS163); } \\
17.0 \text { (MNHN.F.SAS4); } \\
15.5 \text { (MUSM 223) }\end{array}$ & $\begin{array}{c}15.9 \text { (SMNK-PAL } \\
\text { 3815); } 13.6 \\
\text { (MNHN.F.SAO77); } \\
\text { 19.4 (MUSM 156); } \\
18.0 \text { (MUSM 1995) }\end{array}$ & 17.2 \\
\hline DP depth at midshaft & 10.3 & - & $\begin{array}{c}12.4 \text { (MNHN.F.SAS53); } \\
12.8 \\
\text { (MNHN.F.SAS156); } \\
11.0 \\
\text { (MNHN.F.SAS163); } \\
\text { 13.7 (MNHN.F.SAS4); } \\
\text { 13.1 (MUSM 223) }\end{array}$ & $\begin{array}{c}13.5 \text { (SMNK-PAL } \\
\text { 3815). } 12.9 \\
\text { (MNHN.F.SAO77); } \\
\text { 16.8 (MUSM 156); } \\
\text { 16.6 (MUSM 1995) }\end{array}$ & 14.0 \\
\hline
\end{tabular}




\begin{tabular}{|c|c|c|c|c|c|}
\hline Greatest PD length & 19.3 & - & $\begin{array}{c}14.3 \text { (MNHN.F.SAS53); } \\
12.5 \\
\text { (MNHN.F.SAS156); }\end{array}$ & $\begin{array}{c}11.1 \text { (SMNK-PAL } \\
\text { 3815); (MUSM 1995); } \\
\text { 14.8 (MUSM 1995) }\end{array}$ & - \\
\hline Greatest ML width & $13 *$ & - & $\begin{array}{c}17.2 \text { (MNHN.F.SAS53); } \\
16.2 \\
\text { (MNHN.F.SAS156) }\end{array}$ & $\begin{array}{c}15.5 \text { (SMNK-PAL } \\
3815) ; 24.0 \text { (MUSM } \\
1995)\end{array}$ & - \\
\hline Greatest DP depth & 14.4 & - & $\begin{array}{c}17.6 \text { (MNHN.F.SAS53); } \\
17.7 \\
\text { (MNHN.F.SAS156) }\end{array}$ & $\begin{array}{c}16.8 \text { (SMNK-PAL } \\
\text { 3815); } 22.8 \text { (MUSM } \\
1995)\end{array}$ & - \\
\hline \multicolumn{6}{|c|}{ Palmar sesamoid } \\
\hline Greatest diameter & 28.4 & - & $\begin{array}{c}22.4 \text { (MNHN.F.SAS2); } \\
32.9 \text { (MNHN.F.SAS53); } \\
28.4 \text { (MUSM 223) }\end{array}$ & $\begin{array}{c}27.7 \text { (SMNK-PAL } \\
3815) ; 35.9 \text { (MUSM } \\
1995)\end{array}$ & - \\
\hline Greatest DP depth & 6.2 & - & $\begin{array}{c}5.5 \text { (MNHN.F.SAS2); } \\
9.1 \text { (MNHN.F.SAS53); } \\
7.6 \text { (MUSM 223) }\end{array}$ & $\begin{array}{c}8.0(\mathrm{SMNK}-\mathrm{PAL} \\
3815) ; 9.0(\mathrm{MUSM} \\
1995)\end{array}$ & - \\
\hline
\end{tabular}

Footnotes: If no specimen number is given after a measurement, it is that of the holotype of the species; *, estimate. DP, dorsopalmar; ML, mediolateral; PD, proximodistal.

Table 20. Scaphoid proportions in Thalassocnus and other Megatheria.

\begin{tabular}{|c|c|c|c|c|c|}
\hline Taxon & Specimen number & ML width (W) & PD length (L) & $\mathrm{M} / \mathrm{L}$ & $\begin{array}{l}\text { Species value } \\
\text { (mean if } \\
\text { several } \\
\text { specimens) }\end{array}$ \\
\hline $\begin{array}{l}\text { ?T. natans, ?T. } \\
\text { littoralis }\end{array}$ & MNHN.F.SAS57 & 41.0 & 29.0 & 1.41 & 1.41 \\
\hline \multirow[t]{2}{*}{ T. carolomartini } & SMNK-PAL 3815 & 40.9 & 23.9 & 1.71 & 1.72 \\
\hline & MUSM 1995 & 47.0 & 27.1 & 1.73 & \\
\hline \multirow[t]{2}{*}{ T. yaucensis } & MUSM 37 & 40.4 & 21.1 & 1.91 & 1.88 \\
\hline & MUSM 347 & 45.8 & 24.8 & 1.85 & \\
\hline Nothrotheriops & LACM 119804 & 53.5 & 35.9 & 1.49 & 1.49 \\
\hline Nothrotherium & MCL 1020 & 31.8 & 26.0 & 1.22 & 1.22 \\
\hline Mionothropus & $\begin{array}{c}\text { LACM } \\
4609 / 117533\end{array}$ & 41.7 & 26.0 & 1.60 & 1.60 \\
\hline Megatherium & MNHN.F.PAM294 & 146.4 & 89.9 & 1.63 & 1.63 \\
\hline
\end{tabular}

Footnotes: ML, mediolateral; PD, proximodistal.

Table 21. Lunar proportions in Thalassocnus and other Megatheria.

\begin{tabular}{|c|c|c|c|c|c|}
\hline Taxon & Specimen number & ML width (W) & PD length (L) & $\mathrm{M} / \mathrm{L}$ & $\begin{array}{l}\text { Species value } \\
\text { (mean if } \\
\text { several } \\
\text { specimens) }\end{array}$ \\
\hline T. antiquus & MUSM 228 & 20.0 & 27.6 & 0.72 & 0.72 \\
\hline T. natans & MNHN.F.SAS734 & 32.9 & 30.6 & 1.08 & 1.08 \\
\hline \multirow[t]{2}{*}{ T. littoralis } & MNHN.F.SAS182 & 33.2 & 31.1 & 1.07 & 1.06 \\
\hline & MUSM 223 & 30.2 & 28.7 & 1.05 & \\
\hline
\end{tabular}




$\begin{array}{lccccc}\text { T. carolomartini } & \text { SMNK-PAL 3815 } & 31.3 & 25.2 & 1.24 & 1.25 \\ & \text { MUSM 1995 } & 38.1 & 30.5 & 1.25 & \\ \text { Nothrotheriops } & \text { LACM 156468 } & 31.9 & 34.3 & 0.93 & 0.93 \\ \text { Nothrotherium } & \text { MCL 1020 } & 14.2 & 19.3 & 0.74 & 0.74 \\ \text { Mionothropus } & \text { LACM } & 22.7 & 30.9 & 0.73 & 0.73 \\ \text { Megatherium } & \text { 4609/117533 } & & & \\ \end{array}$

Footnotes: ML, mediolateral; PD, proximodistal.

Table 22. Trapezium-first metacarpal complex proportions in Thalassocnus and other Megatheria.

\begin{tabular}{lcccc}
\hline Taxon & Specimen number & PD length (L) & DP depth (D) & P/D \\
\hline T. antiquus & MUSM 228 & 32.6 & 16.2 & 2.01 \\
T. littoralis & MNHN.F.SAS53 & 33.4 & 15.8 & 2.11 \\
& MNHN.F.SAS163 & 34.3 & 15.9 & 2.16 \\
& MUSM 223 & 35.8 & 20.3 & 1.76 \\
T. carolomartini & SMNK-PAL 3815 & $30^{*}$ & 15.1 & 1.99 \\
& MUSM 1995 & 39.6 & 19.3 & 2.05 \\
& MUSM 156 & $37^{*}$ & 17.1 & 2.16 \\
T. yaucensis & MUSM 37 & 35.2 & 17.1 & 2.06 \\
Nothrotheriops & LACM 156469 & 56.4 & 18.2 & 3.10 \\
Nothrotherium & MCL 1020 & 35.0 & 8.5 & 4.12 \\
Megatherium & MNHN.F.PAM294 & 71.8 & 48.9 & 1.47 \\
\hline
\end{tabular}

Footnotes: *, estimate. DP, dorsopalmar; PD, proximodistal.

Table 23. Second metacarpal proportions in Thalassocnus and other Megatheria.

\begin{tabular}{lccccc}
\hline Taxon & Specimen number & PD length (L) & DP depth (D) & L/D & $\begin{array}{c}\text { Species value } \\
\text { (mean if } \\
\text { several } \\
\text { specimens) }\end{array}$ \\
\hline T. antiquus & MUSM 228 & 62.5 & 16.4 & 3.81 & 3.81 \\
T. natans & MNHN.F.SAS734 & 69.0 & 19.0 & 3.63 & 3.63 \\
T. littoralis & MNHN.F.SAS163 & 59.4 & 16.9 & 3.51 & 3.53 \\
& MNHN.F.SAS371 & 66.5 & 18.8 & 3.54 & \\
& MNHN.F.SAS1604 & 60.2 & 17.3 & 3.48 & \\
T. carolomartini & MUSM 223 & 68.1 & 18.9 & 3.60 & \\
& SMNK-PAL 3815 & 57.1 & 17.7 & 3.23 & 3.40 \\
T. yaucensis & MUSM 1995 & 72.5 & 20.3 & 3.57 & \\
Nothrotheriops & MUSM 37 & 51.7 & 19.7 & 2.62 & 2.62 \\
Nothrotherium & LACM & 89.6 & 26.3 & 3.41 & 3.41 \\
Mionothropus & LACM 4609/117533 & 64.7 & 15.3 & 4.23 & 4.23
\end{tabular}




\begin{tabular}{llllll} 
Megatherium & MNHN.F.PAM294 & 144.3 & 40.0 & 3.61 & 3.61 \\
\hline
\end{tabular}

Footnotes: DP, dorsopalmar; PD, proximodistal.

Table 24. Width of ungual phalanx of the second digit in Thalassocnus and other nothrotheriids.

\begin{tabular}{lcccc}
\hline Taxon & $\begin{array}{c}\text { Specimen } \\
\text { number }\end{array}$ & $\begin{array}{c}\text { DV depth of horizontal } \\
\text { ramus of mandible (D) }\end{array}$ & $\begin{array}{c}\text { ML width at } \\
\text { proximal end (W) }\end{array}$ & D/W \\
\hline T. antiquus & MUSM 228 & 42.5 & 25.6 & 0.60 \\
T. littoralis & MUSM 223 & 45.4 & 28.1 & 0.62 \\
T. yaucensis & MUSM 37 & 46.4 & 30.0 & 0.65 \\
Nothrotherium & MCL 1020 & 32.4 & 14.4 & 0.44 \\
Mionothropus & LACM & 45.1 & 21.5 & 0.48 \\
& $4609 / 11753$ & & & \\
& 3 & & & \\
\hline
\end{tabular}

Footnotes: DV, dorsoventral; ML, mediolateral.

Table 25. Curvature of the ungual process of the second digit in Thalassocnus.

\begin{tabular}{lcccc}
\hline Taxon & $\begin{array}{c}\text { Specimen } \\
\text { number }\end{array}$ & $\begin{array}{c}\text { DP depth of ungual } \\
\text { process palmar to } \\
\text { subungual process } \\
\text { (Du) }\end{array}$ & $\begin{array}{c}\text { DP depth at } \\
\text { proximal end (Dp) }\end{array}$ & Du/Dp \\
\hline T. antiquus & MUSM 228 & 24.6 & 26.5 & 0.93 \\
T. littoralis & MNHN.F.SAS53 & $18^{*}$ & 26.5 & 0.68 \\
& MNHN.F.SAS82 & $17^{*}$ & 27.7 & 0.61 \\
& MUSM 223 & 18.2 & 30.4 & 0.60 \\
T. carolomartini & SMNK-PAL & 13.4 & 26.3 & 0.51 \\
T. yaucensis & 3815 & 12.6 & 27.1 & 0.46 \\
& MUSM 37 & 14.0 & 22.9 & 0.61 \\
\hline
\end{tabular}

Footnotes: *, estimates; DP, dorsopalmar.

Table 26. Third metacarpal proportions in Thalassocnus and other Megatheria.

\begin{tabular}{lccccc}
\hline Taxon & Specimen number & PD length (L) & $\begin{array}{c}\text { DP depth at } \\
\text { midshaft (D) }\end{array}$ & L/D & $\begin{array}{c}\text { Species value } \\
\text { (mean if } \\
\text { several } \\
\text { specimens) }\end{array}$ \\
\hline T. antiquus & MUSM 228 & $75^{*}$ & 17.6 & 4.26 & 4.26 \\
T. natans & MNHN.F.SAS734 & 77.7 & 22.2 & 3.50 & 3.50 \\
T. littoralis & MNHN.F.SAS53 & 73.1 & 20.0 & 3.66 & 3.63 \\
& MNHN.F.SAS212 & 71.7 & 19.6 & 3.66 & \\
& MNHN.F.SAS765 & 76.5 & 20.3 & 3.77 & \\
& MNHN.F.SAS779 & 72.3 & 19.0 & 3.81 & \\
& MNHN.F.SAS1605 & 73.5 & 21.4 & 3.43 & \\
& MUSM 223 & 77.7 & 22.3 & 3.48 &
\end{tabular}




\begin{tabular}{lccccc} 
T. carolomartini & SMNK-PAL 3815 & 71.2 & 19.3 & 3.69 & 3.42 \\
& MUSM 156 & 78.7 & 25 & 3.15 & \\
T. yaucensis & MUSM 1034 & 67.9 & 21.1 & 3.22 & 3.22 \\
Nothrotheriops & LACM & 88.9 & 25.7 & 3.46 & 3.46 \\
& 15179=128737 & & & & \\
Nothrotherium & MCL 1020 & 55.7 & 12.3 & 4.53 & 4.53 \\
Mionothropus & LACM 4609/117533 & 69.4 & 20.9 & 3.32 & 3.32 \\
Megatherium & MNHN.F.PAM294 & 194 & 62.1 & 3.12 & 3.12 \\
\hline
\end{tabular}

Footnotes: *, estimates; DP, dorsopalmar; PD, proximodistal.

Table 27. Fourth metacarpal proportions in Thalassocnus and other Megatheria.

\begin{tabular}{lccccc}
\hline Taxon & Specimen number & PD length (L) & $\begin{array}{c}\text { DP depth at } \\
\text { midshaft (D) }\end{array}$ & L/D & $\begin{array}{c}\text { Species value } \\
\text { (mean if } \\
\text { several } \\
\text { specimens) }\end{array}$ \\
\hline T. antiquus & MUSM 228 & 84.3 & 18.4 & 4.58 & 4.58 \\
T. natans & MNHN.F.SAS734 & 93.3 & 19.1 & 4.88 & 4.88 \\
T. littoralis & MNHN.F.SAS53 & 84.3 & 20.1 & 4.19 & 4.51 \\
& MNHN.F.SAS742 & 73.8 & 16.7 & 4.42 & \\
& MNHN.F.SAS763 & 87.8 & 17.1 & 5.13 & \\
T. carolomartini & MUSM 223 & 91.1 & 21.2 & 4.30 & \\
& MUSM1995 & 93.3 & 22.8 & 4.09 & 4.06 \\
T. yaucensis & SMNK-PAL 3815 & 86 & 21.3 & 4.04 & \\
Nothrotheriops & MUSM 37 & 79.4 & 21.3 & 3.73 & 3.79 \\
Nothrotherium & MUSM 2073 & 97.2 & 25.2 & 3.86 & \\
Mionothropus & LACM 119753 & 123.5 & 25.8 & 4.79 & 4.79 \\
Megatherium & MNL 1020 & 68.8 & 12.0 & 5.73 & 5.73 \\
\hline
\end{tabular}

Footnotes: DP, dorsopalmar; PD, proximodistal.

Table 28. Fifth metacarpal proportions in Thalassocnus and other Megatheria.

\begin{tabular}{lccccc}
\hline Taxon & Specimen number & PD length (L) & $\begin{array}{c}\text { DP depth at } \\
\text { midshaft (D) }\end{array}$ & L/D & $\begin{array}{c}\text { Species value } \\
\text { (mean if } \\
\text { several } \\
\text { specimens) }\end{array}$ \\
\hline T. antiquus & MUSM 228 & $74^{*}$ & 10.3 & 7.18 & 7.18 \\
T. littoralis & MNHN.F.SAS156 & 89.0 & 12.8 & 6.95 & 7.12 \\
& MNHN.F.SAS1604 & 80.9 & 11.0 & 7.35 & \\
$T$. carolomartini & MUSM 223 & 92.2 & 13.1 & 7.04 & \\
& MUSM1995 & 98.8 & 16.6 & 5.95 & 6.08 \\
$T$. yaucensis & SMNK-PAL 3815 & 83.7 & 13.5 & 6.20 & \\
& MUSM 37 & 78.7 & 14.0 & 5.62 & 5.62
\end{tabular}




\begin{tabular}{lccccc} 
Nothrotheriops & LACM 156467 & 119.0 & 20.5 & 5.80 & 5.80 \\
Nothrotherium & MCL 1020 & 67.0 & 7.4 & 9.05 & 9.05 \\
Mionothropus & LACM 4609/117533 & 94.4 & 11.1 & 8.50 & 8.50 \\
Megatherium & MNHN.F.PAM294 & 257 & 44.5 & 5.78 & 5.78 \\
\hline
\end{tabular}

Footnotes: *, estimates. DP, dorsopalmar; PD, proximodistal.

Table 29. Falciform proportions in Thalassocnus and other nothrotheriids.

\begin{tabular}{|c|c|c|c|c|c|}
\hline Taxon & $\begin{array}{l}\text { Specimen } \\
\text { number }\end{array}$ & Diameter (Di) & DP depth (D) & $\mathrm{D} / \mathrm{Di}$ & $\begin{array}{l}\text { Species value } \\
\text { (mean if } \\
\text { several } \\
\text { specimens) }\end{array}$ \\
\hline T. antiquus & MUSM 228 & 28.4 & 6.2 & 0.22 & 0.22 \\
\hline \multirow[t]{2}{*}{ T. littoralis } & MNHN.F.SAS53 & 32.9 & 9.1 & 0.28 & 0.26 \\
\hline & MUSM 223 & 28.4 & 7.1 & 0.25 & \\
\hline \multirow[t]{2}{*}{ T. carolomartini } & MUSM1995 & 35.9 & 9.0 & 0.25 & 0.27 \\
\hline & $\begin{array}{c}\text { SMNK-PAL } \\
3815\end{array}$ & 27.7 & 8.0 & 0.29 & \\
\hline \multirow[t]{2}{*}{ Nothrotheriops } & not numbered & 34.0 & 8.9 & 0.26 & 0.38 \\
\hline & LACM 119767 & 43.4 & 21.4 & 0.49 & \\
\hline Nothrotherium & MCL 1020 & 19.9 & 5.5 & 0.28 & 0.28 \\
\hline Mionothropus & $\begin{array}{c}\text { LACM } \\
4609 / 117533\end{array}$ & 31.4 & 7.3 & 0.23 & 0.23 \\
\hline
\end{tabular}

Footnotes: DP, dorsopalmar.

Table 30. Summary of anatomical comparisons with functional significance.

\begin{tabular}{|c|c|c|c|c|c|c|c|c|}
\hline \multicolumn{2}{|c|}{ Region and structure } & $\begin{array}{l}\text { Inferred } \\
\text { movement/function }\end{array}$ & \multicolumn{6}{|c|}{ Comparison } \\
\hline scanula & & & $\begin{array}{l}\text { other } \\
\text { sloths }\end{array}$ & $\begin{array}{l}T . \\
\text { a. }\end{array}$ & $\begin{array}{l}\text { Con } \\
T . \\
n .\end{array}$ & & T.c. & T. $y$ \\
\hline scapula & $\begin{array}{l}\text { postscapular fossa, teres } \\
\text { major }\end{array}$ & $\begin{array}{l}\text { shoulder flexion } \\
\text { strength }\end{array}$ & $\varnothing$ & $\varnothing$ & $\varnothing$ & + & $?$ & + \\
\hline clavicle & $\begin{array}{l}\text { absence of facet for } \\
\text { sternum }\end{array}$ & $\begin{array}{l}\text { shoulder movements } \\
\text { amplitude }\end{array}$ & $\varnothing$ & ? & $\varnothing$ & + & $?$ & + \\
\hline \multirow[t]{7}{*}{ humerus } & general shortness & $\begin{array}{l}\text { mechanical advantage of } \\
\text { shoulder flexion; } \\
\text { digging/aquatic } \\
\text { function? }\end{array}$ & $\varnothing$ & + & + & + & $?$ & ? \\
\hline & wide proximal epiphysis & $?$ & $\varnothing$ & + & + & + & + & + \\
\hline & $\begin{array}{l}\text { deltoid crest for same } \\
\text { muscle }\end{array}$ & $\begin{array}{l}\text { abduction and flexion of } \\
\text { the arm }\end{array}$ & $\varnothing$ & $\varnothing$ & $\varnothing$ & + & $?$ & ? \\
\hline & depth of radial fossa & interlocking of elbow & $\varnothing$ & + & + & + & $?$ & - \\
\hline & depth of coronoid fossa & $\begin{array}{l}\text { interlocking of elbow; } \\
\text { maximum flexion of } \\
\text { elbow }\end{array}$ & $\varnothing$ & $\varnothing$ & $\varnothing$ & $\varnothing$ & $?$ & - \\
\hline & depth of olecranon fossa & $\begin{array}{l}\text { interlocking of elbow; } \\
\text { maximum extension of } \\
\text { elbow }\end{array}$ & $\varnothing$ & + & + & + & + & + \\
\hline & shape of capitulum & stability of elbow & $\varnothing$ & $\varnothing$ & $\varnothing$ & $\varnothing$ & $\varnothing$ & - \\
\hline
\end{tabular}




\begin{tabular}{|c|c|c|c|c|c|c|c|c|}
\hline \multirow[t]{5}{*}{ ulna } & general stoutness & $\begin{array}{l}\text { shape of the } \\
\text { antebrachium? }\end{array}$ & $\varnothing$ & $\varnothing$ & $\varnothing$ & $\varnothing$ & $\varnothing$ & + \\
\hline & $\begin{array}{l}\text { medial fossa for flexor } \\
\text { digitorum profundus }\end{array}$ & $\begin{array}{l}\text { wrist and digits flexion } \\
\text { strength }\end{array}$ & $\varnothing$ & $?$ & + & + & $?$ & $?$ \\
\hline & $\begin{array}{l}\text { anconeal and coronoid } \\
\text { processes }\end{array}$ & interlocking of elbow & $\varnothing$ & $?$ & + & + & $?$ & + \\
\hline & $\begin{array}{l}\text { development of articular } \\
\text { circumference }\end{array}$ & $\begin{array}{l}\text { distal radioulnar joint } \\
\text { stability }\end{array}$ & $\varnothing$ & $?$ & $\varnothing$ & + & + & + \\
\hline & $\begin{array}{l}\text { development of carpal } \\
\text { facet relative to shaft }\end{array}$ & $\begin{array}{l}\text { correlation with ulnar } \\
\text { proportions? }\end{array}$ & $\varnothing$ & - & - & - & -- & --- \\
\hline \multirow[t]{2}{*}{$\begin{array}{l}\text { articulated } \\
\text { humerus-ulna }\end{array}$} & $\begin{array}{l}\text { maximum angle between } \\
\text { shafts }\end{array}$ & $\begin{array}{l}\text { maximum extension of } \\
\text { elbow }\end{array}$ & $\varnothing$ & $?$ & + & + & $?$ & $?$ \\
\hline & $\begin{array}{l}\text { minimum angle between } \\
\text { shafts }\end{array}$ & $\begin{array}{l}\text { maximum flexion of } \\
\text { elbow }\end{array}$ & $\varnothing$ & $?$ & - & - & $?$ & $?$ \\
\hline \multirow[t]{11}{*}{ radius } & general shortness & $\begin{array}{l}\text { digging/aquatic } \\
\text { function? }\end{array}$ & $\varnothing$ & + & + & + & $?$ & ++ \\
\hline & $\begin{array}{l}\text { anterior fossa of pronator } \\
\text { ridge, supinator insertion }\end{array}$ & supination strength & $\varnothing$ & + & + & ++ & $?$ & +++ \\
\hline & $\begin{array}{l}\text { thickness of pronator } \\
\text { ridge }\end{array}$ & pronation strength & $\varnothing$ & $\varnothing$ & $\varnothing$ & $\varnothing$ & $?$ & + \\
\hline & $\begin{array}{l}\text { development of pronator } \\
\text { ridge }\end{array}$ & shape of antebrachium & $\varnothing$ & + & + & ++ & $?$ & +++ \\
\hline & $\begin{array}{l}\text { medial edge of pronator } \\
\text { ridge, same muscle }\end{array}$ & $\begin{array}{l}\text { pronation of } \\
\text { antebrachium strength }\end{array}$ & $\varnothing$ & $\varnothing$ & $\varnothing$ & $\varnothing$ & $?$ & + \\
\hline & concavity of humeral facet & stability of elbow & $\varnothing$ & + & + & + & $?$ & $\varnothing$ \\
\hline & $\begin{array}{l}\text { crest for interosseous } \\
\text { membrane }\end{array}$ & $\begin{array}{l}\text { stability of } \\
\text { antebrachium }\end{array}$ & + & + & + & + & + & + \\
\hline & $\begin{array}{l}\text { development of radial } \\
\text { notch }\end{array}$ & $\begin{array}{l}\text { stability of distal } \\
\text { radioulnar joint }\end{array}$ & $\varnothing$ & $?$ & $\varnothing$ & + & ++ & ++ \\
\hline & width of carpal facet & pectoral paddling? & $\varnothing$ & $?$ & + & + & ++ & ++ \\
\hline & $\begin{array}{l}\text { depth of extensor carpi } \\
\text { radialis groove }\end{array}$ & interlocking of wrist & $\varnothing$ & $\varnothing$ & $\varnothing$ & $\varnothing$ & + & + \\
\hline & $\begin{array}{l}\text { development of } \\
\text { posterodistal process }\end{array}$ & interlocking of wrist & $\varnothing$ & + & + & + & + & + \\
\hline \multirow[t]{2}{*}{ carpus } & width of carpals & pectoral paddling? & $\varnothing$ & $\varnothing$ & + & + & ++ & +++ \\
\hline & $\begin{array}{l}\text { distal extension of radial } \\
\text { facet of lunar }\end{array}$ & $\begin{array}{l}\text { wrist flexion-extension } \\
\text { amplitude }\end{array}$ & $\varnothing$ & + & + & $\varnothing$ & $\varnothing$ & $?$ \\
\hline \multirow[t]{8}{*}{ metacarpus } & $\begin{array}{l}\text { shortening of metacarpals } \\
\text { II-V }\end{array}$ & $\begin{array}{l}\text { mechanical advantage of } \\
\text { flexors of wrist and } \\
\text { digits }\end{array}$ & \pm & $\varnothing$ & + & ++ & +++ & ++++ \\
\hline & $\begin{array}{l}\text { presence of facet for } \\
\text { cuneiform on } \mathrm{Mc} \mathrm{V}\end{array}$ & abduction of $\mathrm{Mc} \mathrm{V}$ & $\varnothing$ & $\varnothing$ & $\varnothing$ & + & + & $\varnothing$ \\
\hline & $\begin{array}{l}\text { tuberosity on Mc V for } \\
\text { extensor carpi ulnaris }\end{array}$ & $\begin{array}{l}\text { extension and/or ulnar } \\
\text { deviation }\end{array}$ & $\varnothing$ & $?$ & $?$ & $\varnothing$ & - & - \\
\hline & torsion of digit II & $?$ & $\varnothing$ & $\varnothing$ & $\varnothing$ & + & + & + \\
\hline & $\begin{array}{l}\text { digit II, } \\
\text { metacarpophalangeal joint }\end{array}$ & $\begin{array}{l}\text { amplitude of } \\
\text { mediolateral deviation }\end{array}$ & $\varnothing$ & $\varnothing$ & $\varnothing$ & $\varnothing$ & + & + \\
\hline & & interlocking & $\varnothing$ & $\varnothing$ & $\varnothing$ & $\varnothing$ & - & - \\
\hline & $\begin{array}{l}\text { fossae on second phalanx } \\
\text { of digit II }\end{array}$ & $\begin{array}{l}\text { amplitude of } \\
\text { flexion/extension of } \\
\text { ungual over second } \\
\text { phalanx }\end{array}$ & $\varnothing$ & $\varnothing$ & $\varnothing$ & + & + & + \\
\hline & width of ungual phalanx II & $?$ & $\varnothing$ & + & $?$ & ++ & $?$ & +++ \\
\hline
\end{tabular}




\begin{tabular}{|c|c|c|c|c|c|c|c|c|}
\hline & $\begin{array}{l}\text { mediolateral constriction } \\
\text { of ungual process of digit } \\
\text { III }\end{array}$ & $?$ & $\varnothing$ & + & + & + & + & + \\
\hline & $\begin{array}{l}\text { medial curvature of } \\
\text { process of digit IV }\end{array}$ & $?$ & $\varnothing$ & + & + & + & + & + \\
\hline sesamoids & thickening of falciform & $\begin{array}{l}\text { flexion of digits/wrist } \\
\text { strength }\end{array}$ & \pm & $\varnothing$ & $?$ & + & + & ? \\
\hline
\end{tabular}

Footnotes: T.a., T. antiquus; T.n., T. natans; T.l., T. littoralis; T.c., T. carolomartini; T.y., T. yaucensis; ø, not significant difference; ?, no data: \pm , variable.

Table 31. Common forelimb features of Thalassocnus and Desmostylia

\begin{tabular}{ll}
\hline Anatomical feature & $\begin{array}{l}\text { Reference for } \\
\text { desmostylian feature }\end{array}$ \\
\hline $\begin{array}{l}\text { Humerus short with proximal epiphysis widened } \\
\text { Development of deltoid crest (humerus) }\end{array}$ & (Inuzuka 2000) \\
$\begin{array}{l}\text { Shortness of ulna and radius } \\
\text { (Inuzuka 2000) }\end{array}$ \\
$\begin{array}{l}\text { Radius (and ulna) expanded distally } \\
\text { Large styloid process preventing any significant hyperextension; in Thalassocnus it is } \\
\text { found as the posterodistal process } \\
\begin{array}{l}\text { Thickening of shafts of antebrachial elements } \\
\text { Contact of Mc V, cuneiform, and unciform (only in Paleoparadoxia for }\end{array} \\
\text { desmostylians) }\end{array}$ \\
\hline
\end{tabular}


Electronic supplementary material

Online Resource 1. Specimen numbers of Thalassocnus forelimb material. Abbreviations: (R), right; (L), left; (R\&L), right and left; (R or L), right or left (unknown laterality). 


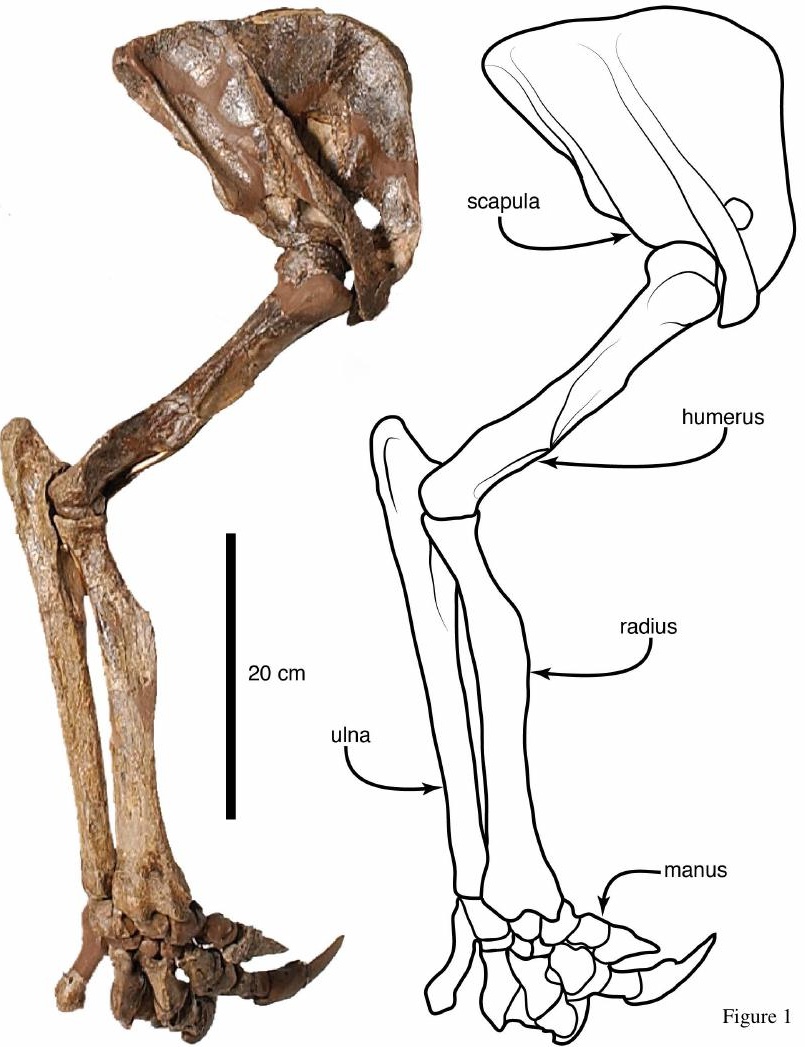




\section{a}

articular facet

scapular end

$5 \mathrm{~cm}$

sternal end

b

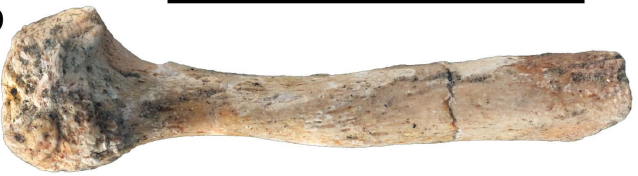

Figure 3 

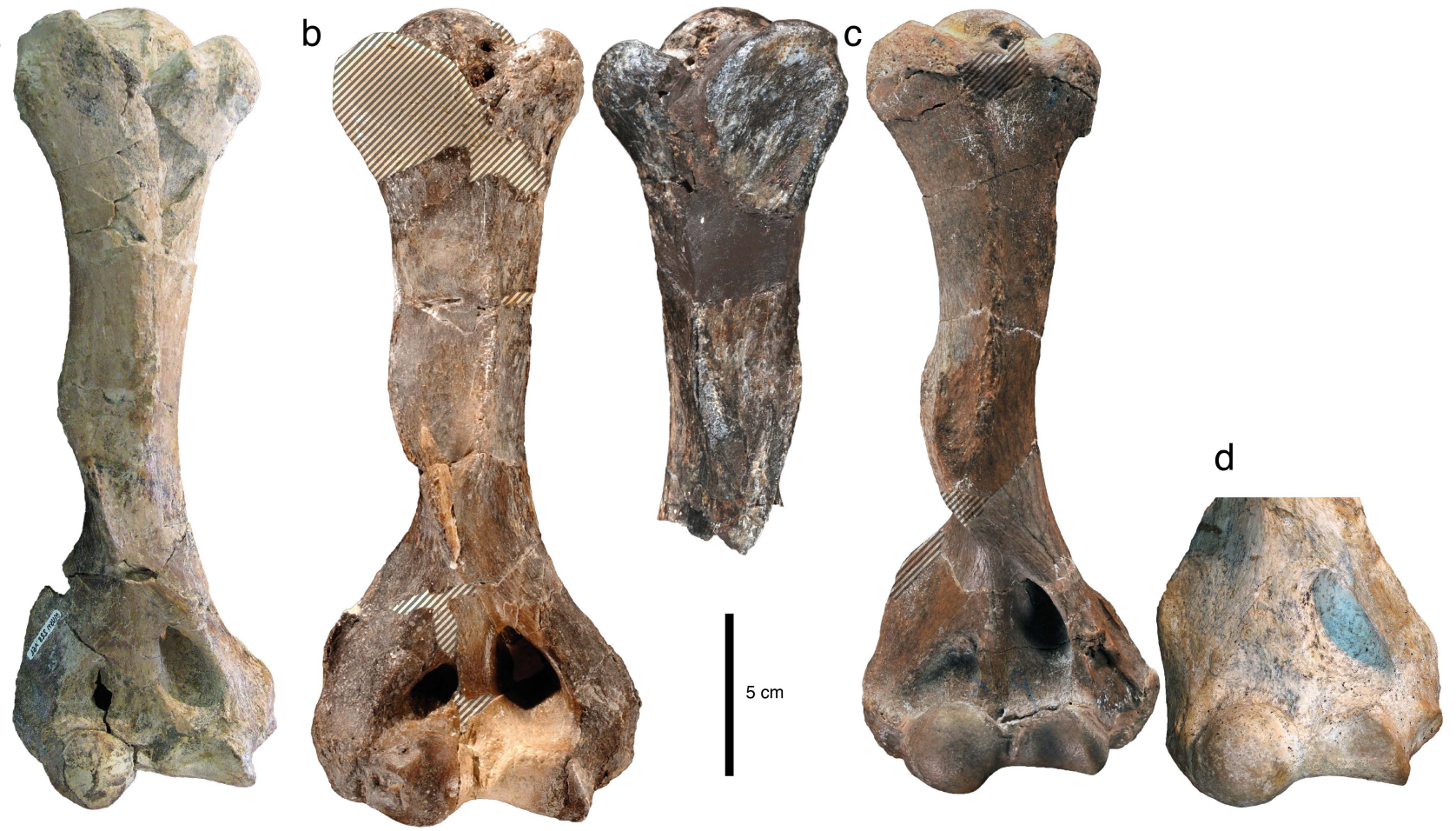

T. antiquus

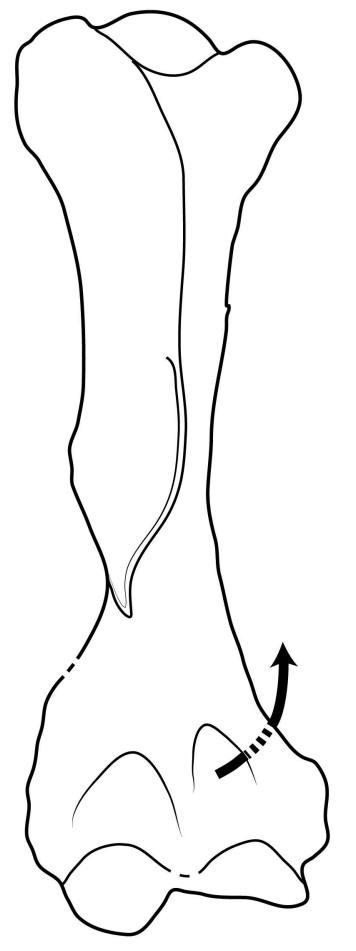

T. natans

T. littoralis
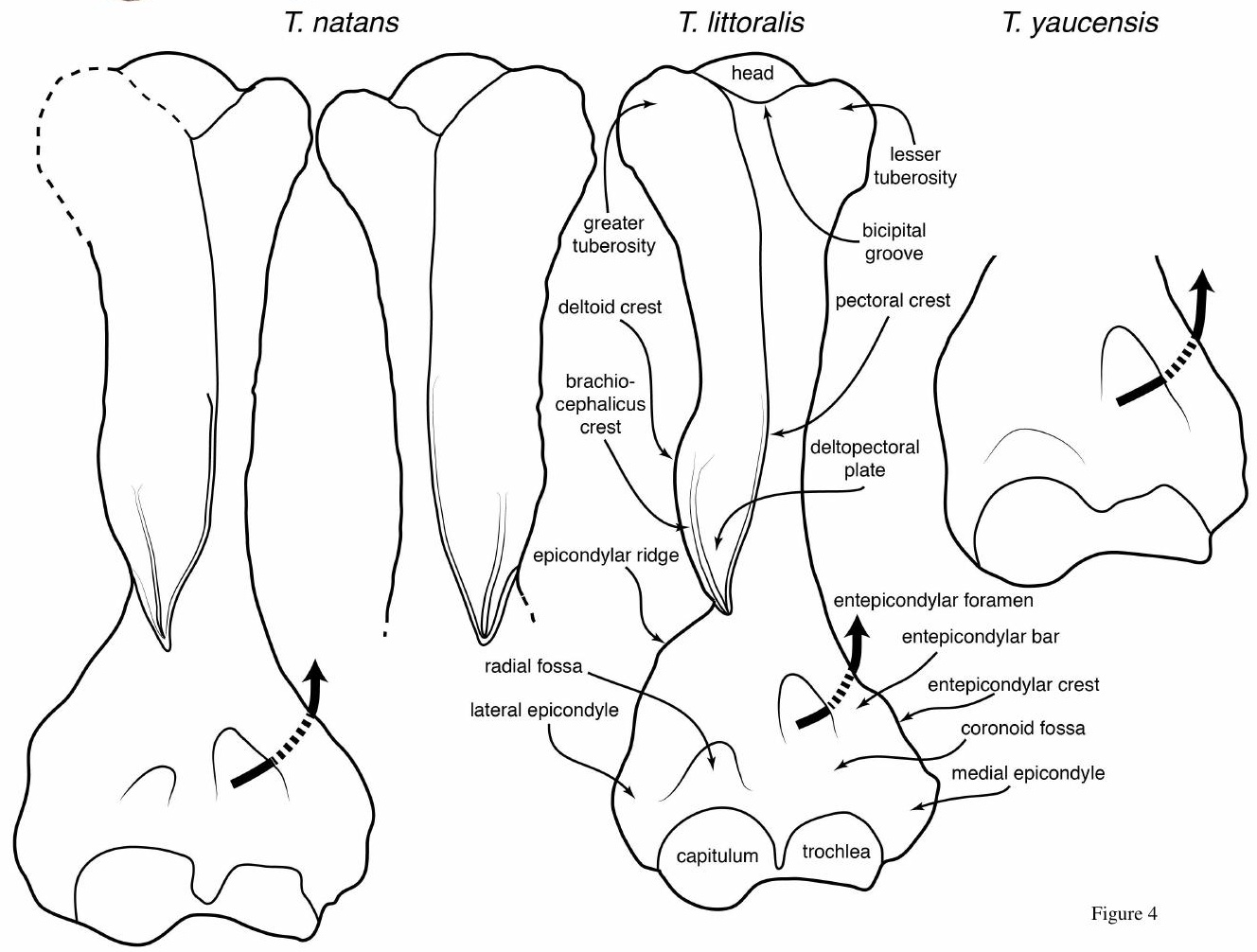
a

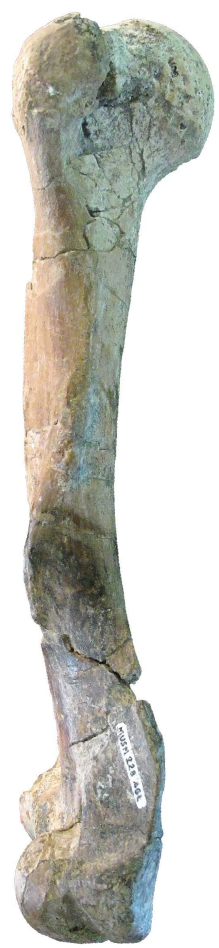

T. antiquus

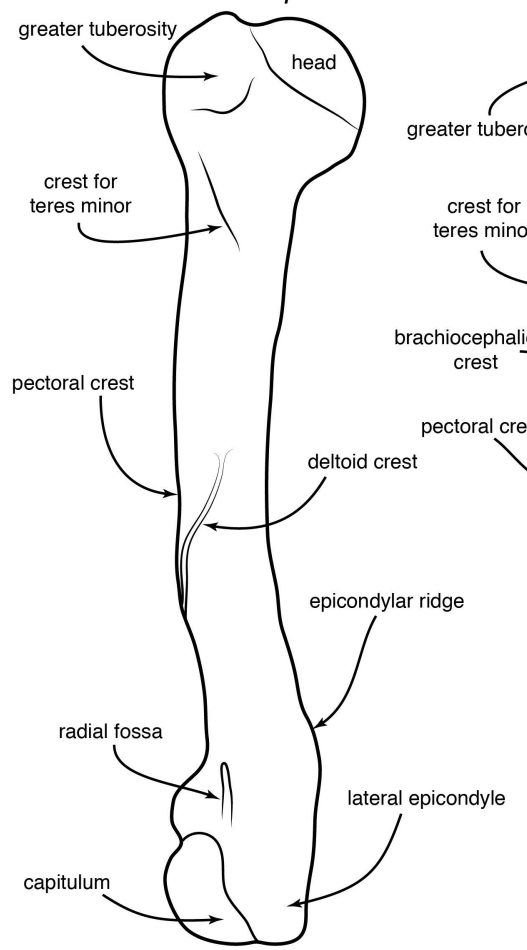

C

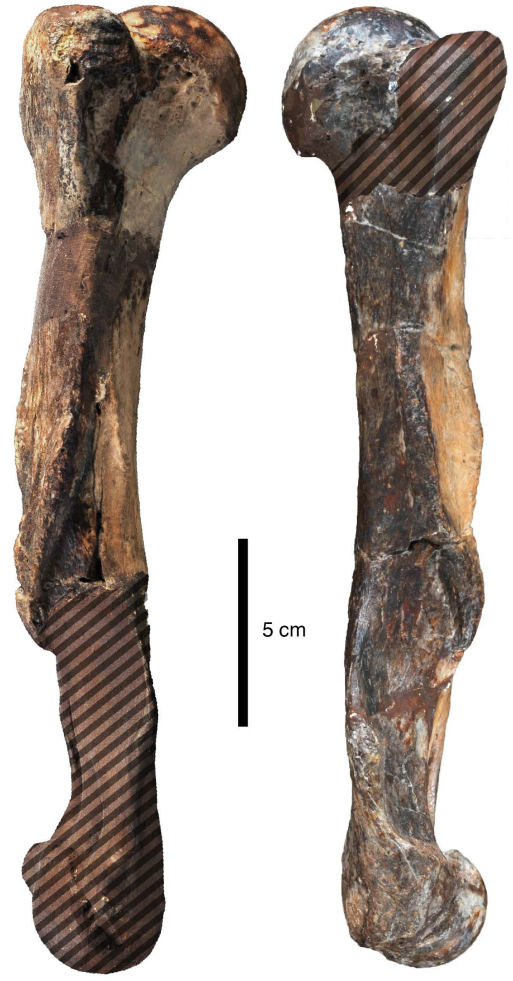

T. natans
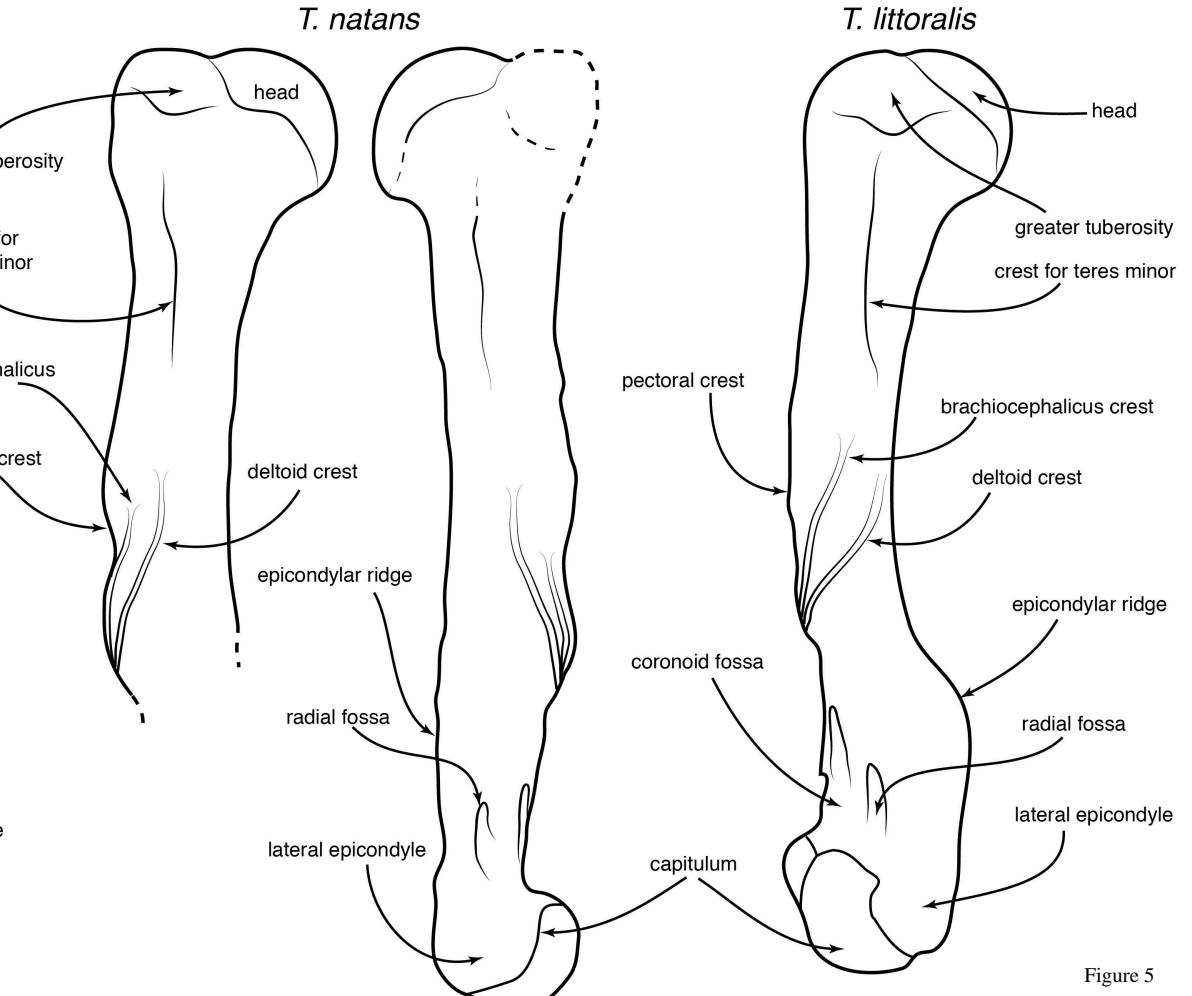
a

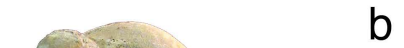

T. antiquus

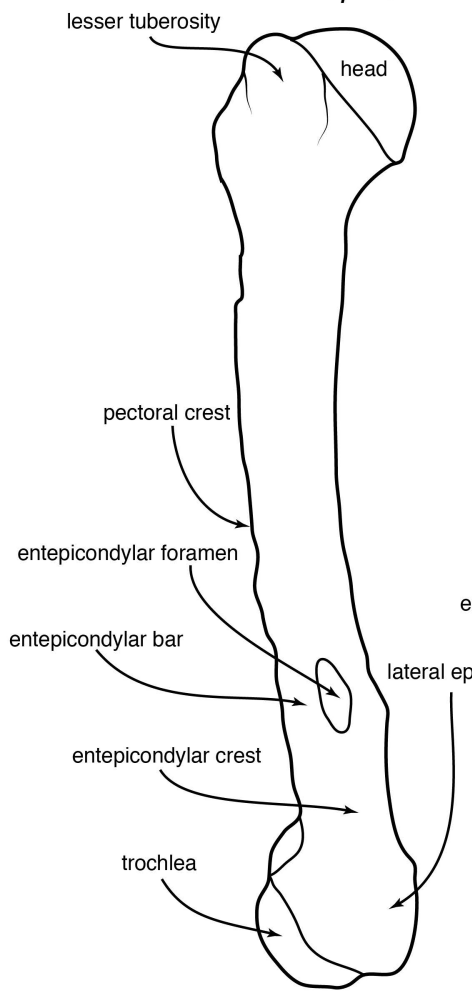

b

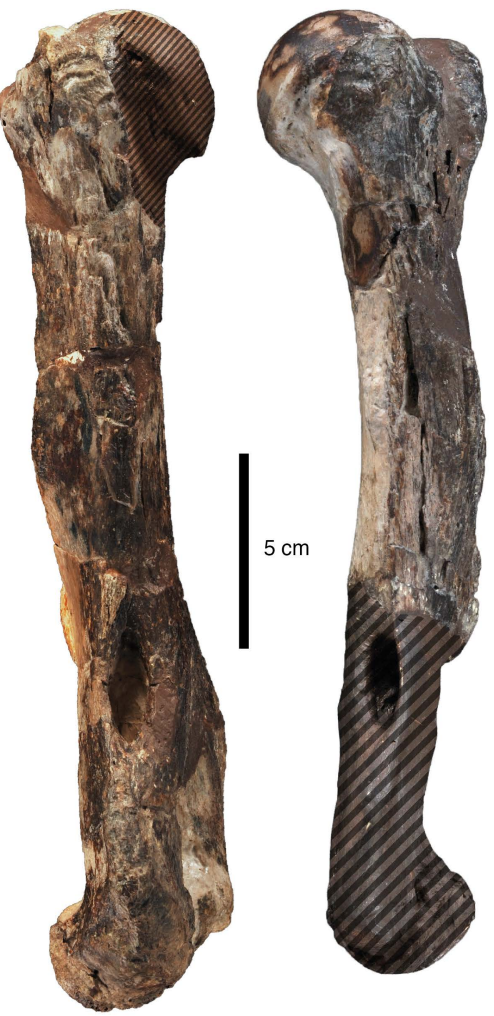

T. natans

lesser tuberosity

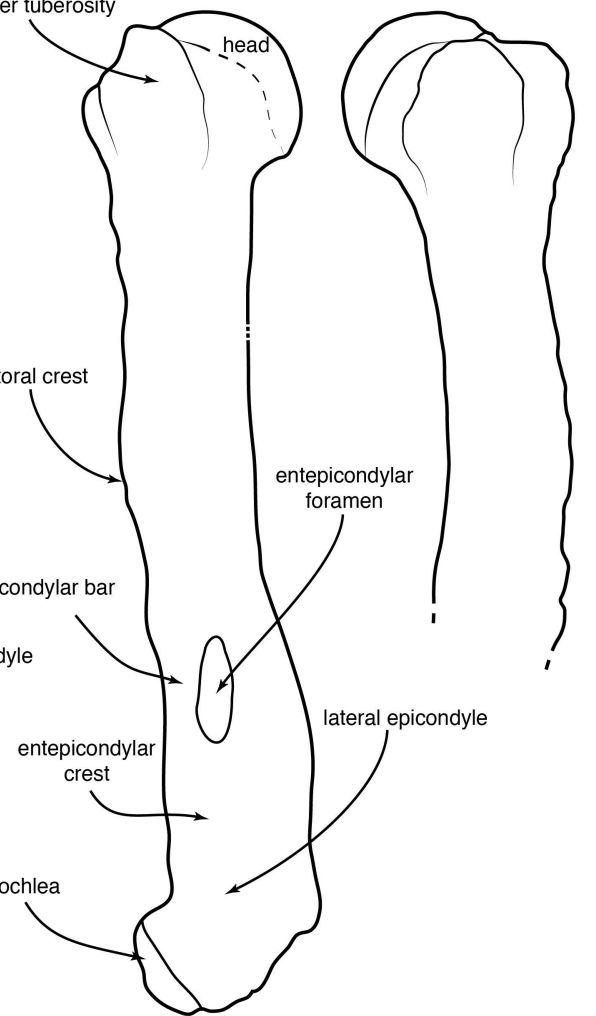

C

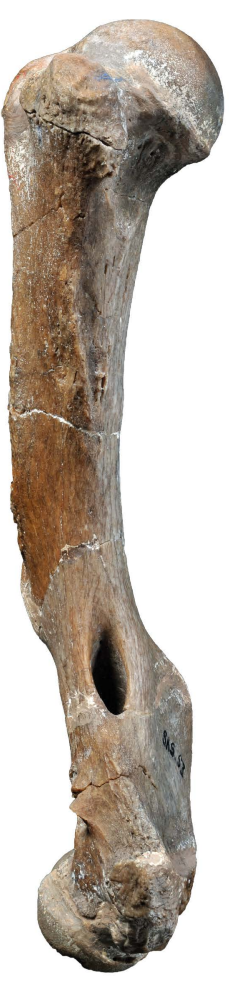

T. littoralis

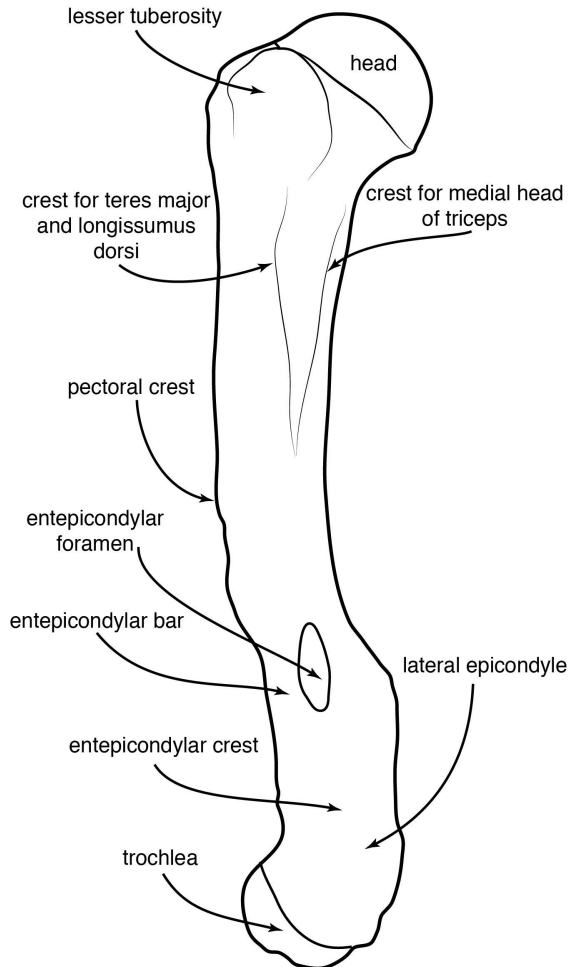

Figure 7 


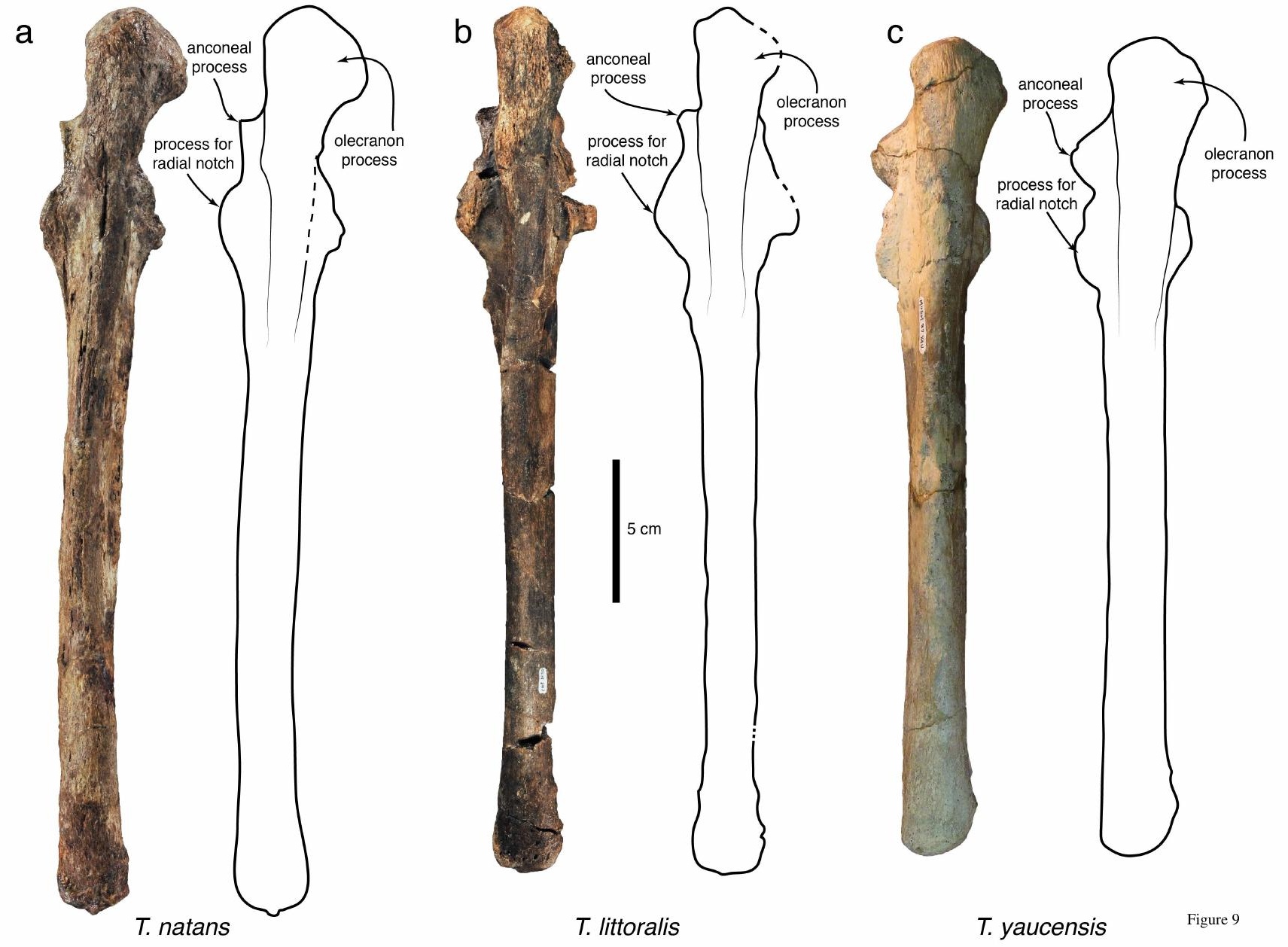


a

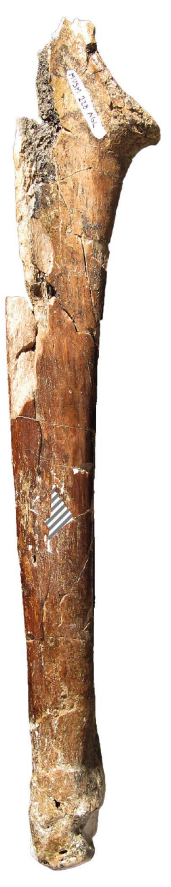

b

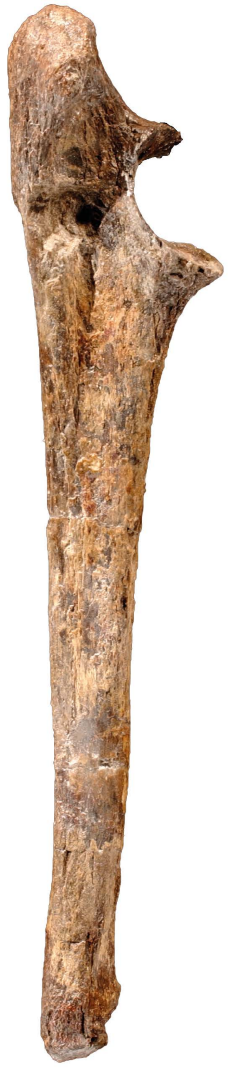

C

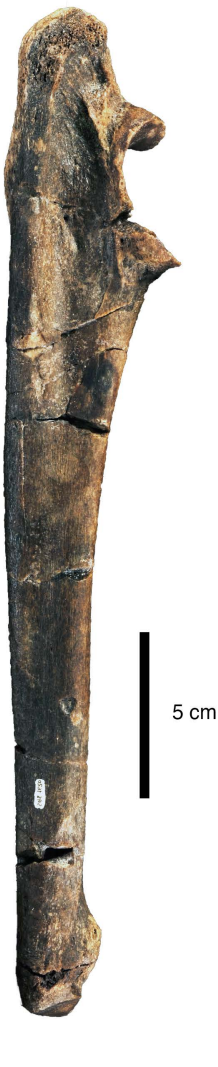

d

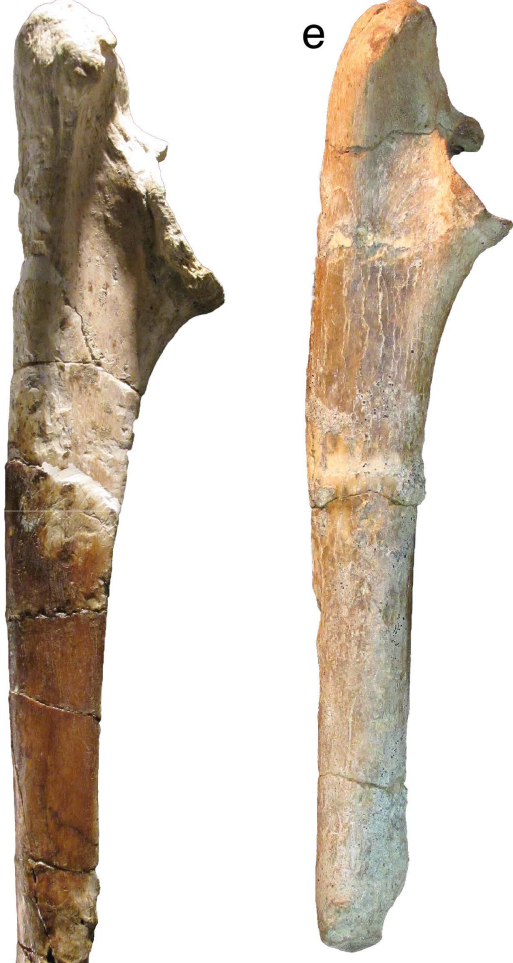

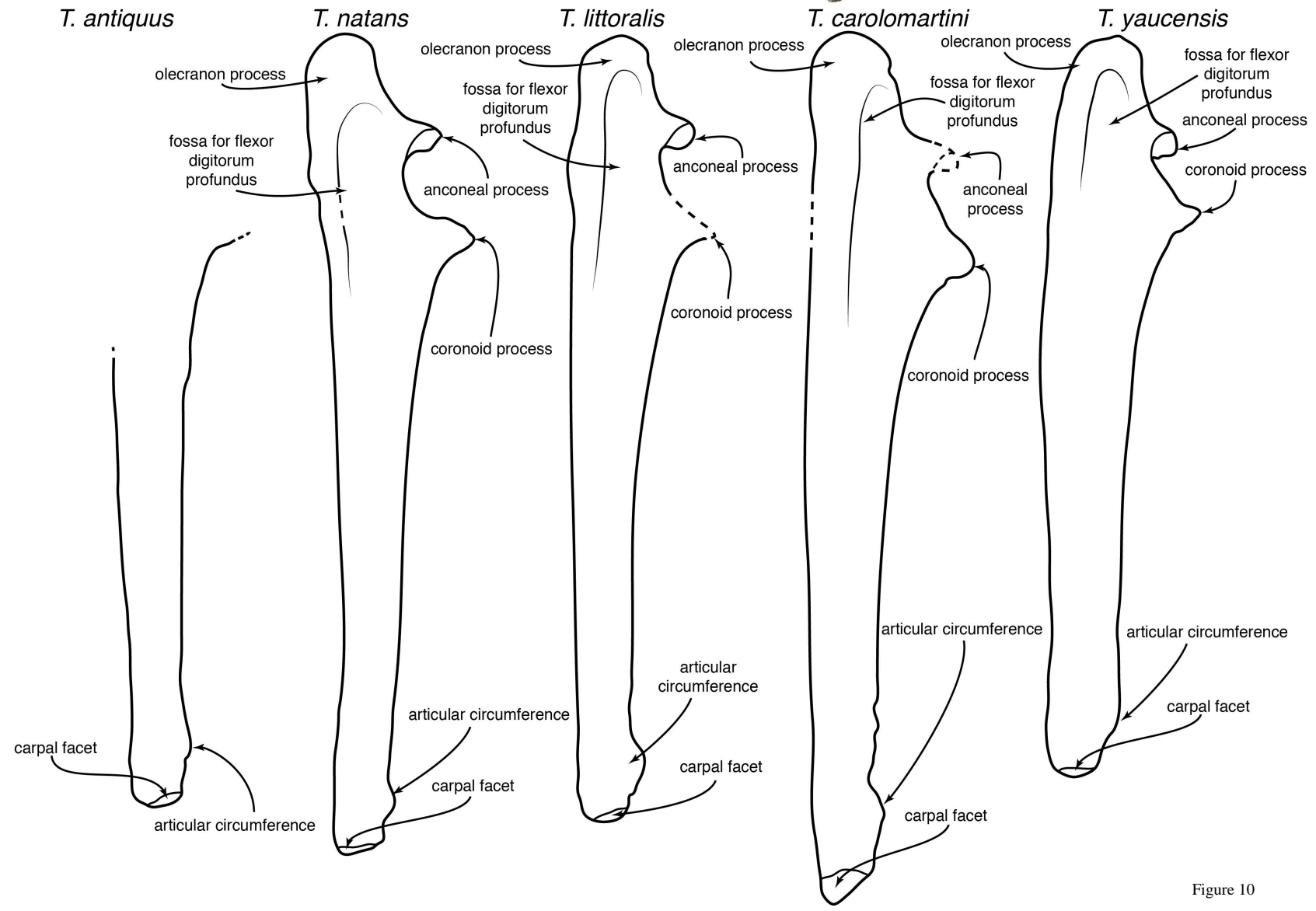



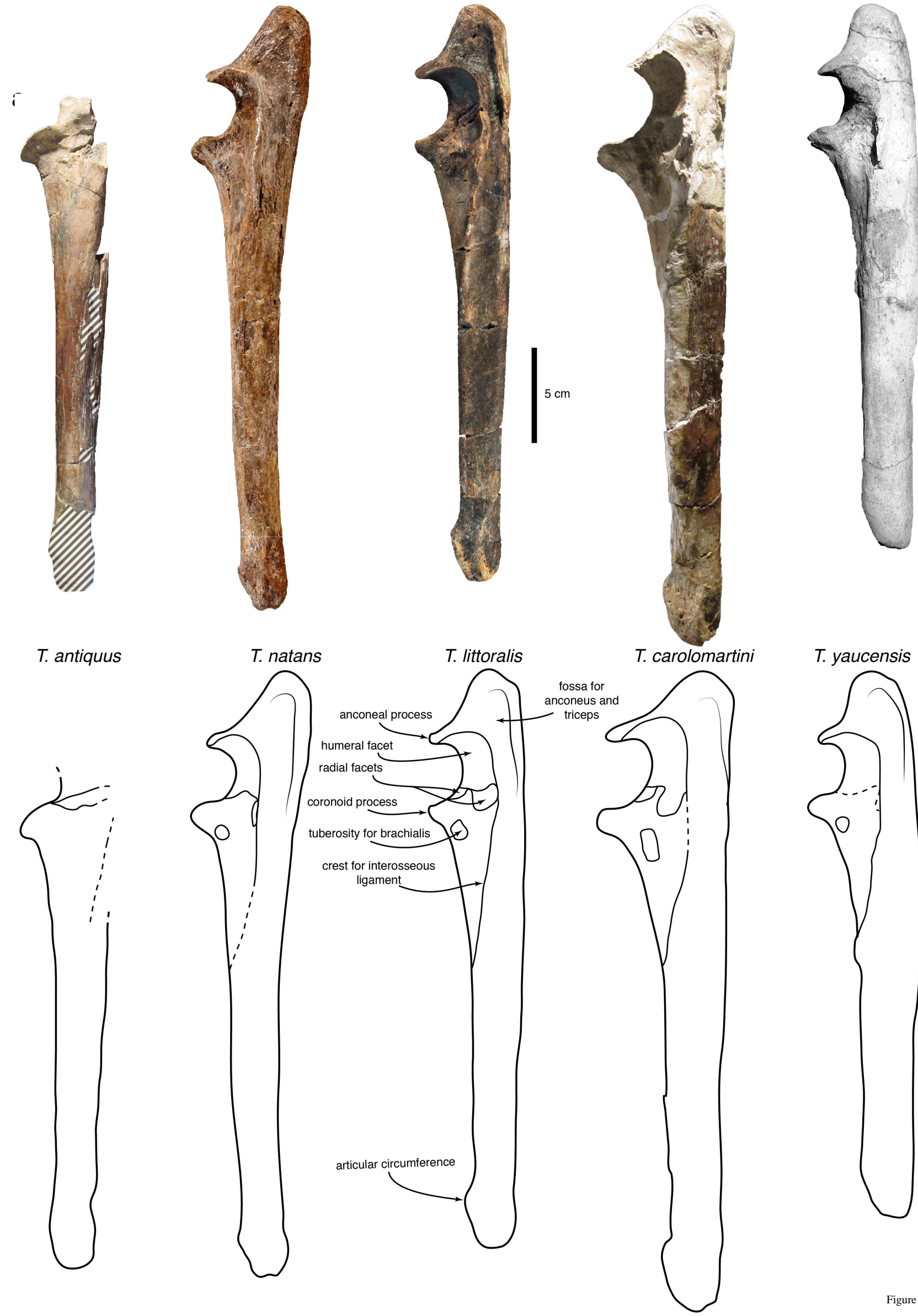

T. antiquus

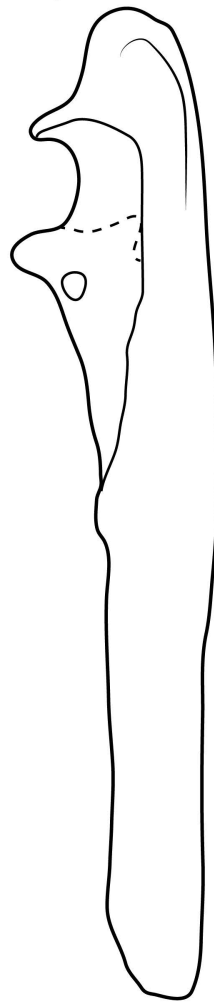


a

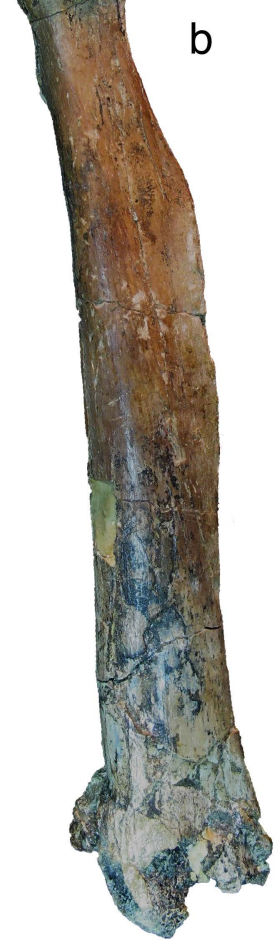

C

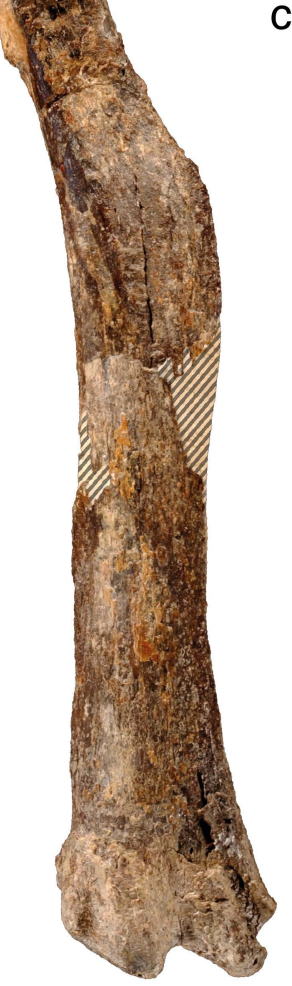

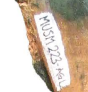

$5 \mathrm{~cm}$

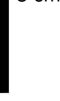

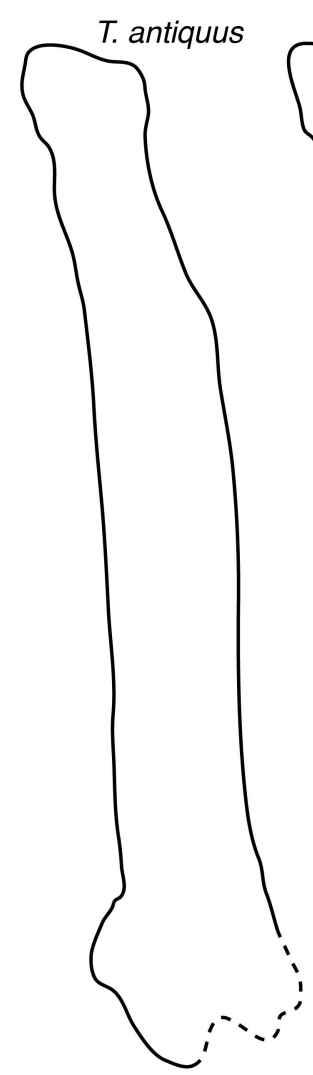

Figure 12

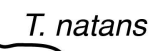




$$
\text { lind }
$$


a

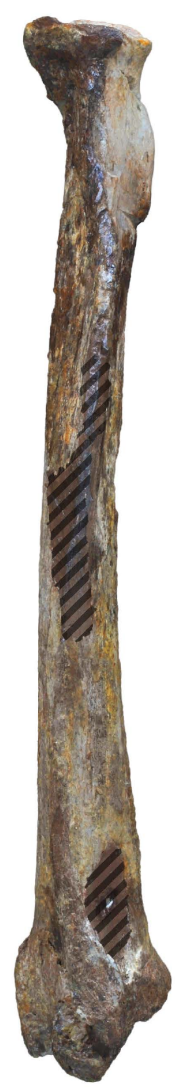

T. natans

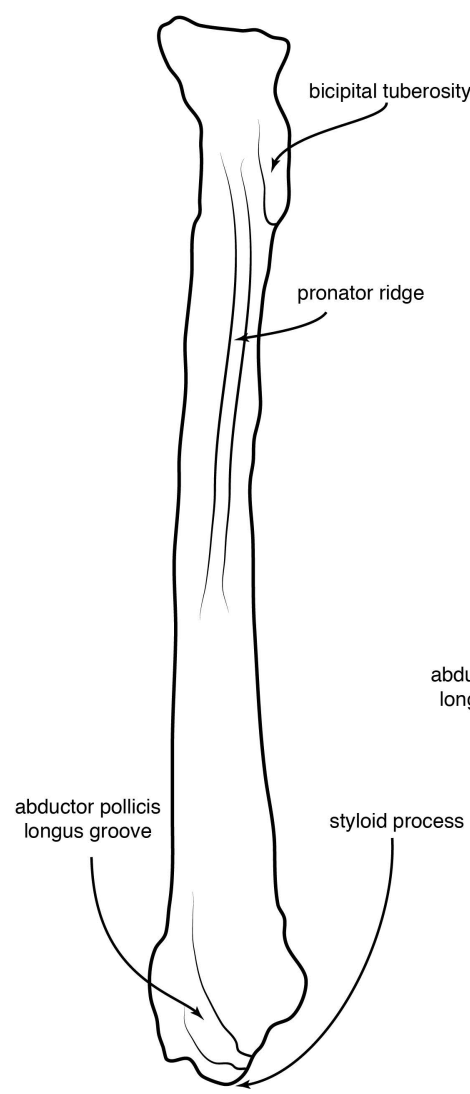

b

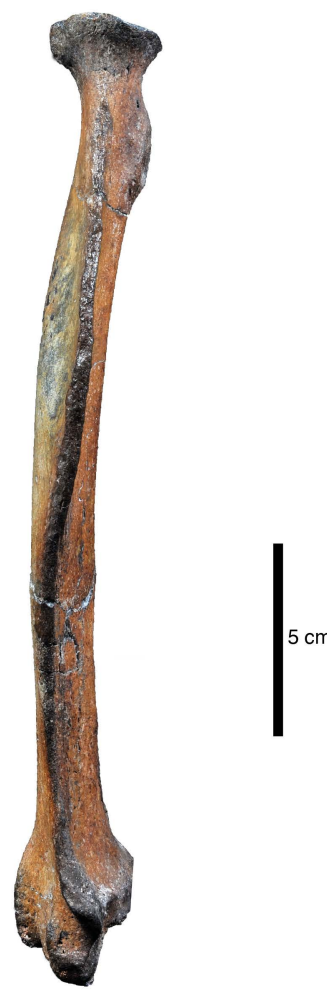

T. littoralis

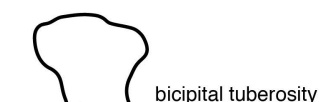

C

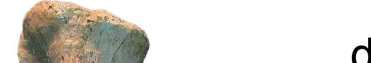

d 
a

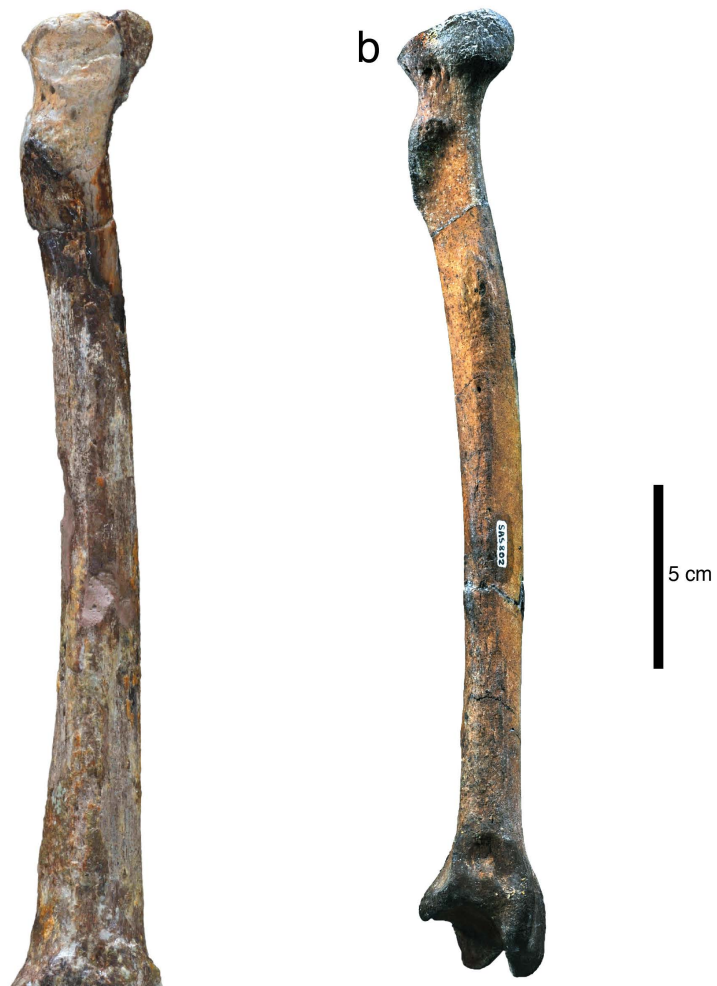

C

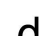

d 

a

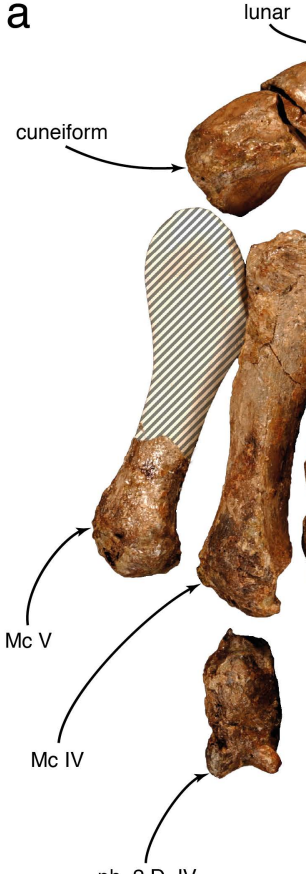

ph. 2 D. IV
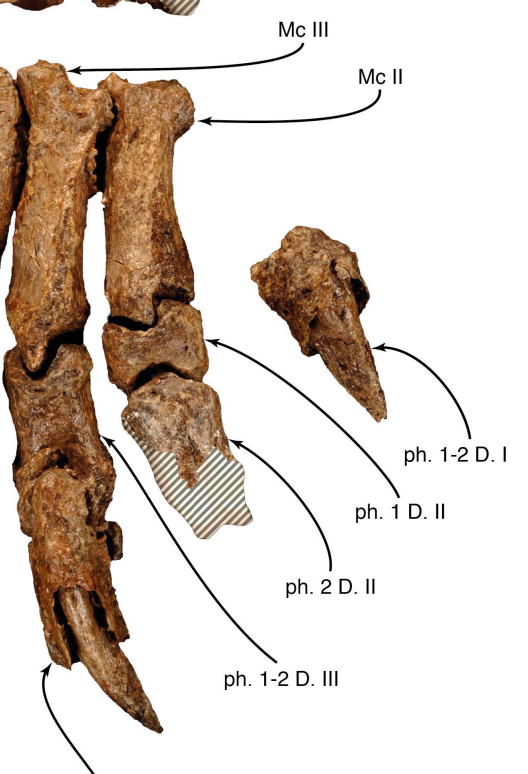

ph. 3 D. III

ph. 1-2 D. III
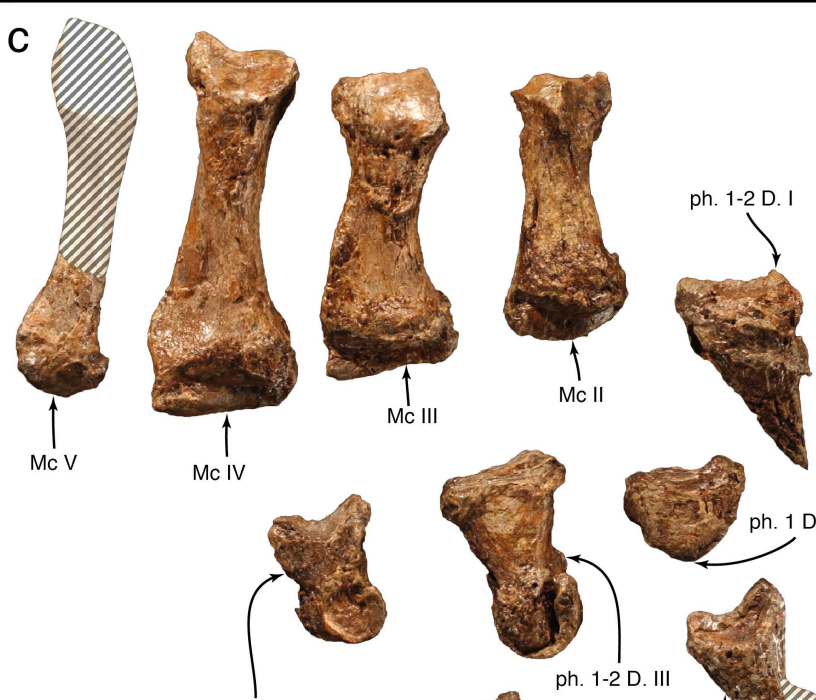

ph. 2 D. IV

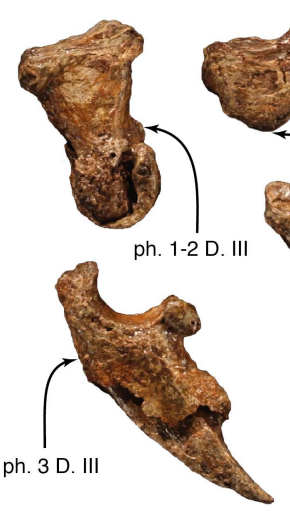

ph. 1 D. II

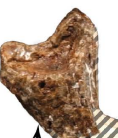

ph. 3 D. III

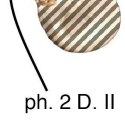

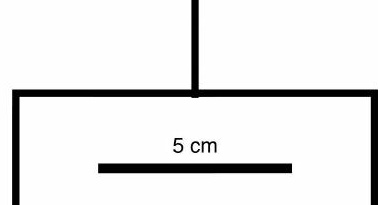




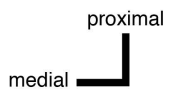

a

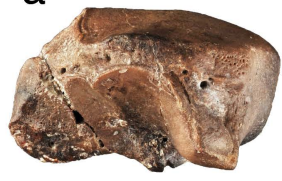

palmar

b

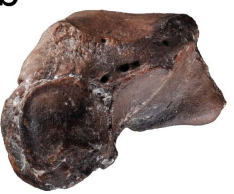

C

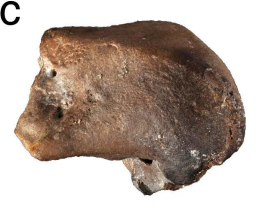

lateral

d

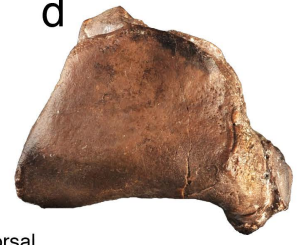

medial

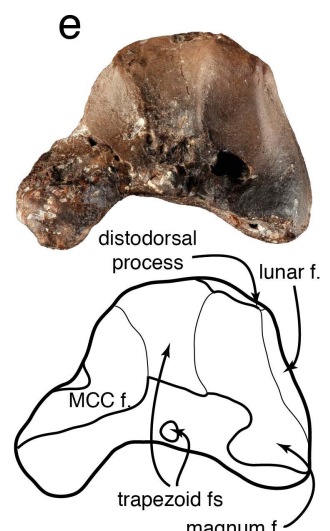

Figure 18

distodorsal

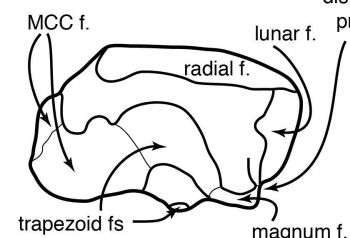

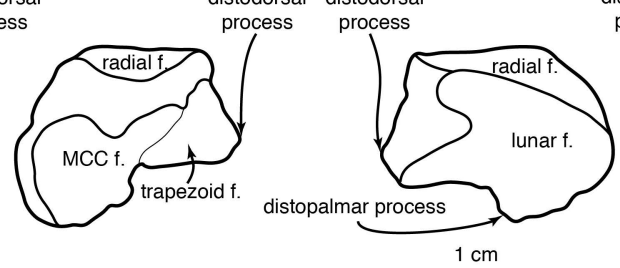
process

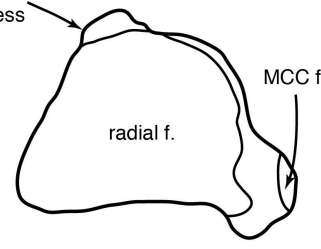


a

b 


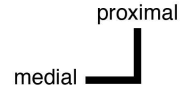

a
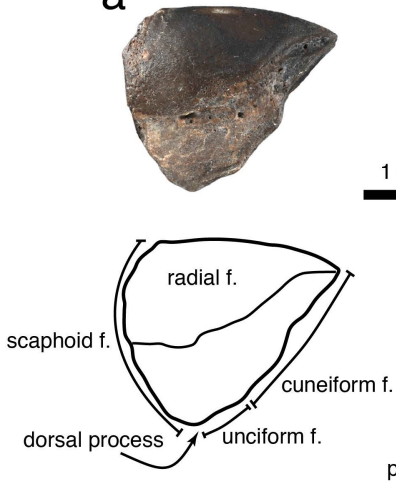

proximal

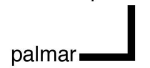

b

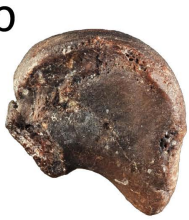

dorsal

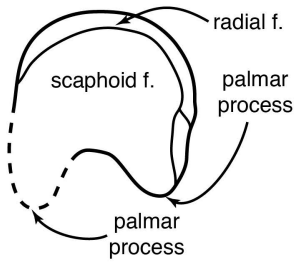

C

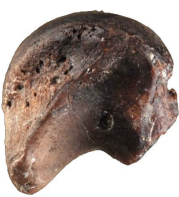

radial $\mathrm{f}$.

palmar process 
a

T. antiquus b

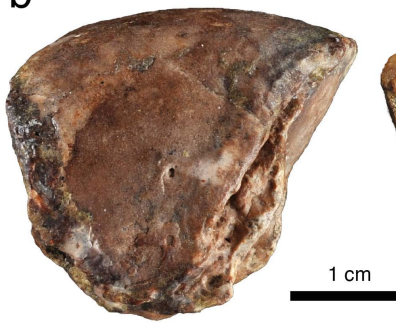

T. natans
C

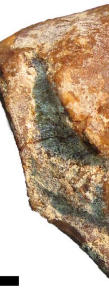

-

T. carolomartini radial $f$.

scaphoid f.

dorsal
process

Figure 21 


\section{a}

\section{b \\ proximal $f$.}

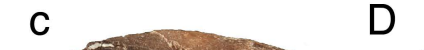


proximal

dorsal
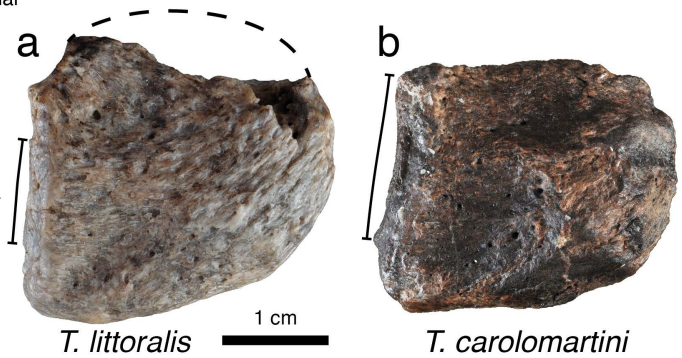

Figure 24

T. littoralis

T. carolomartini 
proximal

dorsal

a

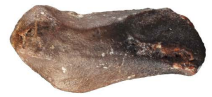

scaphoid $\mathrm{f}$.

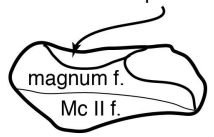

Figure 25 lateral

b

$1 \mathrm{~cm}$
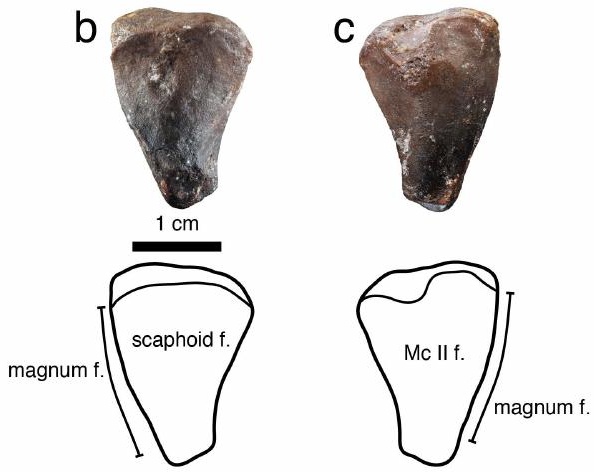

medial

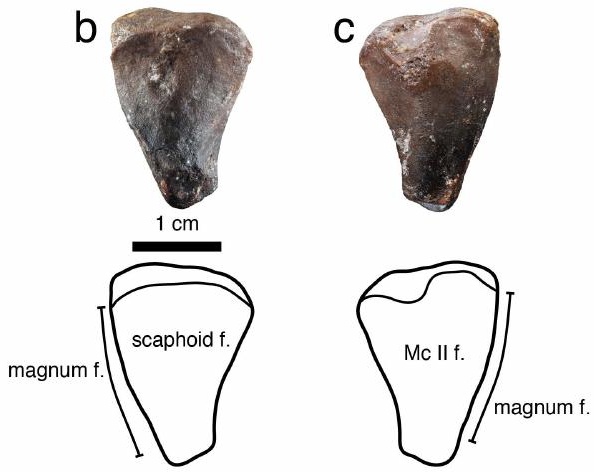
dorsal

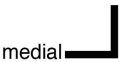




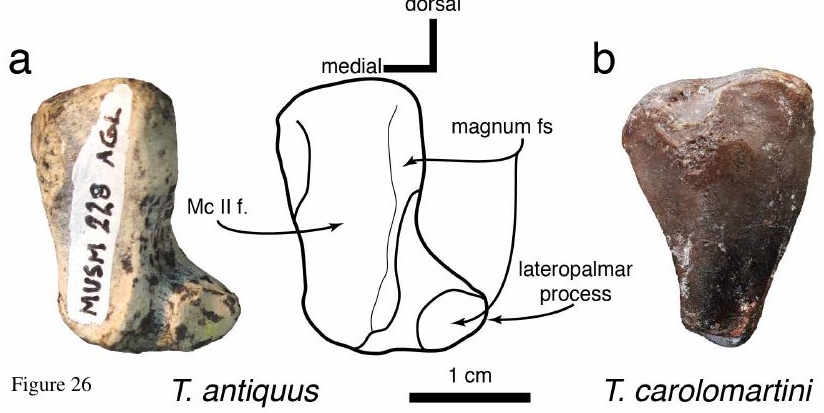




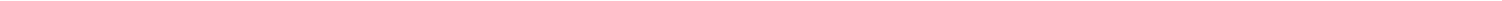



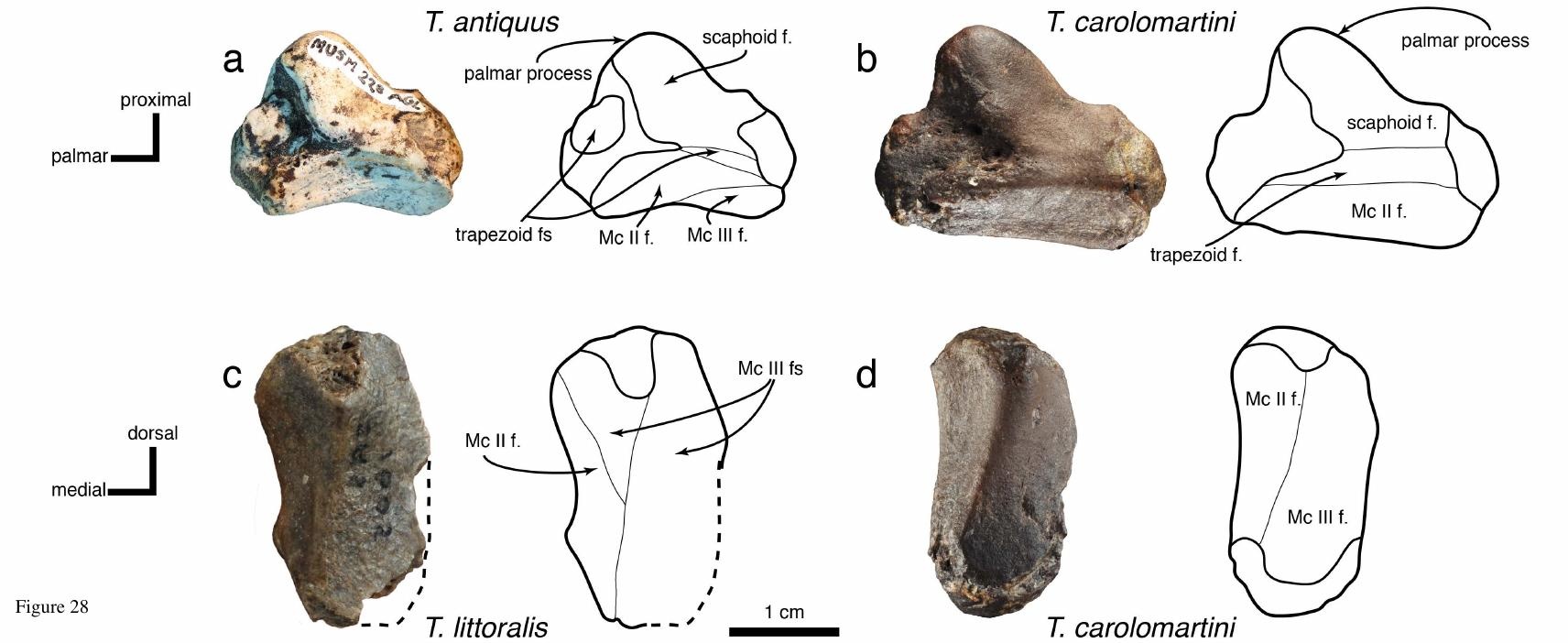


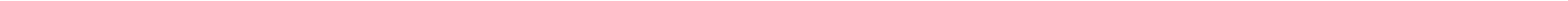


proximal

medial

a

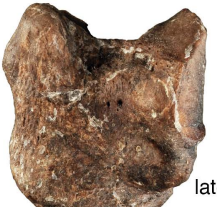

medioproximal

lateroproximal process

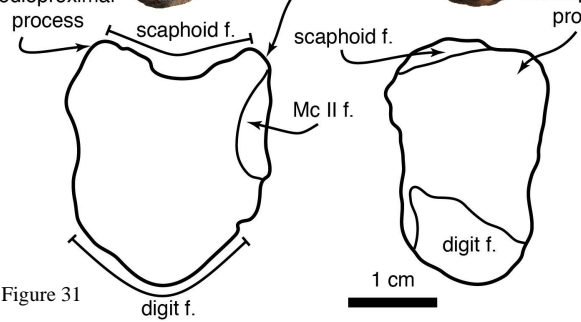

dorsal

C

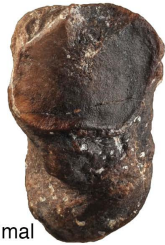

scaphoid f.

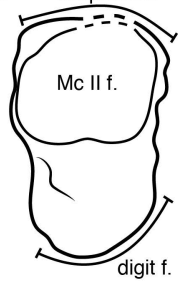


Figure 32 proximal

medial

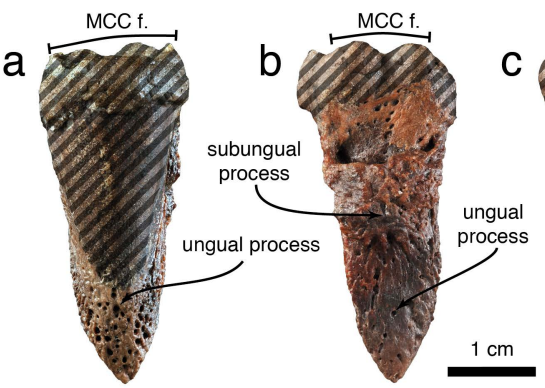

dorsal

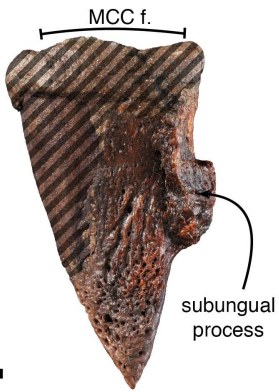


medial proximal

a
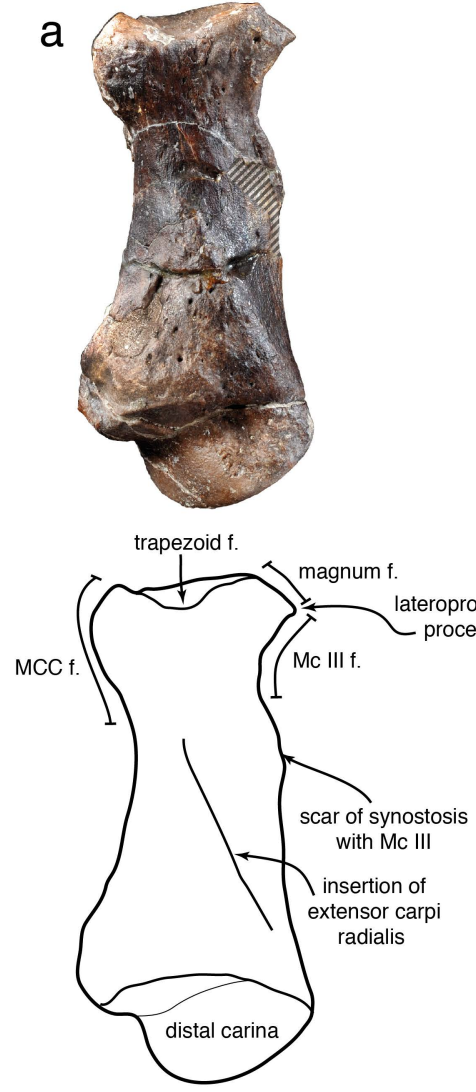

proximal

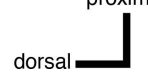

dorsal

C
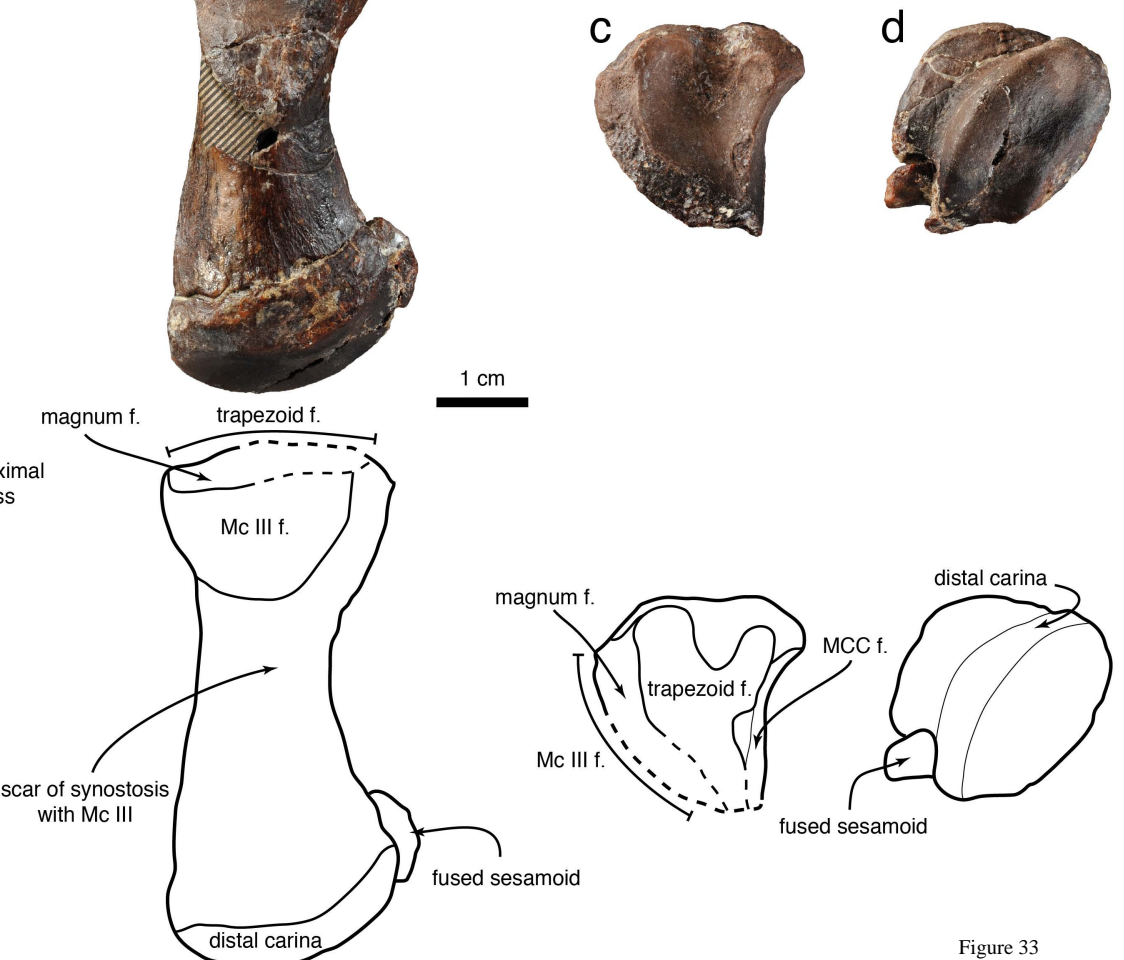

$1 \mathrm{~cm}$

b
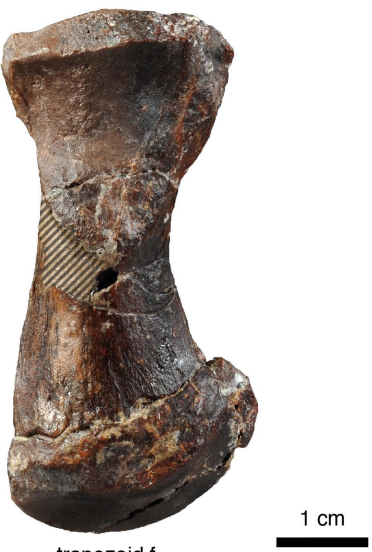

trapezoid $\mathrm{f}$.

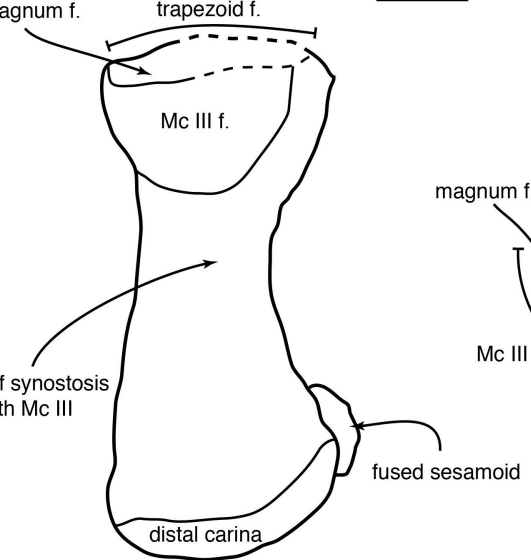

medial dorsal 
proximal

medial

a

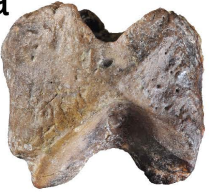

d

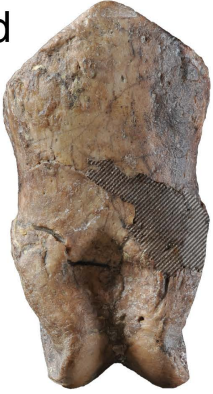

g

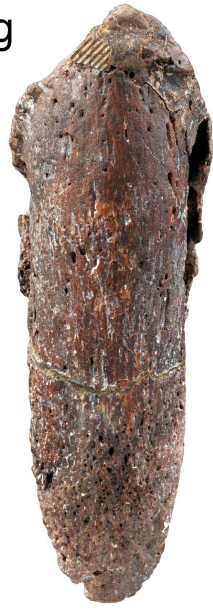

b

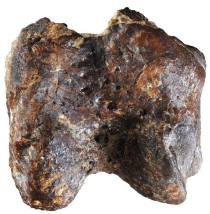

e

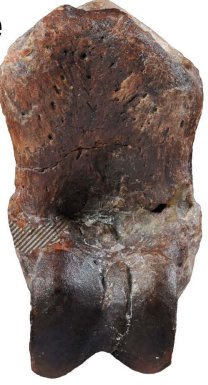

C

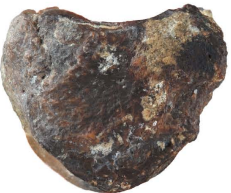

f

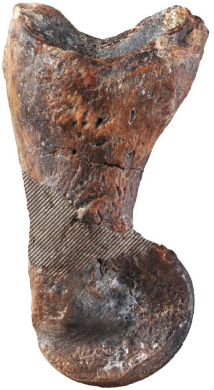

$1 \mathrm{~cm}$

h

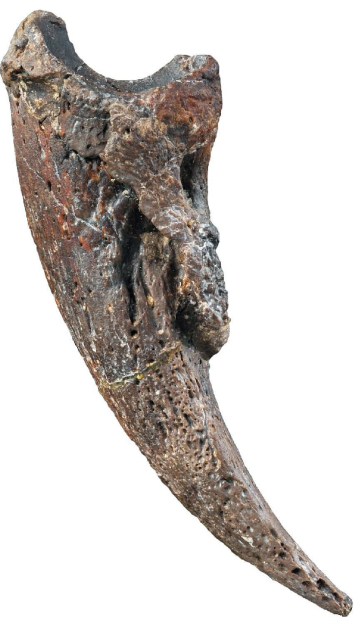




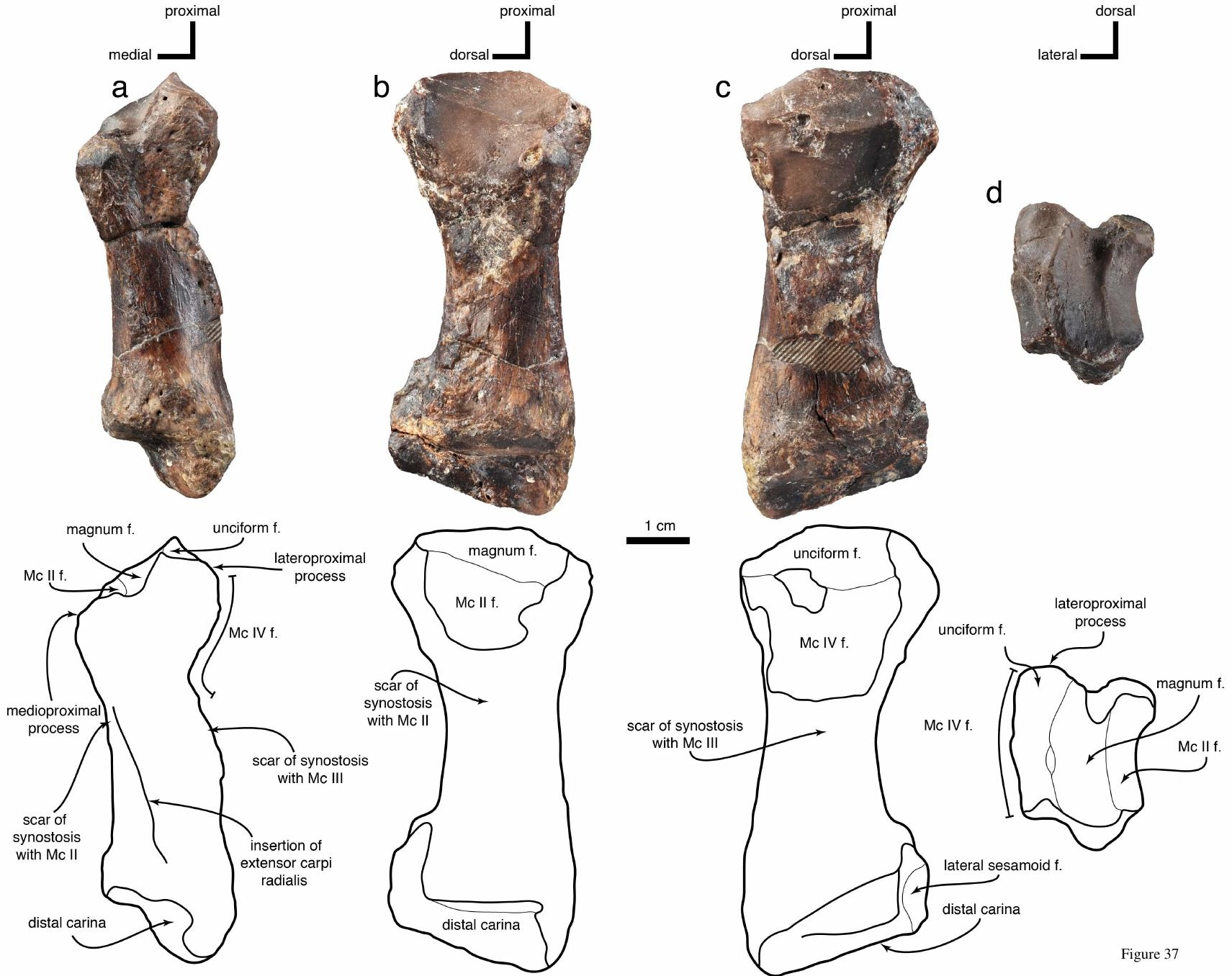




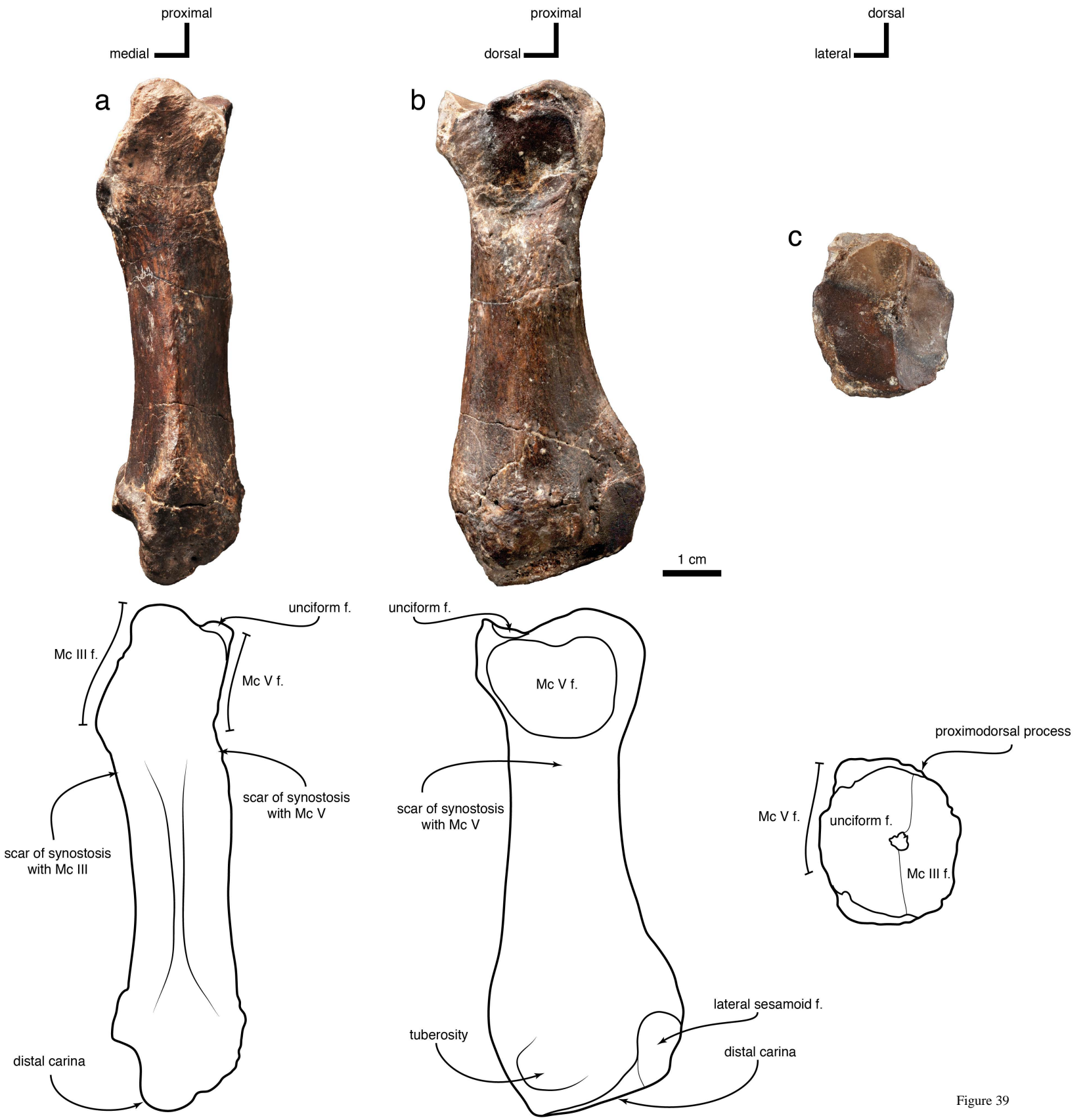


proximal

medial

a

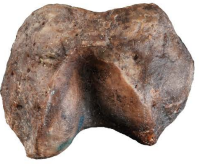

C

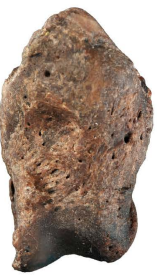

f

Figure 41 lateral

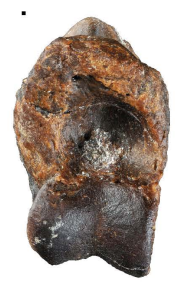

b

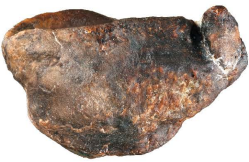

e

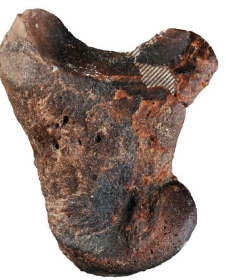

g

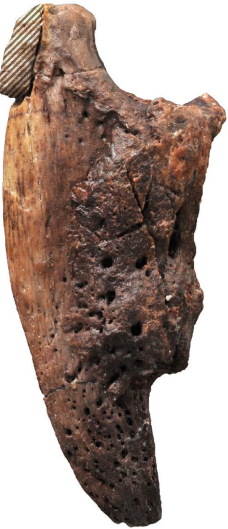


lateral

a

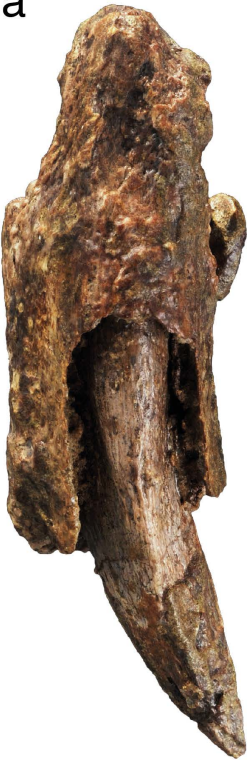

palmar

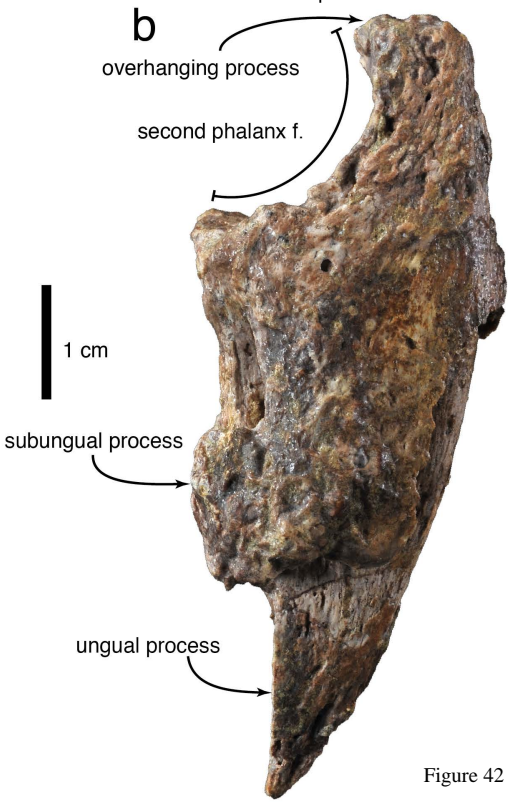


palmar

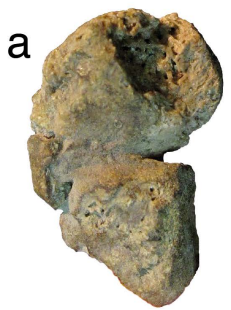

T. antiquus

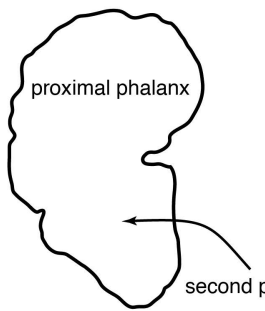

medial

b

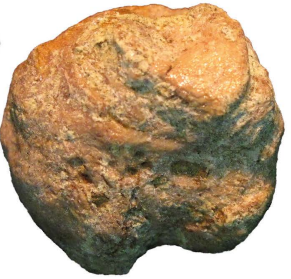

medial

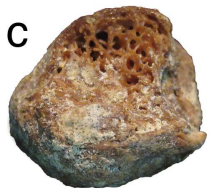

T. carolomartini

\section{$1 \mathrm{~cm}$}

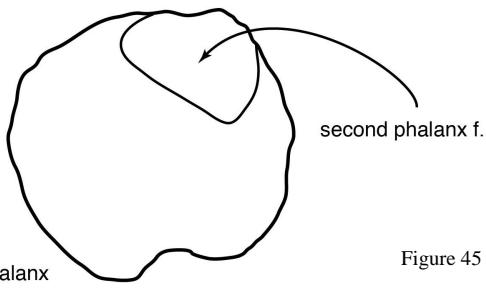


a

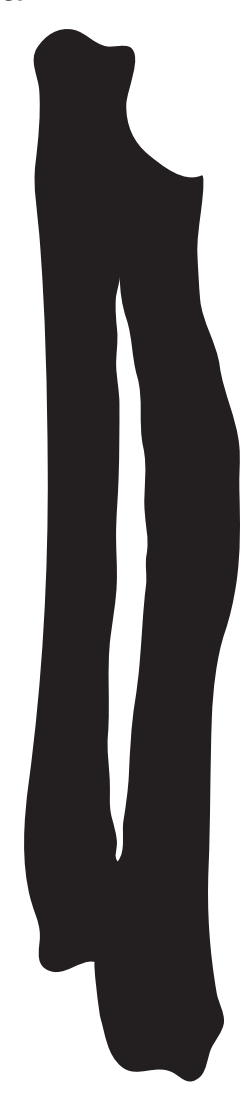

d
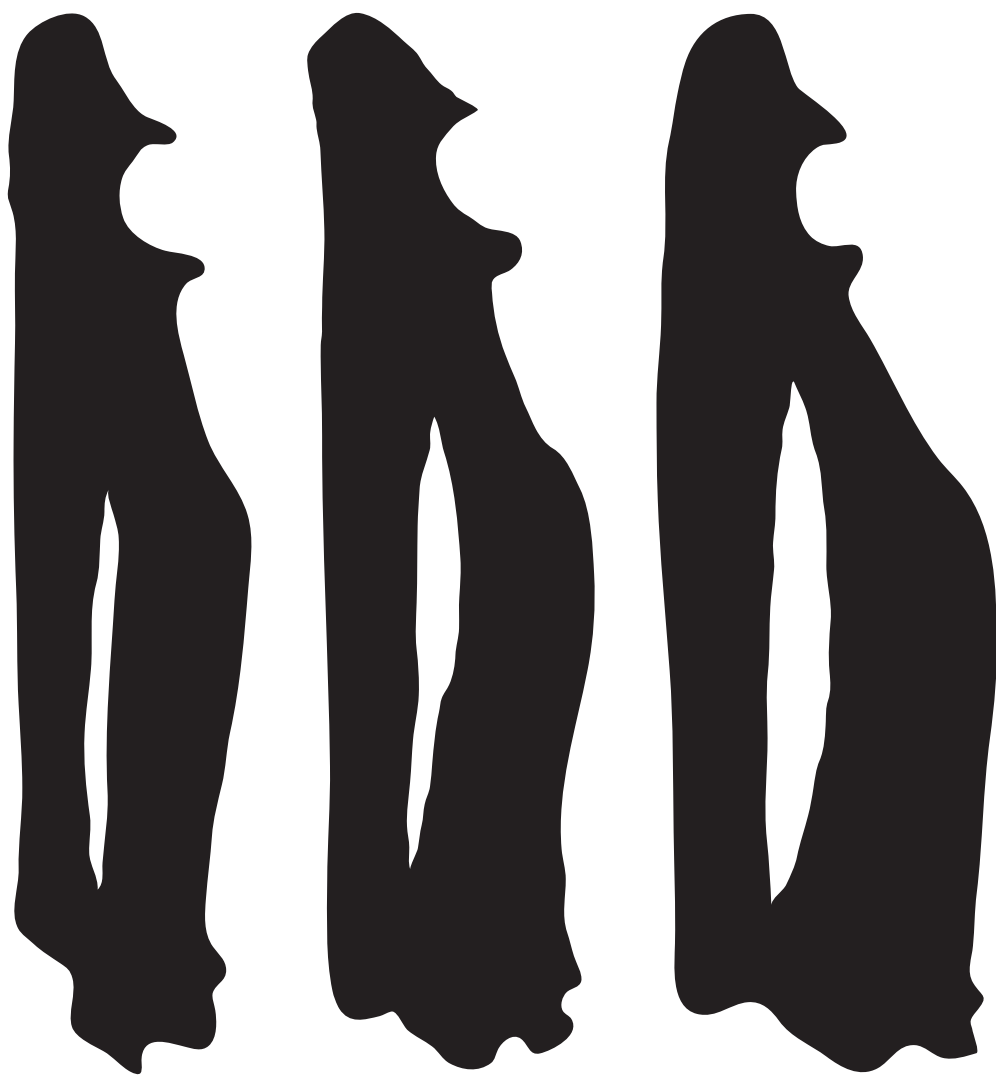

$\mathrm{f}$
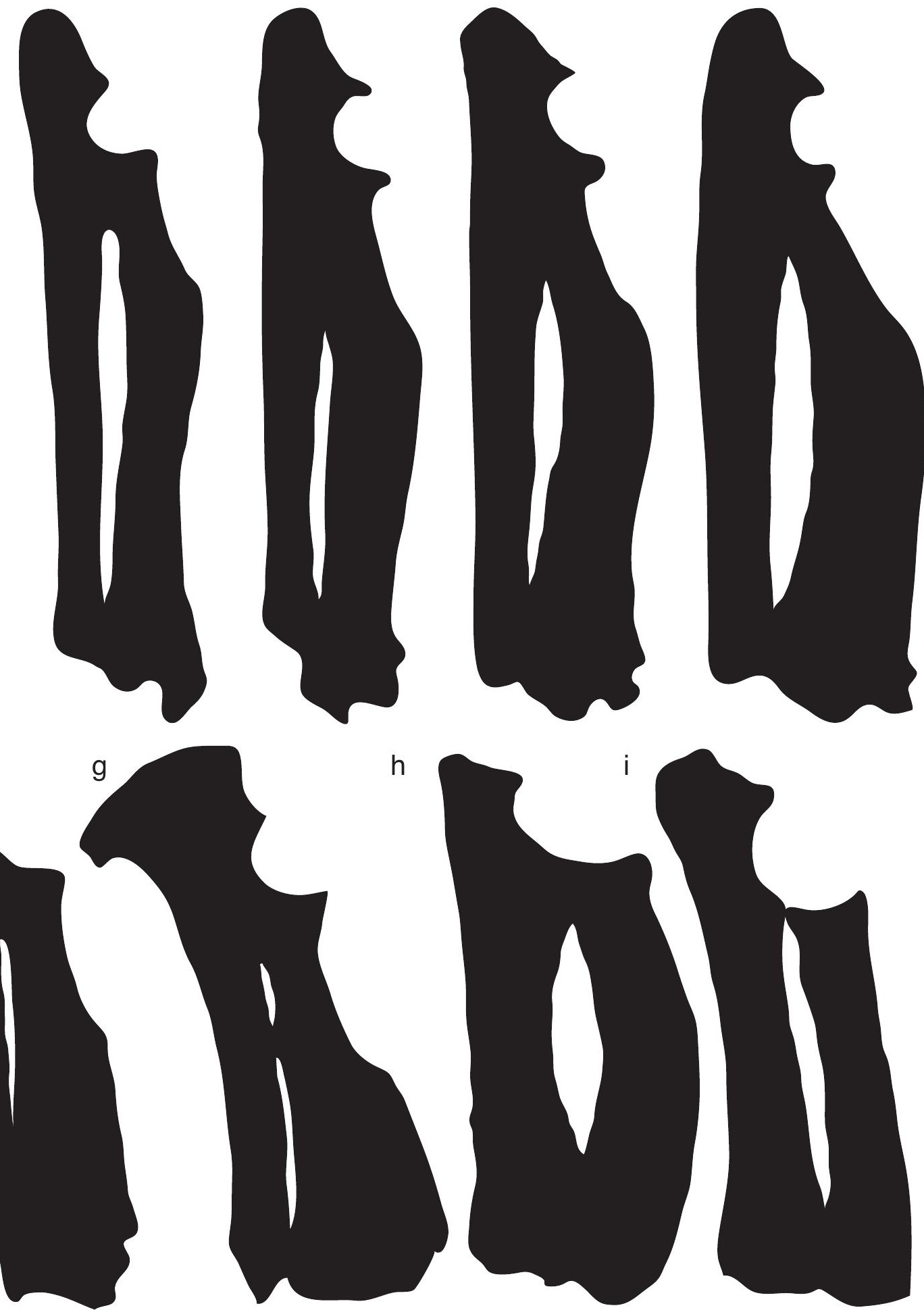